\title{
Análise e implementação de modelos não newtonianos no sistema FreeFlow-2D
}

\author{
Ricardo da Silva Siquieri ${ }^{1}$ \\ Murilo Francisco Tomé2
}

24 de maio de 2002

\footnotetext{
${ }^{1}$ Aluno de Mestrado bolsista FAPESP

${ }^{2}$ Orientador ICMC/USP
} 
"Gastei uma hora pensando em um verso que a pena não quer escrever. No entanto ele está cá dentro inquieto, vivo. Ele está cá dentro e não quer sair. Mas a poesia deste momento inunda minha vida inteira." (Carlos Drummond de Andrade) 
Dedico este trabalho aos meus pais, Jair e Iraci. 


\section{Agradecimentos}

A Deus pela vida.

Ao meu orientador Prof. Murilo Francisco Tomé pelo apoio, incentivo, dedicação e amizade.

Aos professores Norberto Mangiavacchi, Antônio Castelo Filho, José Alberto Cuminato e Armando de Oliveira Fortuna, pelas valiosas sugestões e pela amizade.

Aos professores da Unesp de Presidente Prudente onde me formei, pelo importante incentivo em dar continuidade em meus estudos em Matemática. Em especial aos Professores Messias Meneguetti Junior, José Roberto Nogueira e Suetônio de Almeida Meira.

À minha família, pelo grande apoio e incentivo em todos os momentos da minha vida. Em especial os meus pais Jair e Iraci e meus irmãos Renata e Rafael.

Aos amigos do LCAD, pelas ajudas e sugestões e principalmente pela amizade que se formou. Em especial à Maria Luisa, à Luciane (Lu Grossi), à Juliana, ao Fabrício, ao Marcelo (Loquinho), ao Fernando (Pio), ao Helton e ao Valdemir, pelas importantes dicas no momento final do projeto.

A todos os meus amigos e amigas da USP, em especial ao Luciano, ao Otavio, ao José Flavio, ao Daniel, ao Sergio, ao Esdras, ao Juliano (Zuzu), ao Emerson (Wruck), ao Claudemir, ao Orlando, à Dirlene, à Hildebrane (Hild), à Karina, à Erica, à Cilene, à Vera e a Maria Alice, aos amigos da UNESP, à Gilcilene, à Sara, à Kemelli, à Dayene, à Raquel, ao João Paulo e ao José Paulo, pelos bons momentos de descontração.

Agradeço a FAPESP, pelo suporte financeiro para o desenvolvimento deste projeto.

Finalmente agradeço a todos aqueles que diretamente ou indiretamente colaboram para a realização deste trabalho. 


\begin{abstract}
This work presents an extention of the Freeflow-2D system to non-Newtonian free surface flows. The governing equations are solved by the finite difference method on a staggered grid. Marker particles are used to describe the fluid providing the location and the visualization of the free surface. The methodology employed is based on the GENSMAC method. The fluid is modelled by the Cross and powerlaw models. Numerical examples are presented. The code is validated by making a comparison between analytical and numerical solutions.
\end{abstract}




\section{Resumo}

O presente trabalho consiste em uma extensão do sistema FreeFlow-2D para simular escoamentos de fluidos não newtonianos bidimensionais com superfícies livres, onde o fluido é descrito pelos modelos de Cross ou o modelo "power-law". O método numérico empregado é o método GENSMAC. As equações governantes são aproximadas pelo método de diferenças finitas em uma malha deslocada e partículas marcadoras são utilizadas para a visualização do escoamento e localização da superfície livre. Resultados numéricos são apresentados. Em particular, a presente implementação é validada comparando-se a solução numérica com uma solução analítica. 


\section{Sumário}

Introdução 1

1 Equações Governantes 3

1.1 Equações Básicas . . . . . . . . . . . . . . . . . . . . 3

1.2 Equação da Taxa de Deformação . . . . . . . . . . . . . . 6

1.3 Adimensionalização . . . . . . . . . . . . . . . 7

1.4 Condições de Contorno . . . . . . . . . . . . . . . . . 8

2 Método Numérico $\quad 11$

2.1 Introdução . . . . . . . . . . . . . . . . . . 11

2.2 Algoritmo Computacional . . . . . . . . . . . . . . . 12

2.2.1 Cálculo da Taxa de Deformação no Contorno Rígido . . . . . . . . 15

2.3 Definição das Células . . . . . . . . . . . . . . . . 17

3 Aproximações por Diferenças Finitas $\quad 19$

3.1 Equações de Conservação de Quantidade de Movimento . . . . . . . . . . . 20

3.1.1 Discretização da Taxa de Deformação . . . . . . . . . . . . . . 20

3.1.2 Cálculo das Derivadas da Viscosidade . . . . . . . . . . . . . . 22

3.1 .3 Cálculo de $\nu(q) \ldots \ldots \ldots \ldots \ldots$

3.2 Discretização dos Termos Convectivos . . . . . . . . . . . . 25

3.3 Discretização das Condições de Contorno na Superfície Livre . . . . . . . . 29

3.4 Discretização da Taxa de Deformação no Contorno . . . . . . . . . . . . 33

3.5 Equação de Poisson . . . . . . . . . . . . . . . . . . . 36

3.6 Velocidades Finais . . . . . . . . . . . . . . 37

3.7 Controle do Passo no Tempo . . . . . . . . . . . . . . . 37

3.8 Movimento das Partículas . . . . . . . . . . . . . . . 38 
4 Ambiente de Simulação FreeFlow-2D 39

4.1 Módulos do Sistema FreeFlow-2D para Fluidos Não Newtonianos . . . . 40

4.1.1 O Modelador (Modflow-2D) . . . . . . . . . . . . 40

4.1 .2 O Simulador $($ Simflow-2D) . . . . . . . . . . . . . 40

4.1 .3 O Visualizador $($ Visflow-2D) . . . . . . . . . . . . . . 43

5 Resultados Numéricos $\quad 45$

5.1 Modelo Power-Law . . . . . . . . . . . . . . . . . . 45

5.1 .1 Simulação do Efeito "Jet Buckling" . . . . . . . . . . . . . . 47

5.1 .2 Validação Quantitativa . . . . . . . . . . . . . . 51

5.2 Modelo de Cross . . . . . . . . . . . . . . . . 56

5.2.1 Simulação de um Jato Incidindo Perpendicularmente em uma Superfície Plana . . . . . . . . . . . . . 56 56

5.2.2 Instabilidade na Simulação Numérica de Escoamentos de Fluidos Não Newtonianos . . . . . . . . . . . . . . . 58

5.2 .3 Validação Quantitativa . . . . . . . . . . . . . . . 61

5.2 .4 Extrudate Swell . . . . . . . . . . . . . . . . . . . 64

5.2 .5 Efeito "Jet Buckling" . . . . . . . . . . . . . . . 68

$\begin{array}{llr}6 & \text { Conclusão } & 71\end{array}$

$\begin{array}{ll}\text { Referências Bibliográficas } & \mathbf{7 4}\end{array}$ 


\section{Lista de Figuras}

2.1 a) Contorno rígido vertical, b) Contorno rígido horizontal. . . . . . . . 15

2.2 Tipos de células no domínio computacional. . . . . . . . . . . 17

3.1 Exemplo de uma célula da malha. . . . . . . . . . . . . . 19

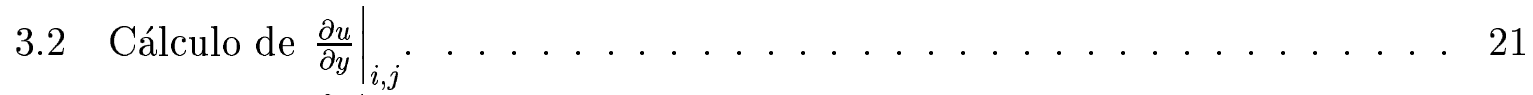

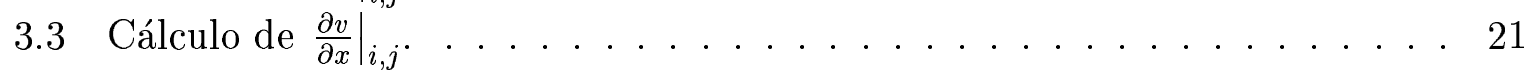

3.4 Stencil usado para calcular $\phi_{A}$ e $\phi_{B}$ usando vários esquemas. . . . . . . . 25

3.5 Célula $\mathrm{S}$ com lado direito em contato com uma célula $\mathrm{E}$. . . . . . . . . 29

3.6 Célula $\mathrm{S}$ com duas faces adjacentes em contato com células E. . . . . . . 31

3.7 Células $(i, j+1)$ e $(i+1, j+1)$, F ou S. . . . . . . . . . 33

3.8 Células $(i, j+1)$ e $(i+1, j+1)$, B ou I. . . . . . . . . . 34

3.9 Células $(i-1, j)$ e $(i+2, j)$, F ou S. . . . . . . . . 35

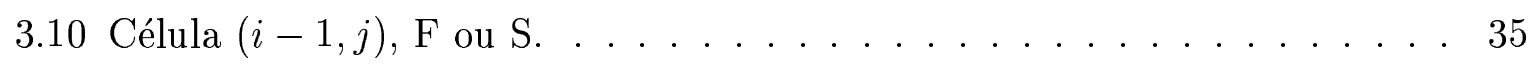

3.11 Célula $(i+2, j), \mathrm{F}$ ou S. . . . . . . . . . . . 35

4.1 Janela de entrada de dados para definição do modelo de escoamento não newtoniano. . . . . . . . . . . . . . . . . 41

4.2 Janela de entrada de dados para os modelos a) Cross e b) power-law. . . . 41

4.3 Visualização da variação da taxa de deformação ("Shear Rate") utilizando o módulo Visflow-2D. . . . . . . . . . . . . . . . . . . 44

4.4 Visualização da variação da viscosidade ("Viscosity") utilizando o módulo Visflow-2D. ............................ 44

5.1 Fluido "shear thinning". . . . . . . . . . . . . . . . 46

5.2 Caso 1 newtoniano. . . . . . . . . . . . . . . . . 48

5.3 Caso 2 não newtoniano. . . . . . . . . . . . . . . . . 48

5.4 Caso 3 newtoniano. . . . . . . . . . . . . . . . . . 49 
5.5 Caso 4 não newtoniano. . . . . . . . . . . . . . . . . . . 49

5.6 Caso 5 não newtoniano. . . . . . . . . . . . . . 50

5.7 Campo de velocidade no tempo $t=0.80 \mathrm{~s}$, para o caso 5 não newtoniano. . 51

5.8 Campo de pressão e viscosidade no tempo $t=0.80 \mathrm{~s}$, para o caso 5 não

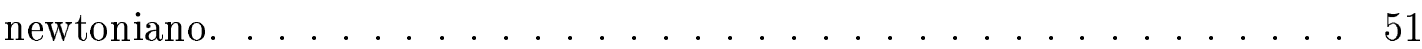

5.9 Escoamento entre duas placas. . . . . . . . . . . . . . . 52

5.10 Solução analítica para vários valores de $n . \quad \ldots \ldots \ldots$. . . . . . . 53

5.11 Malha computacional com $120 \times 20$ células. . . . . . . . . . . . . . 54

5.12 Perfil para $n=0.4 \ldots \ldots \ldots \ldots \ldots \ldots$

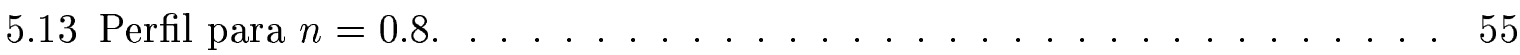

5.14 Campo de velocidade na direção $x$, no tempo $t=25.20 \ldots \ldots \ldots \ldots$

5.15 Campo de viscosidade no tempo $t=25.20 \ldots \ldots \ldots \ldots$

5.16 Representação esquemática do molde para a simulação de um jato incidindo perpendicularmente em uma superfície plana. . . . . . . . . . . . . 57

5.17 Simulação numérica de um jato incidindo em uma superfície plana. . . . . 57

5.18 Variação da viscosidade . . . . . . . . . . . . . . . . . . . 58

5.19 Escoamento entre duas placas paralelas . . . . . . . . . . . . . . 58

5.20 Variação da função $\gamma(q)$ para vários valores de $m$. Com os parâmetros do modelo Cross: $\nu_{0}=0.02, \nu_{\infty}=0.001, K=1$ e $U=0.5, L=0.01 . \ldots .60$

5.21 Simulação numérica de um jato planar utilizando os parâmetros: $\nu_{0}=0.02$, $\nu_{\infty}=0.001, K=1, U=0.5, L=0.01$, e no caso a) $m=1$ e no caso b)

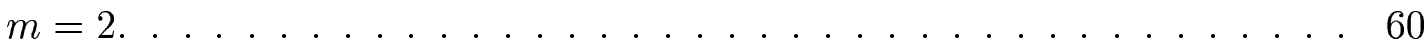

5.22 Solução analítica para vários valores do parâmetro K. . . . . . . . . . . 61

5.23 Comparação entre soluções numéricas e analítica, para um perfil de velocidade com $K=0.0034$, nas três malhas (fina, intermediária e grossa). . . . 63

5.24 Zoom da região mais crítica do perfil de velocidade dado na figura 5.23. . . 63

5.25 Representação esquemática de um molde para a simulação do escoamento "extrudate swell". . . . . . . . . . . . . . . . . . . 64

5.26 Visualização de um jato de agua saindo de uma torneira. . . . . . . . . 65

5.27 Visualização de um jato newtoniano viscoso. . . . . . . . . . . . . 65

5.28 Simulação numérica do "extrudate", para a) newtoniano, b) $K=0.15$, c) $K=0.75$ e d) $K=1.0$, utilizando uma malha $180 \times 40$ células. . . . . . 66 
5.29 Simulação numérica do "extrudate swell", no tempo $t=0.016 \mathrm{~s}$, para a) newtoniano, $S_{r}=1.11807$, b) $K=0.15, S_{r}=1.07228$, c) $K=0.75$, $\left.S_{r}=1.02168 \mathrm{e} \mathrm{d}\right) K=1.0, S_{r}=1.002898 \ldots \ldots \ldots . \ldots . \ldots 67$

5.30 Campo de velocidade no tempo $t=0.016 s$, para $K=0.75 \ldots \ldots$. . . . 67

5.31 Campo de pressão e viscosidade no tempo $t=0.016 \mathrm{~s}$, para $K=0.75 \ldots$. 68

5.32 Jato newtoniano (lado esquerdo) e não newtoniano (lado direito) para tempos diferentes. . . . . . . . . . . . . . . . . 69 


\section{Introdução}

Com o grande avanço da tecnologia computacional e também das técnicas numéricas, tornam-se possíveis a modelagem e simulação de muitos problemas em mecânica dos fluidos. Entre os diversos problemas surgidos, o problema de escoamentos com superfícies livres tem atraido a atenção de um grande número de pesquisadores. Convivemos com esse tipo de escoamento diáriamente, por exemplo a água caindo da torneira, o mel escoando de uma garrafa, a tinta escorrendo na parede. Este tipo de problema aparece também em muitas aplicações industriais tais como; injeção de plásticos, ligas metálicas e fluidos da indústria alimentícia. O estudo de técnicas numéricas para simular problemas de escoamento de fluidos se faz necessário, na medida em que, com os resultados da simulação numérica pode-se otimizar projetos, reduzindo-se assim os custos operacionais e melhorando-se o desempenho dos processos industriais.

Com o objetivo de desenvolver técnicas numéricas para resolver estes problemas, e prever como o escoamento se comporta durante o processo industrial, o grupo de pesquisa em matemática aplicada do ICMC-USP (Instituto de Ciências Matemáticas e de Computação da Universidade de São Paulo) desenvolveu um ambiente de simulação de escoamentos de fluidos incompressíveis bidimensionais, denominado FreeFlow-2D (Oliveira, 1999).

O FreeFlow-2D é um software capaz de simular escoamentos newtonianos incompressíveis com superfícies livres em duas dimensões. Esse ambiente é constituído de três módulos: O Modflow-2D, módulo responsável pela modelagem de moldes e escoamentos; o módulo Simflow-2D que é a parte principal do software onde são implementadas as equações governantes e as condições de contorno, e o módulo Visflow-2D, responsável pela visualização dos dados produzidos pelo simulador.

O módulo Simflow-2D foi implementado com base no método GENSMAC (GeneralizedSimplified-Marker-and-Cell) (Tomé, 1993), que é uma extensão do método SMAC (SimplifiedMarker-and-Cell), voltado para a simulação de escoamentos transientes bidimensionais com superfícies livres em domínios arbitrários. O código GENSMAC emprega a técnica de 
diferenças finitas para resolver numericamente escoamentos incompressíveis numa malha uniforme empregando a velocidade e pressão como variáveis dependentes. A característica principal desse método é o uso de partículas marcadoras que permitem a visualização do escoamento e a localização da superfície livre do fluido.

O FreeFlow-2D possui uma estrutura de dados que permite a extensão de seus módulos, tais como, a extensão do Simflow-2D para escoamentos de fluidos não newtonianos. O estudo de fluidos não newtonianos é bastante complexo e difere em muitos aspectos do estudo de fluidos newtonianos. Os fluidos newtonianos são modelados por apenas uma equação constitutiva, válida para qualquer regime de escoamento. Os fluidos não newtonianos podem ser modelados por inúmeras equações constitutivas, dependendo do tipo do fluido que se quer modelar. Dessa forma, a fim de se analisar um fluido não newtoniano, torna-se necessária em primeiro lugar, a definição do modelo constitutivo que melhor representa as características do fluido e do escoamento.

A importância do estudo de fluidos não newtonianos vem crescendo consideravelmente, devido a grande utilização desse tipo de fluido em diversas atividades econômicas. A comunidade de pesquisadores e profissionais que trabalham com tais problemas tem aumentado consideravelmente nos últimos anos, sendo uma área de grande atuação no momento.

Esse trabalho tem como objetivo o estudo das equações que governam o escoamento de um fluido não newtoniano, bem como estender o sistema FreeFlow-2D para a simulação de problemas de escoamentos de fluidos newtonianos generalizados tipo "power-law" e Cross. 


\section{Capítulo 1}

\section{Equações Governantes}

\subsection{Equações Básicas}

Todos os processos contínuos que ocorrem em um fluido são governados pelas equações derivadas de três princípios básicos: conservação de massa, conservação de quantidade de movimento e conservação de energia. Essas equações (equação de conservação de massa, equação de conservação de quantidade de movimento e equação de conservação de energia) juntas não constituem um sistema fechado, no sentido que existem mais incógnitas que equações. Para fechar o conjunto, é preciso fornecer informações adicionais sobre a natureza do fluido. Aqui considera-se o escoamento transiente, isotérmico e incompressível. Neste caso a equação de conservação de energia não é considerada (ver por exemplo (Ferreira et al., 1997)). O escoamento é regido pelas equações:

- Conservação de massa

$$
\nabla \cdot \mathbf{u}=0
$$

- Conservação de quantidade de movimento (segunda lei de Newton): a taxa de variação temporal de momento do fluido é igual a resultante das forças que atua sobre o fluido.

$$
\rho \frac{D \mathbf{u}}{D t}=\nabla \cdot \underline{\underline{\boldsymbol{\sigma}}}+\rho \mathbf{g}
$$

onde $\mathbf{u}(\mathbf{x}, t)$ é a velocidade e $\mathbf{g}$ o campo gravitacional e

$$
\underline{\underline{\sigma}}=-p \underline{\underline{\mathbf{I}}}+\underline{\underline{\tau}}
$$

o tensor das tensões, $p$ a pressão, $\underline{\underline{\mathbf{I}}}$ o tensor identidade e $\underline{\underline{\tau}}$ o tensor extra tensão. 
Nesse trabalho consideram-se fluidos newtonianos generalizados definidos pela equação constitutiva

$$
\underline{\underline{\tau}}=2 \mu(q) \underline{\underline{\mathbf{d}}}
$$

onde $\mu(q)$ é a viscosidade aparente (função conhecida de $q$ ) que depende da taxa de deformação local e do tensor taxa de deformação definido por:

$$
q=\left(2 \operatorname{tr}\left(\underline{\underline{\mathbf{d}}}^{2}\right)\right)^{\frac{1}{2}} \quad \mathrm{e} \quad \underline{\underline{\mathbf{d}}}=\frac{1}{2}\left[(\nabla \mathbf{u})+(\nabla \mathbf{u})^{T}\right]
$$

É conveniente definir a viscosidade cinemática como $\nu=\mu / \rho$.

Assim, as equações (1.1) e (1.2) formam um sistema de equações diferenciais parciais para as incógnitas $\mathbf{u}(\mathbf{x}, t)$ e $p(\mathbf{x}, t)$.

Nesse trabalho consideram-se escoamentos incompressíveis e bidimensionais. Utilizandose coordenadas cartesianas temos

$$
\mathbf{u}(\mathbf{x}, t)=\left(\begin{array}{c}
u(\mathbf{x}, t) \\
v(\mathbf{x}, t)
\end{array}\right) \quad \text { e } \quad \mathbf{x}=\left(\begin{array}{l}
x \\
y
\end{array}\right)
$$

tem-se

$$
\nabla \mathbf{u}=\nabla\left[\begin{array}{c}
u \\
v
\end{array}\right]=\left[\begin{array}{cc}
\frac{\partial u}{\partial x} & \frac{\partial u}{\partial y} \\
\frac{\partial v}{\partial x} & \frac{\partial v}{\partial y}
\end{array}\right] \quad \text { e } \quad(\nabla \mathbf{u})^{T}=\left[\begin{array}{cc}
\frac{\partial u}{\partial x} & \frac{\partial v}{\partial x} \\
\frac{\partial u}{\partial y} & \frac{\partial v}{\partial y}
\end{array}\right]
$$

Então, em (1.5)

$$
\underline{\underline{\mathbf{d}}}=\frac{1}{2}\left[\begin{array}{cc}
2 \frac{\partial u}{\partial x} & \frac{\partial u}{\partial y}+\frac{\partial v}{\partial x} \\
\frac{\partial v}{\partial x}+\frac{\partial u}{\partial y} & 2 \frac{\partial v}{\partial y}
\end{array}\right]
$$

e portanto

$$
\underline{\boldsymbol{\tau}}=\mu(q)\left[\begin{array}{cc}
2 \frac{\partial u}{\partial x} & \frac{\partial u}{\partial y}+\frac{\partial v}{\partial x} \\
\frac{\partial v}{\partial x}+\frac{\partial u}{\partial y} & 2 \frac{\partial v}{\partial y}
\end{array}\right]
$$


Logo (1.3) pode ser escrita como

$$
\begin{gathered}
\underline{\underline{\sigma}}=\left[\begin{array}{cc}
-p & 0 \\
0 & -p
\end{array}\right]+\mu(q)\left[\begin{array}{cc}
2 \frac{\partial u}{\partial x} & \frac{\partial u}{\partial y}+\frac{\partial v}{\partial x} \\
\frac{\partial u}{\partial y}+\frac{\partial v}{\partial x} & 2 \frac{\partial v}{\partial y}
\end{array}\right] \\
=\left[\begin{array}{cc}
-p+2 \mu(q) \frac{\partial u}{\partial x} & \mu(q)\left(\frac{\partial u}{\partial y}+\frac{\partial v}{\partial x}\right) \\
\mu(q)\left(\frac{\partial u}{\partial y}+\frac{\partial v}{\partial x}\right) & -p+2 \mu(q) \frac{\partial v}{\partial y}
\end{array}\right] .
\end{gathered}
$$

Assim,

$\nabla \cdot \underline{\underline{\sigma}}=\left[\begin{array}{c}-\frac{\partial p}{\partial x}+\mu(q)\left(\frac{\partial^{2} u}{\partial x^{2}}+\frac{\partial^{2} u}{\partial y^{2}}\right)+\mu(q) \frac{\partial}{\partial x}\left(\frac{\partial u}{\partial x}+\frac{\partial v}{\partial y}\right)+2 \frac{\partial \mu(q)}{\partial x} \frac{\partial u}{\partial x}+\frac{\partial \mu(q)}{\partial y}\left(\frac{\partial u}{\partial y}+\frac{\partial v}{\partial x}\right) \\ -\frac{\partial p}{\partial y}+\mu(q)\left(\frac{\partial^{2} v}{\partial x^{2}}+\frac{\partial^{2} v}{\partial y^{2}}\right)+\mu(q) \frac{\partial}{\partial y}\left(\frac{\partial u}{\partial x}+\frac{\partial v}{\partial y}\right)+2 \frac{\partial \mu(q)}{\partial y} \frac{\partial v}{\partial y}+\frac{\partial \mu(q)}{\partial x}\left(\frac{\partial u}{\partial y}+\frac{\partial v}{\partial x}\right)\end{array}\right]$

Utilizando a equação da continuidade, $\nabla \cdot \underline{\underline{\sigma}}$ se reduz a

$$
\nabla \cdot \underline{\underline{\boldsymbol{\sigma}}}=\left[\begin{array}{c}
-\frac{\partial p}{\partial x}+\mu(q)\left(\frac{\partial^{2} u}{\partial x^{2}}+\frac{\partial^{2} u}{\partial y^{2}}\right)+2 \frac{\partial \mu(q)}{\partial x} \frac{\partial u}{\partial x}+\frac{\partial \mu(q)}{\partial y}\left(\frac{\partial u}{\partial y}+\frac{\partial v}{\partial x}\right) \\
-\frac{\partial p}{\partial y}+\mu(q)\left(\frac{\partial^{2} v}{\partial x^{2}}+\frac{\partial^{2} v}{\partial y^{2}}\right)+2 \frac{\partial \mu(q)}{\partial y} \frac{\partial v}{\partial y}+\frac{\partial \mu(q)}{\partial x}\left(\frac{\partial u}{\partial y}+\frac{\partial v}{\partial x}\right)
\end{array}\right]
$$

Logo, a equação (1.7) pode ser escrita como

$$
\nabla \cdot \underline{\underline{\boldsymbol{\sigma}}}=-\nabla p+\mu(q) \nabla^{2} \mathbf{u}+(\nabla \mu(q))\left[(\nabla \mathbf{u})+(\nabla \mathbf{u})^{T}\right]
$$

Por outro lado, aplicando o operador diferencial

$$
\frac{D}{D t}=\frac{\partial}{\partial t}+(\mathbf{u} \cdot \nabla)
$$

sobre o vetor $\mathbf{u}$, obtém-se

$$
\frac{D \mathbf{u}}{D t}=\frac{\partial \mathbf{u}}{\partial t}+(\mathbf{u} \cdot \nabla) \mathbf{u}
$$

que na forma conservativa é dado por

$$
\frac{D \mathbf{u}}{D t}=\frac{\partial \mathbf{u}}{\partial t}+\nabla \cdot(\mathbf{u u})
$$

onde

$$
\nabla \cdot(\mathbf{u u})=\nabla\left[\begin{array}{cc}
u^{2} & (u v) \\
(u v) & v^{2}
\end{array}\right]=\left[\begin{array}{c}
\frac{\partial u^{2}}{\partial x}+\frac{\partial(u v)}{\partial y} \\
\frac{\partial(u v)}{\partial x}+\frac{\partial v^{2}}{\partial y}
\end{array}\right]
$$


e obtém-se

$$
\frac{D \mathbf{u}}{D t}=\frac{\partial \mathbf{u}}{\partial t}+\nabla \cdot(\mathbf{u u})=\left[\begin{array}{l}
\frac{\partial u}{\partial t}+\frac{\partial u^{2}}{\partial x}+\frac{\partial(u v)}{\partial y} \\
\frac{\partial v}{\partial t}+\frac{\partial(u v)}{\partial x}+\frac{\partial v^{2}}{\partial y}
\end{array}\right]
$$

Dividindo (1.2) por $\rho$ tem-se

$$
\frac{D \mathbf{u}}{D t}=\frac{1}{\rho} \nabla \cdot \underline{\underline{\sigma}}+\mathbf{g}
$$

Assim, a partir dos valores obtidos em (1.7) e (1.8), substituidos em (1.9), juntamente com a equação da conservação de massa, obtêm-se em coordenadas cartesianas bidimensionais as equações de quantidade de movimento para escoamentos incompressíveis transiente e isotérmico.

- Equações de conservação de quantidade de movimento

$$
\begin{aligned}
\frac{\partial u}{\partial t}= & -\frac{1}{\rho} \frac{\partial p}{\partial x}-\frac{\partial\left(u^{2}\right)}{\partial x}-\frac{\partial(u v)}{\partial y}+\nu(q)\left(\frac{\partial^{2} u}{\partial x^{2}}+\frac{\partial^{2} u}{\partial y^{2}}\right) \\
& +\left[2 \frac{\partial u}{\partial x} \frac{\partial \nu(q)}{\partial x}+\left(\frac{\partial u}{\partial y}+\frac{\partial v}{\partial x}\right) \frac{\partial \nu(q)}{\partial y}\right]+g_{x} \\
\frac{\partial v}{\partial t}= & -\frac{1}{\rho} \frac{\partial p}{\partial y}-\frac{\partial\left(v^{2}\right)}{\partial y}-\frac{\partial(u v)}{\partial x}+\nu(q)\left(\frac{\partial^{2} v}{\partial x^{2}}+\frac{\partial^{2} v}{\partial y^{2}}\right) \\
& +\left[2 \frac{\partial v}{\partial y} \frac{\partial \nu(q)}{\partial y}+\left(\frac{\partial u}{\partial y}+\frac{\partial v}{\partial x}\right) \frac{\partial \nu(q)}{\partial x}\right]+g_{y},
\end{aligned}
$$

onde $\mathbf{g}=\left(g_{x}, g_{y}\right), \mathbf{u}=(u(x, y, t), v(x, y, t))$ e $p=p(x, y, t)$ é a pressão.

- Equação de conservação de massa

$$
\frac{\partial u}{\partial x}+\frac{\partial v}{\partial y}=0
$$

\subsection{Equação da Taxa de Deformação}

A taxa de deformação local é definida pela equação

$$
q=\left(2 \operatorname{tr}\left(\underline{\underline{\mathbf{d}}}^{2}\right)\right)^{\frac{1}{2}}
$$


onde $\underline{\underline{\mathbf{d}}}=\frac{1}{2}\left[(\nabla \mathbf{u})+(\nabla \mathbf{u})^{T}\right]$. Em coordenadas cartesianas bidimensionais, a equação (1.12) pode ser escrita da seguinte forma

$$
q=\left[2\left(\frac{\partial u}{\partial x}\right)^{2}+2\left(\frac{\partial v}{\partial y}\right)^{2}+\left(\frac{\partial u}{\partial y}+\frac{\partial v}{\partial x}\right)^{2}\right]^{\frac{1}{2}}
$$

A viscosidade cinemática $\nu(q)$ é uma função conhecida da taxa de deformação. Os modelos mais utilizados para representar a viscosidade de fluidos newtonianos generalizados são os modelos do tipo Cross e "power-law" dados por

- Cross:

$$
\nu(q)=\nu_{\infty}+\frac{\left(\nu_{0}-\nu_{\infty}\right)}{\left(1+(K q)^{m}\right)}
$$

sendo $m, \nu_{0}, \nu_{\infty}$ e $K$, constantes positivas.

- "Power-law":

$$
\nu(q)=K q^{n-1}
$$

sendo $K$ uma constante positiva.

\subsection{Adimensionalização}

Considerando-se que o escoamento é caracterizado por um comprimento característico $L$, uma velocidade característica $U$ e uma viscosidade cinemática $\nu_{0}$. Definem-se as variáveis adimensionais pelas trasnformações

$$
\begin{aligned}
u & =U \bar{u}, \\
x & =L \bar{x}, \\
\nu & =\nu_{0} \bar{\nu} \\
t & =\frac{L}{U} \bar{t} \\
p & =\rho U^{2} \bar{p} \\
q & =\frac{U}{L} \bar{q}, \\
g & =g \bar{g} .
\end{aligned}
$$


Substituindo-se essas variáveis nas equações (1.10) e (1.11), obtêm-se as equações na forma adimensional (as barras foram omitidas por simplicidade).

É conveniente escrever as equações na forma vetorial,

$$
\begin{gathered}
\frac{\partial \mathbf{u}}{\partial t}=-\nabla p+N(\mathbf{u}), \\
\nabla \cdot \mathbf{u}=0,
\end{gathered}
$$

onde $N(\mathbf{u})=\left(\begin{array}{c}N_{1}(\mathbf{u}) \\ N_{2}(\mathbf{u})\end{array}\right)$ é dado por:

$$
\begin{aligned}
N_{1}= & -C O N V(u)+\frac{1}{R e} \nu(q)\left(\frac{\partial^{2} u}{\partial x^{2}}+\frac{\partial^{2} u}{\partial y^{2}}\right)+\frac{1}{R e}\left[2 \frac{\partial u}{\partial x} \frac{\partial \nu(q)}{\partial x}+\left(\frac{\partial u}{\partial y}+\frac{\partial v}{\partial x}\right) \frac{\partial \nu(q)}{\partial y}\right] \\
& +\frac{1}{F r^{2}} g_{x}
\end{aligned}
$$

$$
\begin{aligned}
N_{2}= & -C O N V(v)+\frac{1}{R e} \nu(q)\left(\frac{\partial^{2} v}{\partial x^{2}}+\frac{\partial^{2} v}{\partial y^{2}}\right)+\frac{1}{R e}\left[2 \frac{\partial v}{\partial y} \frac{\partial \nu(q)}{\partial y}+\left(\frac{\partial u}{\partial y}+\frac{\partial v}{\partial x}\right) \frac{\partial \nu(q)}{\partial x}\right] \\
& +\frac{1}{F r^{2}} g_{y}
\end{aligned}
$$

onde $C O N V(v)=\frac{\partial v^{2}}{\partial y}+\frac{\partial(u v)}{\partial x}$ e $C O N V(u)=\frac{\partial u^{2}}{\partial x}+\frac{\partial(u v)}{\partial y}$ são os termos convectivos da equação, Re é uma constante adimensional denominada número de Reynolds, dada por $R e=\frac{\rho L U}{\mu}$ e $F r$ é conhecido como número de Froude, dado por $F r=\frac{U}{\sqrt{L|g|}}$.

A taxa de deformação adimensionalizada é dada por

$$
q=\left[2\left(\frac{\partial u}{\partial x}\right)^{2}+2\left(\frac{\partial v}{\partial y}\right)^{2}+\left(\frac{\partial u}{\partial y}+\frac{\partial v}{\partial x}\right)^{2}\right]^{\frac{1}{2}}
$$

\subsection{Condições de Contorno}

Neste trabalho vamos tratar escoamentos transientes com superfície livre de um fluido viscoso dentro de uma atmosfera passiva, na qual pode-se tomar a pressão inicial como sendo nula. As condições de contorno a serem impostas são: 
- Contorno rígido: No contorno rígido a condição utilizada é a "no-slip" (não deslizamento),

$$
\mathbf{u}=\mathbf{u}_{b}
$$

onde $\mathbf{u}_{b}$ é a velocidade no contorno rígido. Usualmente o contorno está fixo e estacionário, e nesse caso toma-se $\mathbf{u}_{b}=0$.

- Contorno de simetria: A condição de simetria utilizada é a "free-slip",

$$
u_{n}=0 \text { e } \frac{\partial u_{t}}{\partial n}=0 \text { (no eixo de simetria) }
$$

onde $u_{n}$ é a velocidade na direção normal ao eixo de simetria e $u_{t}$ é a velocidade tangencial.

- Injetor: Condição de entrada de fluido,

$$
u=u_{i n f} \quad \text { e } \quad v=0
$$

onde $u_{\text {inf }}$ é a velocidade no injetor.

- Ejetor: Condição de saída do fluido

$$
\frac{\partial u_{t}}{\partial n}=0 \quad \text { e } u_{n}=u_{o u t}
$$

onde $u_{n}$ é a velocidade normal ao ejetor e $u_{t}$ é a velocidade tangencial ao ejetor.

- Na superfície livre: Com a ausência da tensão superficial, as componentes de tensão normal e tangencial devem ser contínuas sobre tais superfícies. Exige-se então que ambas as tensões se anulem (Tomé, 1993)

$$
\begin{aligned}
& \mathbf{n} \cdot(\underline{\underline{\boldsymbol{\sigma}}} \cdot \mathbf{n})=0, \\
& \mathbf{m} \cdot(\underline{\underline{\boldsymbol{\sigma}}} \cdot \mathbf{n})=0,
\end{aligned}
$$

onde $\mathbf{n}=\left(n_{x}, n_{y}\right)$ é um vetor unitário exterior à superfície, e $\mathbf{m}=\left(m_{x}, m_{y}\right)=$ $\left(-n_{y}, n_{x}\right)$, um vetor tangente unitário.

Considerando coordenadas cartesianas, as equações (1.18) e (1.19) podem ser escritas na forma adimensional como (Tomé et al., 1996),

$$
\begin{gathered}
-p+2 \frac{\nu(q)}{R e}\left[\frac{\partial u}{\partial x} n_{x}^{2}+\left(\frac{\partial u}{\partial y}+\frac{\partial v}{\partial x}\right) n_{x} n_{y}+\frac{\partial v}{\partial y} n_{y}^{2}\right]=0 \\
2\left(\frac{\partial v}{\partial y}-\frac{\partial u}{\partial x}\right) n_{y} n_{x}+\left(\frac{\partial u}{\partial y}+\frac{\partial v}{\partial x}\right)\left(n_{x}^{2}-n_{y}^{2}\right)=0 .
\end{gathered}
$$




\section{Capítulo 2}

\section{Método Numérico}

\subsection{Introdução}

O método MAC (Marker-and-Cell) foi uma das primeiras tentativas bem sucedidas a ser utilizada em escoamentos incompressíveis com superfícies livres. Ele emprega uma malha fixa de volumes de controle, em que a posição do fluido em movimento é determinada por um conjunto de partículas marcadoras sem massa, sem volume ou quaisquer outras propriedades. As posições dessas partículas são obtidas de acordo com o campo de velocidade atualizado no tempo.

Vários outros pesquisadores apresentaram modificações, extensões ou variações da metodologia MAC, dentre eles podem-se citar os trabalhos de Hirt e Shannon (Hirt e Shannon, 1968) e Nichols e Hirt (Nichols e Hirt, 1973) que aplicaram as condições de contorno fisicamente corretas na fronteira livre do fluido. Amsden e Harlow (Amsden e Harlow, 1970) introduziram o método SMAC (Simplified-Marker-and-Cell) para eliminar as dificuldades associadas com a aplicação das condições de fronteira do MAC. Utilizando as mesmas condições de contorno empregadas por Hirt e Shannon, Tomé e Mckee (Tomé, 1993) desenvolveram o método GENSMAC, caracterizado como uma generalização do método SMAC para o tratamento de domínios bidimensionais arbitrários.

Nesse trabalho, para simular numericamente o movimento geral de escoamentos incompressíveis com superfícies livres adota-se a filosofia de malhas fixas, em particular o método GENSMAC. 


\subsection{Algoritmo Computacional}

A idéia básica do método GENSMAC é resolver as equações de conservação de quantidade de movimento sobre uma malha diferenciada no tempo $t=t_{0}+\delta t$, utilizando partículas marcadoras para representar o fluido. Uma vez encontrado o valor instantâneo de $\mathbf{u}(\mathbf{x}, t)$, as posições das partículas são atualizadas resolvendo $d \mathbf{x} / d t=\mathbf{u}$. Para calcular o valor da velocidade atualizada procede-se como segue.

Supõe-se que em um dado tempo $t_{0}$, o campo de velocidades $\mathbf{u}\left(\mathbf{x}, t_{0}\right)$ é conhecido e as condições de fronteira para a velocidade e pressão são dadas.

O campo de velocidade atualizado $\mathbf{u}(\mathbf{x}, t)$, é calculado como segue (Tomé et al., 1996):

1. Usando-se $\mathbf{u}\left(\mathbf{x}, t_{0}\right)$, calcula-se $q\left(\mathbf{x}, t_{0}\right)$ e $\nu\left(q\left(\mathbf{x}, t_{0}\right)\right)$.

2. Seja $\widetilde{p}\left(\mathbf{x}, t_{0}\right)$ um campo de pressão satisfazendo a condição de contorno para a pressão na superfície livre em $t=t_{0}$.

3. Calcula-se um campo de velocidade intermediário $\widetilde{\mathbf{u}}(\mathbf{x}, t)$, utilizando-se (1.13)

$$
\frac{\partial \widetilde{\mathbf{u}}}{\partial t}=-\nabla \widetilde{p}+N(\mathbf{u})
$$

onde $N(\mathbf{u})$ é dado por (1.15) e (1.16), com $\widetilde{\mathbf{u}}\left(\mathbf{x}, t_{0}\right)=\mathbf{u}\left(\mathbf{x}, t_{0}\right)$, utilizando-se a condição de fronteira correta para $\widetilde{\mathbf{u}}\left(\mathbf{x}, t_{0}\right)$.

A equação (2.1) é resolvida através do método de Euler explícito.

Subtraindo a equação (2.1) de (1.13) tem-se

$$
\frac{\partial}{\partial t}(\mathbf{u}-\widetilde{\mathbf{u}})=-\nabla(p-\widetilde{p})
$$

Aplicando-se o operador rotacional a ambos os lados de (2.2) vem

$$
\nabla \times\left[\frac{\partial}{\partial t}(\mathbf{u}-\widetilde{\mathbf{u}})\right]=\nabla \times(-\nabla(p-\widetilde{p}))
$$

donde obtém-se

$$
\nabla \times\left[\frac{\partial}{\partial t}(\mathbf{u}-\widetilde{\mathbf{u}})\right]=0
$$

Comutando os operadores vem

$$
\frac{\partial}{\partial t}[\nabla \times(\mathbf{u}-\widetilde{\mathbf{u}})]=0,
$$


ou seja

$$
\nabla \times(\mathbf{u}-\widetilde{\mathbf{u}})=f(x), \quad t \in\left[t_{0}, t_{0}+\delta t\right] \text { para algum } f(x) .
$$

$\operatorname{Mas} \mathbf{u}=\widetilde{\mathbf{u}}$ em $t=t_{0}, \log$,

$$
\nabla \times \mathbf{u}=\nabla \times \widetilde{\mathbf{u}} \quad \text { em } \quad t=t_{0}
$$

o que implica em

$$
f(x)=0 .
$$

Com isso segue que

$$
\nabla \times(\mathbf{u}-\widetilde{\mathbf{u}})=0 \quad \text { para } \quad t \in\left[t_{0}, t_{0}+\delta t\right]
$$

Assim, as "vorticidades" associadas a u e $\widetilde{\mathbf{u}}$ são iguais. Porém, $\widetilde{\mathbf{u}}$ não satisfaz $\nabla \cdot \widetilde{\mathbf{u}}=0$. Logo, seja uma função escalar $\psi(\mathbf{x}, t)$ tal que

$$
\mathbf{u}(\mathbf{x}, t)=\widetilde{\mathbf{u}}(\mathbf{x}, t)-\nabla \psi(\mathbf{x}, t)
$$

Aplicando o divergente em ambos os lados da equação (2.3), tem-se

$$
\nabla \cdot \mathbf{u}(\mathbf{x}, t)=\nabla \cdot \widetilde{\mathbf{u}}(\mathbf{x}, t)-\nabla^{2} \psi(\mathbf{x}, t)
$$

Impondo-se conservação de massa obtém-se a equação de Poisson para a função $\psi$

$$
\nabla^{2} \psi(\mathbf{x}, t)=\nabla \cdot \widetilde{\mathbf{u}}(\mathbf{x}, t)
$$

As condições de fronteira para $\psi$ são:

Condição homogênea de Newmann

$$
\frac{\partial \psi}{\partial n}=0, \text { sobre a fronteira rígida }
$$

e condição homogênea de Dirichlet

$$
\psi=0, \text { na superfície livre, }
$$

onde $n$ é a direção normal ao contorno rígido (Tomé, 1993). 
4. Cálculo da velocidade.

De (2.3) obtém-se o campo de velocidade atualizado

$$
\mathbf{u}(\mathbf{x}, t)=\widetilde{\mathbf{u}}(\mathbf{x}, t)-\nabla \psi(\mathbf{x}, t)
$$

5. Cálculo da pressão. Atualizar a pressão da seguinte maneira. Substituindo (2.5) em $(2.2)$, tem-se

$$
\frac{\partial(-\nabla \psi)}{\partial t}=-\nabla(p-\widetilde{p})
$$

Então,

$$
\frac{\partial \psi(\mathbf{x}, t)}{\partial t}=p-\widetilde{p}
$$

pode-se aproximar por

$$
\frac{\psi(\mathbf{x}, t)-\psi\left(\mathbf{x}, t_{0}\right)}{\delta t}=p-\widetilde{p}
$$

Sendo $\mathbf{u}\left(\mathbf{x}, t_{0}\right)=\widetilde{\mathbf{u}}\left(\mathbf{x}, t_{0}\right)$, e através de $(2.5)$, tem-se que

$$
\nabla \psi\left(\mathbf{x}, t_{0}\right)=0
$$

implica que $\psi\left(\mathbf{x}, t_{0}\right)$ é constante. Com $\psi\left(\mathbf{x}, t_{0}\right)=0$, a equação (2.6) torna-se

$$
p \cong \widetilde{p}+\frac{\psi}{\delta t}
$$

onde $\delta t$ é o passo no tempo. O método GENSMAC resolve de forma explícita a equação de Poisson discretizada (um sistema linear sparso e simétrico, para obter a velocidade potencial $\psi$ ).

6. Atualização das posições das partículas.

O último passo envolve o movimento das partículas marcadoras para suas novas posições. Para a representação do fluido, essas partículas são criadas nos injetores e ejetadas em todo o domínio, permitindo-se assim uma visualização do escoamento e a obtenção da orientação da superfície livre.

As coordenadas das partículas virtuais são armazenadas a cada ciclo de cálculo e então atualizadas resolvendo-se

$$
\frac{d x}{d t}=u \quad \text { e } \quad \frac{d y}{d t}=v
$$

Isso fornece as novas coordenadas das partículas e, então determina se ela se moverá para uma nova célula, ou se deixará o domínio através do ejetor. 


\subsubsection{Cálculo da Taxa de Deformação no Contorno Rígido}

No cálculo da velocidade $\widetilde{\mathbf{u}}$, são necessários os valores de $q$ na fronteira rígida. Estes valores são obtidos da seguinte forma.

a)

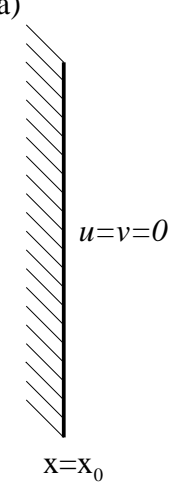

b)

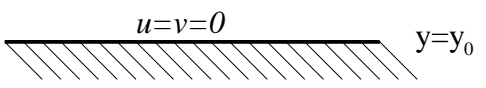

Figura 2.1: a) Contorno rígido vertical, b) Contorno rígido horizontal.

Considerando-se a condição de contorno de não deslizamento.

- Contorno rígido vertical:

No contorno rígido vertical $x=x_{0}$ tem-se (ver figura $2.1 \mathrm{a}$ )

$$
u\left(x_{0}, y\right)=0 \quad \text { e } \quad v\left(x_{0}, y\right)=0
$$

$\log 0$

$$
\frac{\partial u}{\partial y}=0 \quad \text { e } \quad \frac{\partial v}{\partial y}=0 \quad \text { para } x=x_{0}
$$

substituindo-se (2.8) e (2.9) em (1.17) obtém-se

$$
q\left(x_{0}, y\right)=\left[2\left(\frac{\partial u}{\partial x}\right)^{2}+\left(\frac{\partial v}{\partial x}\right)^{2}\right]^{\frac{1}{2}}
$$

Por continuidade $\frac{\partial u}{\partial x}=-\frac{\partial v}{\partial y}=0$. Logo, $q$ no contorno rígido vertical reduz-se a

$$
q\left(x_{0}, y\right)=\left|\frac{\partial v}{\partial x}\right|
$$

- Contorno rígido horizontal:

No contorno rígido horizontal $y=y_{0}$ tem-se (ver figura $2.1 \mathrm{~b}$ )

$$
u\left(x, y_{0}\right)=0 \quad \text { e } \quad v\left(x, y_{0}\right)=0
$$


Logo

$$
\frac{\partial u}{\partial x}=0 \quad \text { e } \quad \frac{\partial v}{\partial x}=0 \quad \text { para } y=y_{0}
$$

Substituindo-se estas condições na equação (1.17) obtém-se

$$
q\left(x, y_{0}\right)=\left[2\left(\frac{\partial v}{\partial y}\right)^{2}+\left(\frac{\partial u}{\partial y}\right)^{2}\right]^{\frac{1}{2}}
$$

Pela continuidade $\frac{\partial v}{\partial y}=-\frac{\partial u}{\partial x}=0$. Logo, $q$ no contorno rígido horizontal reduz-se a

$$
q\left(x, y_{0}\right)=\left|\frac{\partial u}{\partial y}\right|
$$

Agora se o contorno for um ejetor calcula-se $q$ da seguinte forma. Considere a condição de contorno do ejetor

$$
\frac{\partial u_{t}}{\partial n}=0
$$

se o ejetor estiver no contorno horizontal, $y=y_{0}$,

$$
\frac{\partial u}{\partial y}=0
$$

Então

$$
q\left(x, y_{0}\right)=\left[2\left(\frac{\partial u}{\partial x}\right)^{2}+2\left(\frac{\partial v}{\partial y}\right)^{2}+\left(\frac{\partial v}{\partial x}\right)^{2}\right]^{\frac{1}{2}}
$$

Se o outflow estiver no contorno vertical, $x=x_{0}$,

$$
\frac{\partial v}{\partial x}=0
$$

Então

$$
q\left(x_{0}, y\right)=\left[2\left(\frac{\partial u}{\partial x}\right)^{2}+2\left(\frac{\partial v}{\partial y}\right)^{2}+\left(\frac{\partial u}{\partial y}\right)^{2}\right]^{\frac{1}{2}}
$$




\subsection{Definição das Células}

Como o fluido está continuamente em movimento utiliza-se um procedimento para identificar a região que o contém. As células da malha podem ser:

1. Células do contorno rígido (B): São células que definem a localização do contorno rígido de maneira que as condições de contorno possam ser impostas.

2. Células vazias (E): São células que não contêm fluido.

3. Células cheias (F): São células que contêm fluido e não possuem nenhuma face em contato com células vazias.

4. Células de superfícies livre (S): São células que contêm fluido e têm pelo menos uma adjacência com uma célula vazias. Essas células definem a posição e orientação da superfície livre.

5. Células do injetor (I): São células que definem a entrada de fluido no domínio.

6. Células do ejetor $(\mathrm{O})$ : São células que definem a saída do fluido do domínio.

A figura 2.2 ilustra esses tipos de células durante um ciclo computacional.

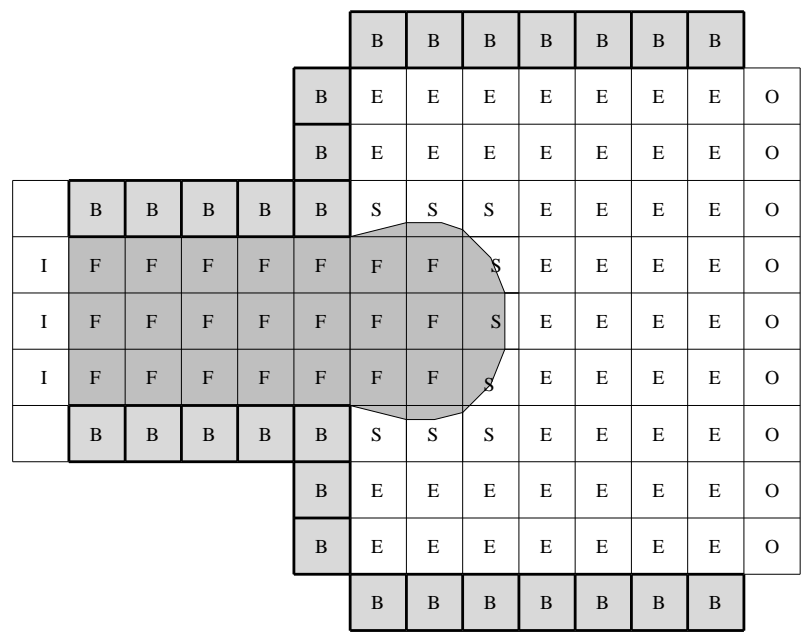

Figura 2.2: Tipos de células no domínio computacional. 


\section{Capítulo 3}

\section{Aproximações por Diferenças Finitas}

Neste trabalho utiliza-se o método de diferenças finitas para obter soluções aproximadas das equações (1.13), (2.4), (2.5) e (2.7). Utiliza-se a técnica de diferenças finitas numa malha deslocada, com células de dimensões $\delta x \times \delta y$. As variáveis discretas $p_{i, j}, \psi_{i, j}$, $\widetilde{D}_{i, j}$ e $q_{i, j}$ que denotam, respectivamente, a pressão, o potencial de velocidade, o divergente e a taxa de deformação discreta, são aproximadas no centro da célula (ver figura 3.1).

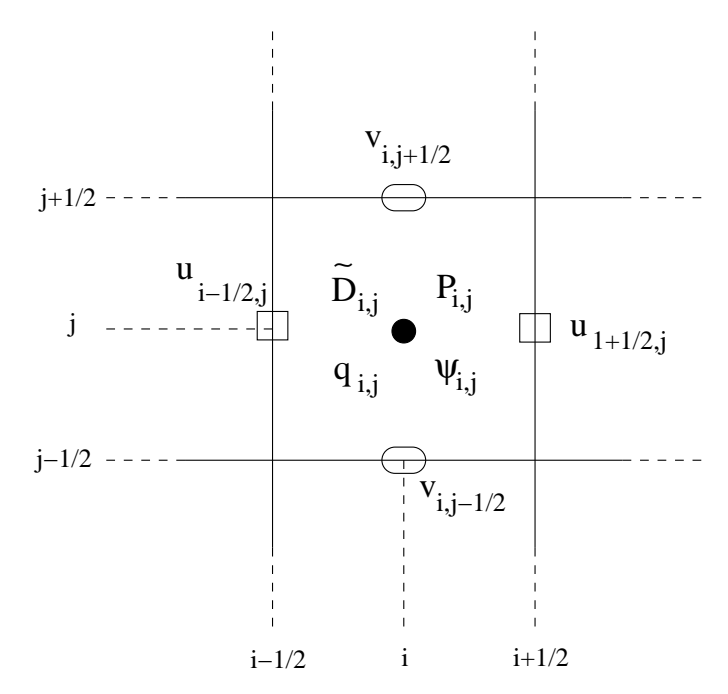

Figura 3.1: Exemplo de uma célula da malha.

As aproximações para as equações (1.13) e (1.14) são feitas utilizando-se diferenças progressivas de primeira ordem para as derivadas temporais, diferenças centrais para os gradientes de pressão e para os termos lineares espaciais que aparecem na equação. A discretização dos termos convectivos merecem uma atenção especial e será discutida em uma seção separada. 


\subsection{Equações de Conservação de Quantidade de Movi- mento}

A discretização das derivadas da equação de conservação de quantidade de movimento (1.13), na direção $x$, são feitas no ponto $\left(i+\frac{1}{2}, j\right)$, e na direção $y$ no ponto $\left(i, j+\frac{1}{2}\right)$.

$$
\begin{gathered}
\left.\frac{\partial \widetilde{u}}{\partial t}\right|_{i+\frac{1}{2}, j}=\frac{\widetilde{u}_{i+\frac{1}{2}, j}^{n+1}-\widetilde{u}_{i+\frac{1}{2}, j}^{n}}{\delta t} \\
\left.\frac{\partial \widetilde{p}}{\partial x}\right|_{i+\frac{1}{2}, j}=\frac{\widetilde{p}_{i+1, j}-\widetilde{p}_{i, j}}{\delta x} .
\end{gathered}
$$

Discretizando-se o termo $\frac{1}{R e} \nu(q)\left(\frac{\partial^{2} u}{\partial x^{2}}+\frac{\partial^{2} u}{\partial y^{2}}\right)$ da equação (1.13), na direção $x$, obtém-se

$$
\frac{1}{R e} \nu\left(q_{i+\frac{1}{2}, j}\right)\left(\frac{u_{i-\frac{1}{2}, j}-2 u_{i+\frac{1}{2}, j}+u_{i+\frac{3}{2}, j}}{\delta x^{2}}+\frac{u_{i+\frac{1}{2}, j-1}-2 u_{i+\frac{1}{2}, j}+u_{i+\frac{1}{2}, j+1}}{\delta y^{2}}\right) .
$$

Discretizando-se o termo $\frac{1}{R e}\left[2 \frac{\partial u}{\partial x} \frac{\partial \nu(q)}{\partial x}+\left(\frac{\partial u}{\partial y}+\frac{\partial v}{\partial x}\right) \frac{\partial \nu(q)}{\partial y}\right]$, da equação (1.13), na direção $x$ obtém-se

$$
\begin{array}{r}
\frac{1}{R e}\left[2\left(\frac{u_{i+\frac{3}{2}, j}-u_{i-\frac{1}{2}, j}}{2 \delta x}\right)\left[\frac{\partial \nu(q)}{\partial x}\right]_{i+\frac{1}{2}, j}+\left[\left(\frac{u_{i+\frac{1}{2}, j+1}-u_{i+\frac{1}{2}, j-1}}{2 \delta y}\right)\right.\right. \\
\left.\left.+\left(\frac{v_{i+1, j+\frac{1}{2}}+v_{i+1, j-\frac{1}{2}}-v_{i, j+\frac{1}{2}}-v_{i, j-\frac{1}{2}}}{2 \delta x}\right)\right]\left[\frac{\partial \nu(q)}{\partial y}\right]_{i+\frac{1}{2}, j}\right]
\end{array}
$$

\subsubsection{Discretização da Taxa de Deformação}

Aplicando-se a equação da taxa de deformação no centro da célula tem-se

$$
q_{i, j}=\left[\left.2\left(\frac{\partial u}{\partial x}\right)^{2}\right|_{i, j}+\left.2\left(\frac{\partial v}{\partial y}\right)^{2}\right|_{i, j}+\left.\left(\frac{\partial u}{\partial y}+\frac{\partial v}{\partial x}\right)^{2}\right|_{i, j}\right]^{\frac{1}{2}}
$$

Aproximando-se essas derivadas por diferenças centrais obtém-se

$$
\left.\frac{\partial u}{\partial x}\right|_{i, j}=\frac{u_{i+\frac{1}{2}, j}-u_{i-\frac{1}{2}, j}}{\delta x}
$$




$$
\begin{aligned}
& \left.\frac{\partial v}{\partial x}\right|_{i, j}=\frac{v_{i+\frac{1}{2}, j}-v_{i-\frac{1}{2}, j}}{\delta x} \\
& \left.\frac{\partial u}{\partial y}\right|_{i, j}=\frac{u_{i, j+\frac{1}{2}}-u_{i, j-\frac{1}{2}}}{\delta y} \\
& \left.\frac{\partial v}{\partial y}\right|_{i, j}=\frac{v_{i, j+\frac{1}{2}}-v_{i, j-\frac{1}{2}}}{\delta y} .
\end{aligned}
$$

Para o cálculo de $u_{i, j+\frac{1}{2}}$ e $u_{i, j-\frac{1}{2}}$, calcula-se a média e então aplica-se diferenças centrais (ver figura 3.2),

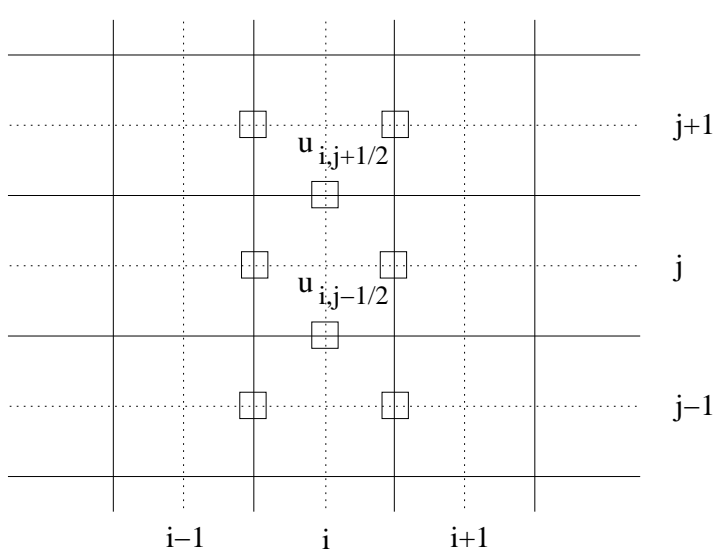

Figura 3.2: Cálculo de $\left.\frac{\partial u}{\partial y}\right|_{i, j}$.

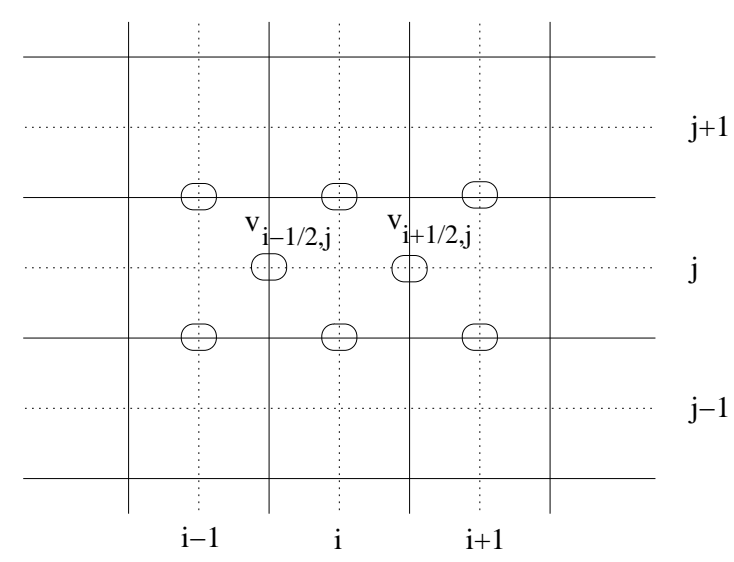

Figura 3.3: Cálculo de $\left.\frac{\partial v}{\partial x}\right|_{i, j}$.

$$
\begin{gathered}
u_{i, j+\frac{1}{2}}=\frac{u_{i+\frac{1}{2}, j+\frac{1}{2}}+u_{i-\frac{1}{2}, j+\frac{1}{2}}}{2}=\frac{1}{4}\left[u_{i+\frac{1}{2}, j}+u_{i+\frac{1}{2}, j+1}+u_{i-\frac{1}{2}, j}+u_{i-\frac{1}{2}, j+1}\right], \\
u_{i, j-\frac{1}{2}}=\frac{u_{i+\frac{1}{2}, j-\frac{1}{2}}+u_{i-\frac{1}{2}, j-\frac{1}{2}}}{2}=\frac{1}{4}\left[u_{i+\frac{1}{2}, j}+u_{i+\frac{1}{2}, j-1}+u_{i-\frac{1}{2}, j}+u_{i-\frac{1}{2}, j-1}\right]
\end{gathered}
$$

$\log 0$

$$
\left.\frac{\partial u}{\partial y}\right|_{i, j}=\frac{1}{4}\left[\frac{u_{i+\frac{1}{2}, j+1}+u_{i-\frac{1}{2}, j+1}-u_{i+\frac{1}{2}, j-1}-u_{i-\frac{1}{2}, j-1}}{\delta y}\right] .
$$


Analogamente, tem-se

$$
\left.\frac{\partial v}{\partial x}\right|_{i, j}=\frac{v_{i+\frac{1}{2}, j}-v_{i-\frac{1}{2}, j}}{\delta x}
$$

Para o cálculo de $v_{i+\frac{1}{2}, j}$ e $v_{i-\frac{1}{2}, j}$, veja a figura 3.3, os valores são obtidos como em (3.2) e (3.3) resultando em

$$
\left.\frac{\partial v}{\partial x}\right|_{i, j}=\frac{1}{4}\left[\frac{v_{i+1, j+\frac{1}{2}}+v_{i+1, j-\frac{1}{2}}-v_{i-1, j+\frac{1}{2}}-v_{i-1, j-\frac{1}{2}}}{\delta x}\right] .
$$

Substituindo-se essas aproximações na equação (3.1) obtém-se

$$
\begin{aligned}
q_{i, j}= & {\left[2\left(\frac{u_{i+\frac{1}{2}, j}-u_{i-\frac{1}{2}, j}}{\delta x}\right)^{2}+2\left(\frac{v_{i, j+\frac{1}{2}}-v_{i, j-\frac{1}{2}}}{\delta y}\right)^{2}\right.} \\
& \left.+\left(\frac{1}{4}\left[\frac{u_{i+\frac{1}{2}, j+1}+u_{i-\frac{1}{2}, j+1}-u_{i+\frac{1}{2}, j-1}-u_{i-\frac{1}{2}, j-1}}{\delta y}\right]^{\frac{1}{2}}\right]\right)^{\frac{1}{2}} . \\
& +\frac{1}{4}\left[\frac{v_{i+1, j+\frac{1}{2}}+v_{i+1, j-\frac{1}{2}}-v_{i-1, j+\frac{1}{2}}-v_{i-1, j-\frac{1}{2}}}{\delta x} .\right.
\end{aligned}
$$

A equação (3.4) é aplicada em cada célula (F) do domínio.

\subsubsection{Cálculo das Derivadas da Viscosidade}

Aproximando-se as derivadas de $\nu(q)$, utilizadas no cálculo de $\widetilde{u}$, tem-se

$$
\begin{gathered}
\left.\frac{\partial \nu(q)}{\partial x}\right|_{i+\frac{1}{2}, j}=\frac{\nu\left(q_{i+1, j}\right)-\nu\left(q_{i, j}\right)}{\delta x}, \\
\left.\frac{\partial \nu(q)}{\partial y}\right|_{i+\frac{1}{2}, j}=\frac{\nu\left(q_{i+\frac{1}{2}, j+\frac{1}{2}}\right)-\nu\left(q_{i+\frac{1}{2}, j-\frac{1}{2}}\right)}{\delta y},
\end{gathered}
$$

onde

$$
q_{i+\frac{1}{2}, j+\frac{1}{2}}=\frac{q_{i+\frac{1}{2}, j}+q_{i+\frac{1}{2}, j+1}}{2}=\frac{1}{4}\left[q_{i, j}+q_{i+1, j}+q_{i, j+1}+q_{i+1, j+1}\right]
$$

e

$$
q_{i+\frac{1}{2}, j-\frac{1}{2}}=\frac{q_{i, j-\frac{1}{2}}+q_{i-1, j-\frac{1}{2}}}{2}=\frac{1}{4}\left[q_{i, j}+q_{i, j-1}+q_{i+1, j}+q_{i+1, j-1}\right]
$$


As discretizações acima são utilizadas somente quando as células forem adjacentes a células (F) ou (S).

Se uma célula (F) for adjacente a uma célula (B) tem-se

$$
\left.\frac{\partial \nu(q)}{\partial x}\right|_{B}=\frac{\left.\nu\left(q_{i+\frac{1}{2}, j+\frac{1}{2}}\right)\right|_{B}-\nu\left(q_{i-\frac{1}{2}, j+\frac{1}{2}}\right)}{\delta x}
$$

$\mathrm{ou}$

$$
\left.\frac{\partial \nu(q)}{\partial x}\right|_{B}=\frac{\nu\left(q_{i+\frac{1}{2}, j+\frac{1}{2}}\right)-\left.\nu\left(q_{i-\frac{1}{2}, j+\frac{1}{2}}\right)\right|_{B}}{\delta x}
$$

analogamente para $\frac{\partial \nu(q)}{\partial y}$. A escolha de (3.5) ou (3.6) é feita dependendo de qual célula é adjacente a fronteira, isto é a direita ou a esquerda. Os valores de

$$
\left.\nu\left(q_{i+\frac{1}{2}, j+\frac{1}{2}}\right)\right|_{B} \quad \text { e }\left.\quad \nu\left(q_{i-\frac{1}{2}, j+\frac{1}{2}}\right)\right|_{B}
$$

são calculados utilizando-se as equações descritas na seção 3.4, de acordo com o tipo de condição de fronteira imposta.

Para as células que são adjacentes à célula (E) tem-se

$$
\left.\frac{\partial \nu(q)}{\partial x}\right|_{S}=\frac{\left.\nu\left(q_{i+\frac{1}{2}, j+\frac{1}{2}}\right)\right|_{S}-\nu\left(q_{i-\frac{1}{2}, j+\frac{1}{2}}\right)}{\delta x}
$$

$\mathrm{ou}$

$$
\left.\frac{\partial \nu(q)}{\partial x}\right|_{S}=\frac{\nu\left(q_{i+\frac{1}{2}, j+\frac{1}{2}}\right)-\left.\nu\left(q_{i-\frac{1}{2}, j+\frac{1}{2}}\right)\right|_{S}}{\delta x}
$$

analogamente para $\frac{\partial \nu(q)}{\partial y}$. A escolha de (3.7) ou (3.8) é feita dependendo de qual célula é adjacente a célula (E), isto é a direita ou a esquerda. Os valores de

$$
\left.\nu\left(q_{i+\frac{1}{2}, j+\frac{1}{2}}\right)\right|_{S} \quad \text { e }\left.\quad \nu\left(q_{i-\frac{1}{2}, j+\frac{1}{2}}\right)\right|_{S}
$$

são obtidos pelas condições de fronteira na superfície livre.

Analogamente para as derivadas de $\nu(q)$, utilizadas no cálculo de $\widetilde{v}$.

\subsubsection{Cálculo de $\nu(q)$}

O valor da viscosidade $\nu(q)$ utilizando-se o modelo Cross, nos pontos $\left(i, j+\frac{1}{2}\right)$ e $\left(i+\frac{1}{2}, j\right)$ é obtido por 


$$
\nu\left(q_{i+\frac{1}{2}, j}\right)=\nu_{\infty}+\frac{\left(\nu_{0}-\nu_{\infty}\right)}{1+\left(k q_{i+\frac{1}{2}, j}\right)^{m}}
$$

e

$$
\nu\left(q_{i, j+\frac{1}{2}}\right)=\nu_{\infty}+\frac{\left(\nu_{0}-\nu_{\infty}\right)}{1+\left(k q_{i, j+\frac{1}{2}}\right)^{m}}
$$

onde

$$
q_{i+\frac{1}{2}, j}=\frac{q_{i+1, j}+q_{i, j}}{2} \quad \text { e } \quad q_{i, j+\frac{1}{2}}=\frac{q_{i, j+1}+q_{i, j}}{2} .
$$

Analogamente para o modelo do tipo "power-law".

Introduzindo-se as aproximações feitas neste capítulo a equação de conservação de quantidade de movimento (1.13), discretizada, na direção $x$ é dada por:

$$
\begin{aligned}
\widetilde{u}_{i+\frac{1}{2}, j}^{n+1}= & u_{i+\frac{1}{2}, j}{ }^{n}+\delta t\left[-\left(\frac{\widetilde{p}_{i+1, j}-\widetilde{p}_{i, j}}{\delta x}\right)-\left.C O N V(u)\right|_{i+\frac{1}{2}, j}\right. \\
& +\frac{1}{R e} \nu\left(q_{i+\frac{1}{2}, j}\right)\left[\left(\frac{u_{i-\frac{1}{2}, j}-2 u_{i+\frac{1}{2}, j}+u_{i+\frac{3}{2}, j}}{\delta x^{2}}\right)+\left(\frac{u_{i+\frac{1}{2}, j-1}-2 u_{i+\frac{1}{2}, j}+u_{i+\frac{1}{2}, j+1}}{\delta y^{2}}\right)\right] \\
& +\frac{1}{R e}\left[2\left(\frac{u_{i+\frac{3}{2}, j}-u_{i-\frac{1}{2}, j}}{2 \delta x}\right)\left[\frac{\partial \nu(q)}{\partial x}\right]_{i+\frac{1}{2}, j}+\left[\left(\frac{u_{i+\frac{1}{2}, j+1}-u_{i+\frac{1}{2}, j-1}}{2 \delta y}\right)\right.\right. \\
& \left.\left.\left.+\left(\frac{v_{i+1, j+\frac{1}{2}}+v_{i+1, j-\frac{1}{2}}-v_{i, j+\frac{1}{2}}-v_{i, j-\frac{1}{2}}}{2 \delta x}\right)\right]\left[\frac{\partial \nu(q)}{\partial y}\right]_{i+\frac{1}{2}, j}\right]+\frac{1}{F r^{2}} g_{x}\right] .
\end{aligned}
$$

Analogamente, a equação (1.13), discretizada, na direção $y$ é dada por:

$$
\begin{aligned}
\widetilde{v}_{i, j+\frac{1}{2}}^{n+1}= & v_{i, j+\frac{1}{2}}{ }^{n}+\delta t\left[-\left(\frac{\widetilde{p}_{i, j+1}-\widetilde{p}_{i, j}}{\delta y}\right)-\left.C O N V(v)\right|_{i, j+\frac{1}{2}}\right. \\
& +\frac{1}{R e} \nu\left(q_{i, j+\frac{1}{2}}\right)\left[\left(\frac{v_{i-1, j+\frac{1}{2}}-2 v_{i, j+\frac{1}{2}}+v_{i+1, j+\frac{1}{2}}}{\delta x^{2}}\right)+\left(\frac{v_{i, j-\frac{1}{2}}-2 v_{i, j+\frac{1}{2}}+v_{i, j+\frac{3}{2}}}{\delta y^{2}}\right)\right] \\
& +\frac{1}{R e}\left[2\left(\frac{v_{i, j+\frac{3}{2}}-v_{i, j-\frac{1}{2}}}{2 \delta y}\right)\left[\frac{\partial \nu(q)}{\partial y}\right]_{i, j+\frac{1}{2}}+\left[\left(\frac{u_{i+\frac{1}{2}, j+1}+u_{i-\frac{1}{2}, j+1}-u_{i+\frac{1}{2}, j}-u_{i-\frac{1}{2}, j}}{2 \delta y}\right)\right.\right. \\
& \left.\left.\left.+\left(\frac{v_{i+1, j+\frac{1}{2}}-v_{i-1, j+\frac{1}{2}}}{2 \delta x}\right)\right]\left[\frac{\partial \nu(q)}{\partial x}\right]_{i, j+\frac{1}{2}}\right]+\frac{1}{F r^{2}} g_{y}\right]
\end{aligned}
$$

onde, $\left[\frac{\partial \nu(q)}{\partial x}\right]_{i+\frac{1}{2}, j},\left[\frac{\partial \nu(q)}{\partial y}\right]_{i+\frac{1}{2}, j},\left[\frac{\partial \nu(q)}{\partial x}\right]_{i, j+\frac{1}{2}} \mathrm{e}\left[\frac{\partial \nu(q)}{\partial y}\right]_{i, j+\frac{1}{2}}$ são obtidos como anteriormente.

Os termos convectivos $(C O N V(u)$ e $C O N V(v))$ são aproximados utilizando-se o método de alta ordem VONOS, discutido a seguir. 


\subsection{Discretização dos Termos Convectivos}

Em dinâmica dos fluidos computacional, a maneira pela qual as derivadas convectivas nas equações de conservação (1.15), (1.16) são aproximadas requer atenção especial, visto que esses termos são responsáveis por muitos fenômenos complexos nos escoamentos e são os principais causadores de dificuldades numéricas nas simulações. Devido a esses fatores, várias técnicas de discretização tem sido desenvolvidas ao longo dos anos (Ferreira et al., 2002), (Varonos e Bergeles, 1998).

Com o objetivo de completar a discretização das equações de conservação de quantidade de movimento iniciada na seção anterior, nesta seção discutem-se as aproximações para as derivadas convectivas, que estão implementadas no código FreeFlow-2D. No presente trabalho adotam-se o esquema de alta ordem VONOS (Variable Order NonOscilatory Scheme) (Varonos e Bergeles, 1998). A escolha do esquema VONOS para a discretização do termo convectivo é devido ao fato de que esquemas de alta ordem reduzem oscilações numéricas fisicamente incorretas ao mesmo tempo que minimizam os efeitos da difusão numérica artíficial. Outros métodos como SMART e o esquema HLPA (Hybrid Linear Parabolic Approximation), poderiam ser utilizados (Ferreira, 2001).

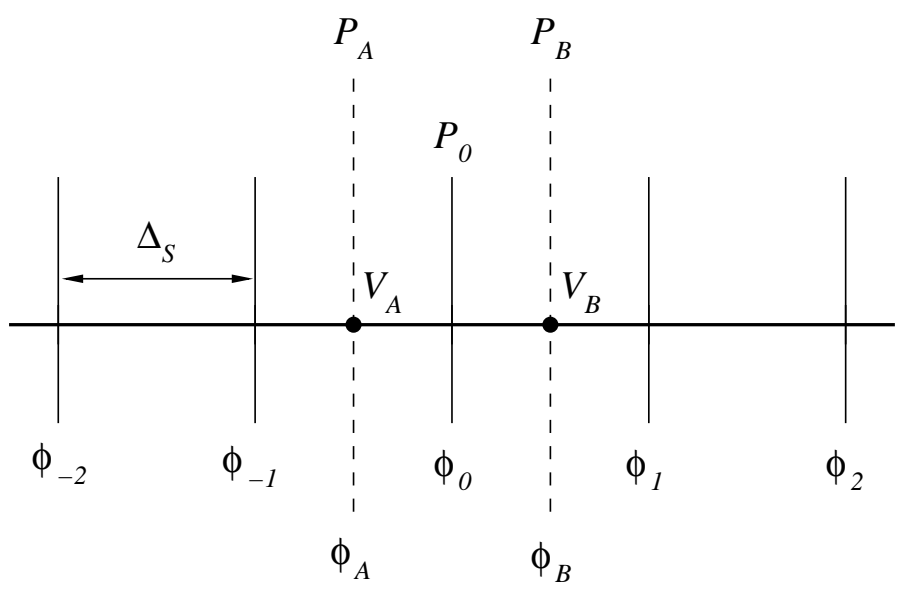

Figura 3.4: Stencil usado para calcular $\phi_{A}$ e $\phi_{B}$ usando vários esquemas.

Considere a figura 3.4, onde $\phi_{A}$ e $\phi_{B}$ são os valores da variável generica $\phi$ nos pontos $P_{A}$ e $P_{B}$, respectivamente. Para calcular a derivada parcial da variável genérica $\phi$ em um ponto $P_{0}$, digamos $\frac{\partial \phi}{\partial s}$, onde $s$ é um dos eixos coordenados, pode-se aproximar pela expressão: 


$$
\left.\frac{\partial \phi}{\partial s}\right|_{P_{0}}=\frac{\phi_{B}-\phi_{A}}{\Delta s} .
$$

Os valores de $\phi_{A}$ e $\phi_{B}$ são obtidos em termos dos valores vizinhos, $\phi_{-2}, \phi_{-1}, \phi_{0}, \phi_{1}$, $\phi_{2}$ e das direções das velocidades convectivas $\left(V_{A}, V_{B}\right)$, como segue.

- Esquema VONOS:

$$
\begin{aligned}
& \text { se } V_{B} \geq 0, \quad \phi_{B}= \begin{cases}\phi_{0}, & \text { se } \widehat{\phi}_{0} \notin[0,1] \\
10 \phi_{0}-9 \phi_{-1}, & \text { se } \widehat{\phi}_{0} \in[0,3 / 74) \\
\frac{3}{8} \phi_{1}+\frac{6}{8} \phi_{0}-\frac{1}{8} \phi_{-1}, & \text { se } \widehat{\phi}_{0} \in[3 / 74,1 / 2) \\
1.5 \phi_{0}-0.5 \phi_{-1}, & \text { se } \widehat{\phi}_{0} \in[1 / 2,2 / 3) \\
\phi_{1}, & \text { se } \widehat{\phi}_{0} \in[2 / 3,1]\end{cases} \\
& \text { se } V_{B}<0, \quad \phi_{B}= \begin{cases}\phi_{1}, & \text { se } \widehat{\phi}_{1} \notin[0,1] \\
10 \phi_{1}-9 \phi_{2}, & \text { se } \widehat{\phi}_{1} \in[0,3 / 74) \\
\frac{3}{8} \phi_{0}+\frac{6}{8} \phi_{1}-\frac{1}{8} \phi_{2}, & \text { se } \widehat{\phi}_{1} \in[3 / 74,1 / 2) \\
1.5 \phi_{1}-0.5 \phi_{2}, & \text { se } \widehat{\phi}_{1} \in[1 / 2,2 / 3) \\
\phi_{0}, & \text { se } \widehat{\phi}_{1} \in[2 / 3,1]\end{cases} \\
& \text { se } V_{A} \geq 0, \quad \phi_{A}= \begin{cases}\phi_{-1}, & \text { se } \widehat{\phi}_{-1} \notin[0,1] \\
10 \phi_{-1}-9 \phi_{-2}, & \text { se } \widehat{\phi}_{-1} \in[0,3 / 74) \\
\frac{3}{8} \phi_{0}+\frac{6}{8} \phi_{-1}-\frac{1}{8} \phi_{-2}, & \text { se } \widehat{\phi}_{-1} \in[3 / 74,1 / 2) \\
1.5 \phi_{-1}-0.5 \phi_{-2}, & \text { se } \widehat{\phi}_{-1} \in[1 / 2,2 / 3) \\
\phi_{0}, & \text { se } \widehat{\phi}_{-1} \in[2 / 3,1]\end{cases} \\
& \text { se } V_{A}<0, \quad \phi_{A}= \begin{cases}\phi_{0}, & \text { se } \widehat{\phi}_{0} \notin[0,1] \\
10 \phi_{0}-9 \phi_{1}, & \text { se } \widehat{\phi}_{0} \in[0,3 / 74) \\
\frac{3}{8} \phi_{-1}+\frac{6}{8} \phi_{0}-\frac{1}{8} \phi_{1}, & \text { se } \widehat{\phi}_{0} \in[3 / 74,1 / 2) \\
1.5 \phi_{0}-0.5 \phi_{1}, & \text { se } \widehat{\phi}_{0} \in[1 / 2,2 / 3) \\
\phi_{-1}, & \text { se } \widehat{\phi}_{0} \in[2 / 1]\end{cases}
\end{aligned}
$$

onde $\widehat{\phi}_{i},(i=-1,0,1)$ é definido em função das velocidades upstream $\left(\phi_{U}\right)$, remoteupstream $\left(\phi_{R}\right)$ e downstream $\left(\phi_{D}\right)$ no ponto $P_{A}$ e $P_{B}$, isto é, de acordo com a direção da velocidade convectiva,

$$
\widehat{\phi}_{i}=\frac{\phi_{U}-\phi_{R}}{\phi_{D}-\phi_{R}}
$$


Por exemplo, considere o ponto $P_{A}$ como mostrado na figura 3.4 e suponha que a velocidade convectiva nesse ponto é positiva $\left(V_{A}>0\right)$. Então os valores de $\phi_{D}, \phi_{U}$ e $\phi_{R}$ são dados por $\phi_{0}, \phi_{-1}$ e $\phi_{-2}$, respectivamente.

Para implementar as expressões acima, considere o termo convectivo da equação (3.9) avaliado em $\left(i+\frac{1}{2}, j\right)$, dado por

$$
C O N V(u)=\left[\frac{\partial u^{2}}{\partial x}+\frac{\partial(u v)}{\partial y}\right]_{i+\frac{1}{2}, j}=\left.\frac{\partial u^{2}}{\partial x}\right|_{i+\frac{1}{2}, j}+\left.\frac{\partial(u v)}{\partial y}\right|_{i+\frac{1}{2}, j}
$$

As derivadas da equação (3.11) podem ser aproximadas por

$$
\begin{gathered}
\left.\frac{\partial(u u)}{\partial x}\right|_{i+\frac{1}{2}, j}=\frac{\hat{u}_{i+1, j} u_{i+1, j}-\hat{u}_{i, j} u_{i, j}}{\delta x} \\
\left.\frac{\partial(u v)}{\partial y}\right|_{i+\frac{1}{2}, j}=\frac{\hat{v}_{i+\frac{1}{2}, j+\frac{1}{2}} u_{i+\frac{1}{2}, j+\frac{1}{2}}-\hat{v}_{i+\frac{1}{2}, j-\frac{1}{2}} u_{i+\frac{1}{2}, j-\frac{1}{2}}}{\delta y}
\end{gathered}
$$

onde $\hat{u}$ e $\hat{v}$ são as velocidades convectivas, e podem ser obtidas pelas médias dos valores vizinhos:

$$
\begin{aligned}
\hat{u}_{i, j} & =\frac{u_{i+\frac{1}{2}, j}+u_{i-\frac{1}{2}, j}}{2}, \\
\hat{u}_{i+1, j} & =\frac{u_{i+\frac{3}{2}, j}+u_{i+\frac{1}{2}, j}}{2}, \\
\hat{v}_{i+\frac{1}{2}, j+\frac{1}{2}} & =\frac{v_{i+1, j+\frac{1}{2}}+v_{i, j+\frac{1}{2}}}{2}, \\
\hat{v}_{i+\frac{1}{2}, j-\frac{1}{2}} & =\frac{v_{i+1, j-\frac{1}{2}}+v_{i, j-\frac{1}{2}}}{2} .
\end{aligned}
$$

As velocidades transportadas são calculadas através do esquema convectivo apresentado anteriormente (VONOS).

Por exemplo, os valores de $u_{i, j}$ e $u_{i+1, j}$ em (3.12) são obtidos como segue:

Definindo-se

$$
S_{i, j}= \begin{cases}0, & \text { se } \hat{u}_{i, j} \geq 0 \\ 1, & \text { caso contrário }\end{cases}
$$

tem-se: 
- VONOS:

$$
\begin{aligned}
& \widehat{\phi}_{i+1, j}=\left(1-S_{i+1, j}\right)\left(\frac{u_{i+\frac{1}{2}, j}-u_{i-\frac{1}{2}, j}}{u_{i+\frac{3}{2}, j}-u_{i-\frac{1}{2}, j}}\right)+S_{i+1, j}\left(\frac{u_{i+\frac{3}{2}, j}-u_{i+\frac{5}{2}, j}}{u_{i+\frac{1}{2}, j}-u_{i+\frac{5}{2}, j}}\right) \\
& u_{i+1, j}=\left(1-S_{i+1, j}\right)\left\{\begin{array}{ll}
u_{i+\frac{1}{2}, j} & \text { se } \widehat{\phi}_{i+1, j} \notin[0,1] \\
10 u_{i+\frac{1}{2}, j}-9 u_{i-\frac{1}{2}, j} & \text { se } \widehat{\phi}_{i+1, j} \in[0,3 / 74) \\
\frac{3}{8} u_{i+\frac{3}{2}, j}+\frac{6}{8} u_{i+\frac{1}{2}, j}-\frac{1}{8} u_{i-\frac{1}{2}, j} & \text { se } \widehat{\phi}_{i+1, j} \in[3 / 74,1 / 2) \\
1.5 u_{i+\frac{1}{2}, j}-0.5 u_{i-\frac{1}{2}, j} & \text { se } \widehat{\phi}_{i+1, j} \in[1 / 2,2 / 3) \\
u_{i+\frac{3}{2}, j} & \text { se } \widehat{\phi}_{i+1, j} \in[2 / 3,1]
\end{array}\right\} \\
& +S_{i+1, j}\left\{\begin{array}{ll}
u_{i+\frac{3}{2}, j} & \text { se } \widehat{\phi}_{i+1, j} \notin[0,1] \\
10 u_{i+\frac{3}{2}, j}-9 u_{i+\frac{5}{2}, j} & \text { se } \widehat{\phi}_{i+1, j} \in[0,3 / 74) \\
\frac{3}{8} u_{i+\frac{1}{2}, j}+\frac{6}{8} u_{i+\frac{3}{2}, j}-\frac{1}{8} u_{i+\frac{5}{2}, j} & \text { se } \widehat{\phi}_{i+1, j} \in[3 / 74,1 / 2) \\
1.5 u_{i+\frac{3}{2}, j}-0.5 u_{i+\frac{5}{2}, j} & \text { se } \widehat{\phi}_{i+1, j} \in[1 / 2,2 / 3) \\
u_{i+\frac{1}{2}, j} & \text { se } \widehat{\phi}_{i+1, j} \in[2 / 3,1]
\end{array}\right\} \\
& \widehat{\phi}_{i, j}=\left(1-S_{i, j}\right)\left(\frac{u_{i-\frac{1}{2}, j}-u_{i-\frac{3}{2}, j}}{u_{i+\frac{1}{2}, j}-u_{i-\frac{3}{2}, j}}\right)+S_{i, j}\left(\frac{u_{i+\frac{1}{2}, j}-u_{i+\frac{3}{2}, j}}{u_{i-\frac{1}{2}, j}-u_{i+\frac{3}{2}, j}}\right) \\
& u_{i, j}=\left(1-S_{i, j}\right)\left\{\begin{array}{ll}
u_{i-\frac{1}{2}, j} & \text { se } \widehat{\phi}_{i, j} \notin[0,1] \\
10 u_{i-\frac{1}{2}, j}-9 u_{i-\frac{3}{2}, j} & \text { se } \widehat{\phi}_{i, j} \in[0,3 / 74) \\
\frac{3}{8} u_{i+\frac{1}{2}, j}+\frac{6}{8} u_{i-\frac{1}{2}, j}-\frac{1}{8} u_{i-\frac{3}{2}, j} & \text { se } \widehat{\phi}_{i, j} \in[3 / 74,1 / 2) \\
1.5 u_{i-\frac{1}{2}, j}-0.5 u_{i-\frac{3}{2}, j} & \text { se } \widehat{\phi}_{i, j} \in[1 / 2,2 / 3) \\
u_{i+\frac{1}{2}, j} & \text { se } \widehat{\phi}_{i, j} \in[2 / 3,1]
\end{array}\right\} \\
& +S_{i, j}\left\{\begin{array}{ll}
u_{i+\frac{1}{2}, j} & \text { se } \widehat{\phi}_{i, j} \notin[0,1] \\
10 u_{i+\frac{1}{2}, j}-9 u_{i+\frac{3}{2}, j} & \text { se } \widehat{\phi}_{i, j} \in[0,3 / 74) \\
\frac{3}{8} u_{i-\frac{1}{2}, j}+\frac{6}{8} u_{i+\frac{1}{2}, j}-\frac{1}{8} u_{i+\frac{3}{2}, j} & \text { se } \widehat{\phi}_{i, j} \in[3 / 74,1 / 2) \\
1.5 u_{i+\frac{1}{2}, j}-0.5 u_{i+\frac{3}{2}, j} & \text { se } \widehat{\phi}_{i, j} \in[1 / 2,2 / 3) \\
u_{i-\frac{1}{2}, j} & \text { se } \widehat{\phi}_{i, j} \in[2 / 3,1]
\end{array}\right\}
\end{aligned}
$$

Os outros termos da equação 3.13 são obtidos de maneira análoga. 


\subsection{Discretização das Condições de Contorno na Su- perfície Livre}

As condições de contorno com superficie livre são (Tomé et al., 1996).

$$
\begin{gathered}
-p+2 \frac{\nu(q)}{R e}\left[\frac{\partial u}{\partial x} n_{x}^{2}+\left(\frac{\partial u}{\partial y}+\frac{\partial v}{\partial x}\right) n_{x} n_{y}+\frac{\partial v}{\partial y} n_{y}^{2}\right]=0 \\
2\left(\frac{\partial v}{\partial y}-\frac{\partial u}{\partial x}\right) n_{y} n_{x}+\left(\frac{\partial u}{\partial y}+\frac{\partial v}{\partial x}\right)\left(n_{x}^{2}-n_{y}^{2}\right)=0
\end{gathered}
$$

Para aplicar essas condições, supõe-se que a malha computacional seja suficientemente fina de modo que a superfície livre intercepta uma célula em dois lados. Ao aproximar as equações (3.14) e (3.15) por diferenças finitas, na superfície livre considera-se três tipos de orientações: vertical, horizontal e inclinada à 45 graus.

a) Célula S com apenas um lado em comum com uma célula E.

Neste caso assume-se que a superfície é horizontal ou vertical.

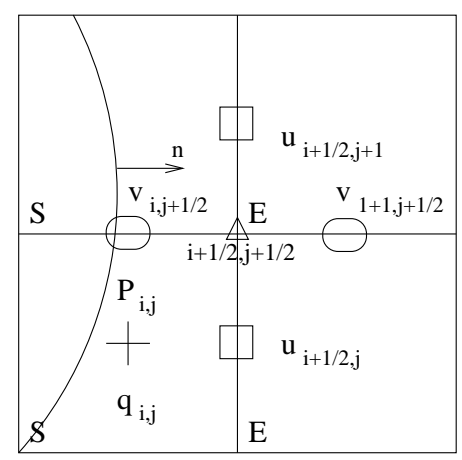

Figura 3.5: Célula S com lado direito em contato com uma célula E.

Considerando-se a figura 3.5 , assume-se que $\mathbf{n}=(1,0)$ e $\mathbf{m}=(0,1)$.

Nesse caso, as equações (3.14) e (3.15) se reduzem a:

$$
\begin{gathered}
-p+2 \frac{\nu(q)}{R e}\left(\frac{\partial u}{\partial x}\right)=0, \\
\frac{\partial u}{\partial y}+\frac{\partial v}{\partial x}=0 .
\end{gathered}
$$

O cálculo de $\widetilde{v}_{i, j+\frac{1}{2}}$ utilizando-se (3.10) requer os valores de $u_{i+\frac{1}{2}, j}, v_{i+1, j+\frac{1}{2}}$ e $p_{i, j}$. Esses valores são calculados como segue: 
Impondo-se conservação de massa para a célula $(i, j)$ da figura 3.5 , tem-se;

$$
\frac{u_{i+\frac{1}{2}, j}-u_{i-\frac{1}{2}, j}}{\delta x}+\frac{v_{i, j+\frac{1}{2}}-v_{i, j-\frac{1}{2}}}{\delta y}=0,
$$

donde obtém-se:

$$
u_{i+\frac{1}{2}, j}=u_{i-\frac{1}{2}, j}-\frac{\delta x}{\delta y}\left(v_{i, j+\frac{1}{2}}-v_{i, j-\frac{1}{2}}\right)
$$

Agora discretizando-se (3.17) no ponto $\left(i+\frac{1}{2}, j+\frac{1}{2}\right)$, tem-se

$$
\frac{u_{i+\frac{1}{2}, j+1}-u_{i+\frac{1}{2}, j}}{\delta y}+\frac{v_{i+1, j+\frac{1}{2}}-v_{i, j+\frac{1}{2}}}{\delta x}=0
$$

logo,

$$
v_{i+1, j+\frac{1}{2}}=v_{i, j+\frac{1}{2}}-\frac{\delta x}{\delta y}\left(u_{i+\frac{1}{2}, j+1}-u_{i+\frac{1}{2}, j}\right) .
$$

A pressão $p_{i, j}$ é então calculada por

$$
p_{i, j}=2 \frac{\nu\left(q_{i, j}\right)}{R e}\left(\frac{u_{i+\frac{1}{2}, j}-u_{i-\frac{1}{2}, j}}{\delta x}\right)
$$

onde $q_{i, j}$ é obtida por

$$
\begin{aligned}
q_{i, j}= & {\left[\left(\frac{u_{i+\frac{1}{2}, j}-u_{i-\frac{1}{2}, j}}{\delta x}\right)^{2}+\left(\frac{v_{i, j+\frac{1}{2}}-v_{i, j-\frac{1}{2}}}{\delta y}\right)^{2}\right.} \\
& \left.+\left(\frac{u_{i, j+1}-u_{i, j}}{\delta y}+\frac{v_{i, j}-v_{i-1, j}}{\delta x}\right)^{2}\right]^{\frac{1}{2}}
\end{aligned}
$$

onde

$$
\begin{aligned}
u_{i, j}=\frac{u_{i+\frac{1}{2}, j}+u_{i-\frac{1}{2}, j}}{2}, & u_{i, j+1}=\frac{u_{i+\frac{1}{2}, j+1}+u_{i-\frac{1}{2}, j+1}}{2} \\
v_{i, j}=\frac{v_{i, j+\frac{1}{2}}+v_{i, j-\frac{1}{2}}}{2}, & v_{i-1, j}=\frac{v_{i-1, j+\frac{1}{2}}+v_{i-1, j-\frac{1}{2}}}{2} .
\end{aligned}
$$

O valor de $\nu\left(q_{i, j}\right)$ é obtido através dos modelos Cross ou "power-law", vistos anteriormente ( seção 1.1).

Quando calcula-se as derivadas de $\nu$ em (3.9) e (3.10), precisa-se do valor de $q_{i+\frac{1}{2}, j+\frac{1}{2}}$. Este valor pode ser obtido aplicando-se (3.4) no canto da célula, que nesse caso reduz-se a: (utilizar (3.17)) 


$$
\begin{aligned}
\left.q_{i+\frac{1}{2}, j+\frac{1}{2}}\right|_{S}= & {\left[2\left(\frac{u_{i+\frac{1}{2}, j+1}+u_{i+\frac{1}{2}, j}-u_{i-\frac{1}{2}, j+1}-u_{i-\frac{1}{2}, j}}{2 \delta x}\right)^{2}\right.} \\
& \left.+2\left(\frac{v_{i, j+\frac{1}{2}}+v_{i+1, j+\frac{1}{2}}-v_{i, j-\frac{1}{2}}-v_{i+1, j-\frac{1}{2}}}{2 \delta y}\right)^{2}\right]^{\frac{1}{2}} .
\end{aligned}
$$

b) Célula S com duas faces adjacentes em contato com células E.

Assume-se que o vetor normal esteja inclinado a 45 graus entre as faces em contato com as células $\mathrm{E} ; \mathbf{n}=\left( \pm \frac{\sqrt{2}}{2}, \pm \frac{\sqrt{2}}{2}\right)$.

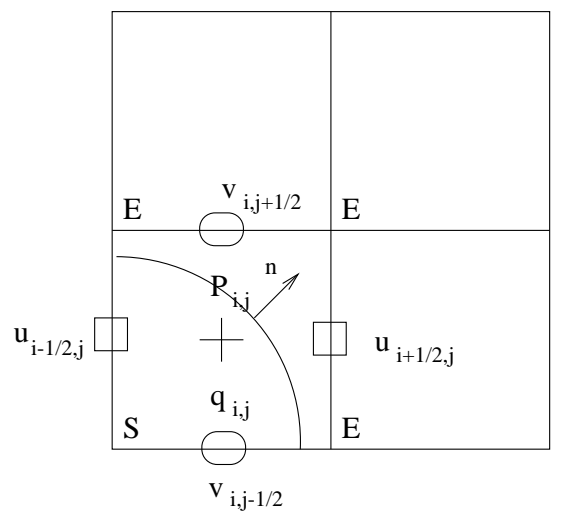

Figura 3.6: Célula S com duas faces adjacentes em contato com células E.

Considerando a configuração da figura 3.6, toma-se $\mathbf{n}=\left(\frac{\sqrt{2}}{2}, \frac{\sqrt{2}}{2}\right)$ e $\mathbf{m}=\left(\frac{\sqrt{2}}{2},-\frac{\sqrt{2}}{2}\right)$. Nesse caso, as equações (3.14) e (3.15) reduzem-se a

$$
\begin{gathered}
-p+\frac{\nu(q)}{R e}\left(\frac{\partial u}{\partial y}+\frac{\partial v}{\partial x}\right)=0 \\
\frac{\partial u}{\partial x}-\frac{\partial v}{\partial y}=0
\end{gathered}
$$

No cálculo de $u_{i+\frac{1}{2}, j}$ e $v_{i, j+\frac{1}{2}}$ da figura 3.6 aplica-se a equação da continuidade e a equação (3.21) no centro da célula, donde obtém-se:

$$
\frac{\partial u}{\partial x}=0 \text { e } \frac{\partial v}{\partial y}=0
$$

Para equação (3.22) ser satisfeita, as velocidades $u_{i+\frac{1}{2}, j}$ e $v_{i, j+\frac{1}{2}}$ devem ser dadas por:

$$
u_{i+\frac{1}{2}, j}=u_{i-\frac{1}{2}, j} \text { e } \quad v_{i, j+\frac{1}{2}}=v_{i, j-\frac{1}{2}} .
$$


A pressão é calculada utilizando-se (3.20), donde obtém-se:

$$
\begin{aligned}
p_{i, j}= & \frac{\nu\left(q_{i, j}\right)}{2 R e}\left[\left(\frac{u_{i+\frac{1}{2}, j}+u_{i-\frac{1}{2}, j}-u_{i+\frac{1}{2}, j-1}-u_{i-\frac{1}{2}, j-1}}{\delta y}\right)\right. \\
& \left.+\left(\frac{v_{i, j+\frac{1}{2}}+v_{i, j-\frac{1}{2}}-v_{i-1, j+\frac{1}{2}}-v_{i-1, j-\frac{1}{2}}}{\delta x}\right)\right] .
\end{aligned}
$$

A taxa de deformação (3.4), nesse caso reduz-se a:

$$
q=\left|\frac{\partial u}{\partial y}+\frac{\partial v}{\partial x}\right|
$$

e é calculada por:

$$
\begin{aligned}
q_{i, j}= & \frac{1}{2} \mid\left(\frac{u_{i+\frac{1}{2}, j}+u_{i-\frac{1}{2}, j}-u_{i+\frac{1}{2}, j-1}-u_{i-\frac{1}{2}, j-1}}{\delta y}\right) \\
& +\left(\frac{v_{i, j+\frac{1}{2}}+v_{i, j-\frac{1}{2}}-v_{i-1, j+\frac{1}{2}}-v_{i-1, j-\frac{1}{2}}}{\delta x}\right) \mid
\end{aligned}
$$

O valor de $\nu\left(q_{i, j}\right)$ é obtido utilizando-se os modelos para a viscosidade, vistos anteriormente ( seção 1.1).

c) Células S com três lados em contato com células E ou com dois lados opostos em contato com células E.

Neste caso, $q_{i, j}$ é zero, a pressão é tomada nula, e uma velocidade é ajustada a fim de satisfazer a equação da continuidade na célula S. Se essa célula aparecer durante a execução de um dado problema, sugere-se que a malha seja refinada. 


\subsection{Discretização da Taxa de Deformação no Con- torno}

O cálculo das derivadas da viscosidade $\left.\left.\frac{\partial \nu(q)}{\partial x}\right|_{i, j+\frac{1}{2}} \mathrm{e} \frac{\partial \nu(q)}{\partial y}\right|_{i+\frac{1}{2}, j}$, requer os valores de $q$ no canto das células.

No cálculo da velocidade $\widetilde{u}$ utiliza-se a derivada $\left.\frac{\partial \nu(q)}{\partial y}\right|_{i+\frac{1}{2}, j}$ que discretizada torna-se

$$
\left.\frac{\partial \nu(q)}{\partial y}\right|_{i+\frac{1}{2}, j}=\frac{\nu\left(q_{i+\frac{1}{2}, j+\frac{1}{2}}\right)-\nu\left(q_{i+\frac{1}{2}, j-\frac{1}{2}}\right)}{\delta y} .
$$

No calculo de $q_{i+\frac{1}{2}, j+\frac{1}{2}}$ e $q_{i+\frac{1}{2}, j-\frac{1}{2}}$ tem-se que verificar se as células vizinhas são, $(\mathrm{F}),(\mathrm{S}),(\mathrm{O})$ ou (I). Para mostrar as aproximações para $q_{i+\frac{1}{2}, j+\frac{1}{2}}$, no cálculo de $\widetilde{u}$ considerase os seguintes casos:

- Caso 1: Se as células $(i, j+1)$ e $(i+1, j+1)$ forem células $\mathrm{F}$ ou $\mathrm{S}$, então o valor de $q_{i+\frac{1}{2}, j+\frac{1}{2}}$ é dado por (ver figura 3.7).

$$
q_{i+\frac{1}{2}, j+\frac{1}{2}}=\left(q_{i, j}+q_{i+1, j}+q_{i, j+1}+q_{i+1, j+1}\right) / 4 .
$$

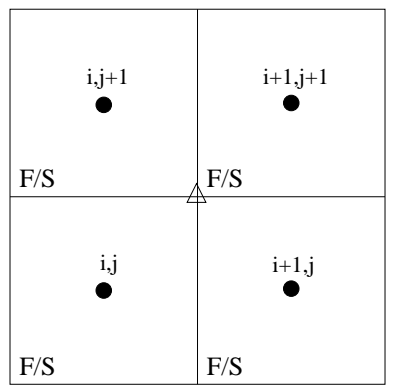

Figura 3.7: Células $(i, j+1)$ e $(i+1, j+1)$, F ou S.

- Caso 2: Se as células $(i, j+1)$ e $(i+1, j+1)$ forem células B ou I, então $q=\left|\frac{\partial u}{\partial y}\right|$ e nesse caso tem-se (ver figura 3.8),

$$
q_{i+\frac{1}{2}, j+\frac{1}{2}}=\left|\frac{u_{i+\frac{1}{2}, j+1}-u_{i+\frac{1}{2}, j}}{\delta y}\right|
$$




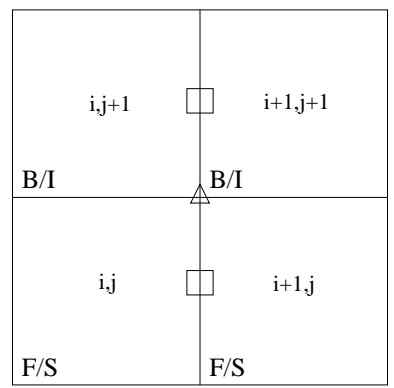

Figura 3.8: Células $(i, j+1)$ e $(i+1, j+1)$, B ou I.

- Caso 3: Se as células $(i, j+1)$ e $(i+1, j+1)$ forem células E, então $q=\sqrt{2\left(\left(\frac{\partial u}{\partial x}\right)^{2}+\left(\frac{\partial v}{\partial y}\right)^{2}\right)}$ (desde que $\frac{\partial u}{\partial y}+\frac{\partial v}{\partial x}=0$ ). O cálculo de $\frac{\partial u}{\partial x}, \frac{\partial v}{\partial y}$, são efetuadas como segue

$$
\left.\frac{\partial v}{\partial y}\right|_{i+\frac{1}{2}, j+\frac{1}{2}}=\left(v_{i, j+\frac{1}{2}}+v_{i+1, j+\frac{1}{2}}-v_{i, j-\frac{1}{2}}-v_{i+1, j-\frac{1}{2}}\right) / 2 \delta y
$$

No cálculo da derivada $\left.\frac{\partial u}{\partial x}\right|_{i+\frac{1}{2}, j+\frac{1}{2}}$ tem-se que levar em consideração se as células $(i-1, j)$ e $(i+2, j)$ são células $\mathrm{F}$ ou $\mathrm{S}$, como segue:

- Caso 3a: Se as células $(i-1, j)$ e $(i+2, j)$ forem células F ou S, então (ver figura 3.9),

$$
\begin{gathered}
u_{i, j+\frac{1}{2}}=\left(u_{i+\frac{1}{2}, j}+u_{i+\frac{1}{2}, j+1}+u_{i-\frac{1}{2}, j}+u_{i-\frac{1}{2}, j+1}\right) / 4.0 \\
u_{i+1, j+\frac{1}{2}}=\left(u_{i+\frac{1}{2}, j}+u_{i+\frac{1}{2}, j+1}+u_{i+\frac{3}{2}, j}+u_{i+\frac{3}{2}, j+1}\right) / 4.0 \\
\left.\frac{\partial u}{\partial x}\right|_{i+\frac{1}{2}, j+\frac{1}{2}}=\frac{\left(u_{i+1, j+\frac{1}{2}}-u_{i, j+\frac{1}{2}}\right)}{\delta x} .
\end{gathered}
$$

- Caso 3b: Se não, se somente a célula $(i-1, j)$ for F ou S, tem-se; ver figura 3.10 ,

$$
\left.\frac{\partial u}{\partial x}\right|_{i+\frac{1}{2}, j+\frac{1}{2}}=\left(u_{i+\frac{1}{2}, j}+u_{i+\frac{1}{2}, j+1}-u_{i-\frac{1}{2}, j}-u_{i-\frac{1}{2}, j+1}\right) / 2 \delta x
$$




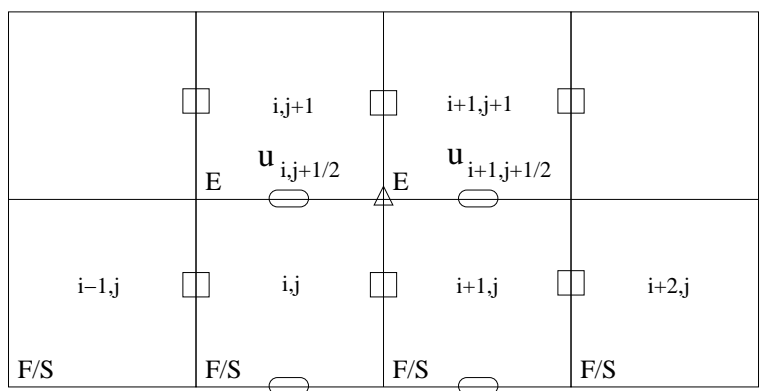

Figura 3.9: Células $(i-1, j)$ e $(i+2, j), \mathrm{F}$ ou S.

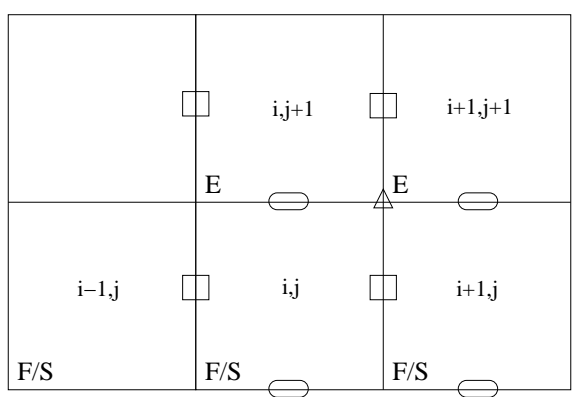

Figura 3.10: Célula $(i-1, j)$, F ou S.

- Caso 3c: Se não, se somente a célula $(i+2, j)$ for $\mathrm{F}$ ou $\mathrm{S}$, tem-se; ver figura 3.11 ,

$$
\left.\frac{\partial u}{\partial x}\right|_{i+\frac{1}{2}, j+\frac{1}{2}}=\left(u_{i+\frac{1}{2}, j}+u_{i+\frac{1}{2}, j+1}-u_{i+\frac{3}{2}, j}-u_{i+\frac{3}{2}, j+1}\right) / 2 \delta x .
$$

Então calcula-se

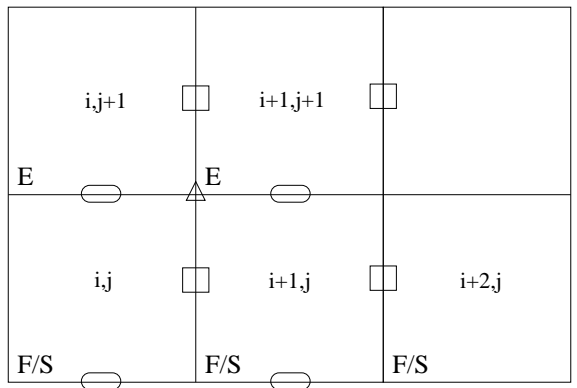

Figura 3.11: Célula $(i+2, j), \mathrm{F}$ ou S.

$$
q_{i+\frac{1}{2}, j+\frac{1}{2}}=\sqrt{2\left(\left(\left.\frac{\partial u}{\partial x}\right|_{i+\frac{1}{2}, j+\frac{1}{2}}\right)^{2}+\left(\left.\frac{\partial v}{\partial y}\right|_{i+\frac{1}{2}, j+\frac{1}{2}}\right)^{2}\right)} .
$$


- Outras configurações de células F/S vizinhas a células B/I/E são tratadas de maneira analoga.

Para a discretização das derivadas $\left.\frac{\partial \nu(q)}{\partial y}\right|_{i, j+\frac{1}{2}}$ e $\left.\frac{\partial \nu(q)}{\partial x}\right|_{i, j+\frac{1}{2}}$, que aparecem no cálculo de $\widetilde{v}$, utiliza-se o mesmo procedimento descrito acima.

\subsection{Equação de Poisson}

A equação de Poisson é dada por:

$$
\nabla^{2} \psi(\mathbf{x}, t)=\nabla \cdot \widetilde{\mathbf{u}}(\mathbf{x}, t)
$$

Discretizando-se (3.24) e utilizando-se o laplaciano com 5 pontos no centro da célula obtém-se

$$
\frac{\psi_{i-1, j}-2 \psi_{i, j}+\psi_{i+1, j}}{\delta x^{2}}+\frac{\psi_{i, j-1}-2 \psi_{i, j}+\psi_{i, j+1}}{\delta y^{2}}=\widetilde{D}_{i, j}
$$

onde

$$
\widetilde{D}_{i, j}=\frac{\widetilde{u}_{i+\frac{1}{2}, j}-\widetilde{u}_{i-\frac{1}{2}, j}}{\delta x}+\frac{\widetilde{v}_{i, j+\frac{1}{2}}-\widetilde{v}_{i, j-\frac{1}{2}}}{\delta y}
$$

A equação (3.25) pode ser escrita como

$$
-\alpha \psi_{i, j-1}-\psi_{i-1, j}+(2+2 \alpha) \psi_{i, j}-\psi_{i+1, j}-\alpha \psi_{i, j+1}=-\delta x^{2} \widetilde{D}_{i, j}
$$

onde $\alpha=\frac{\delta_{x}^{2}}{\delta_{y}^{2}}$.

A equação de poisson discretizada (3.27) resulta em um sistema de equações lineares que pode ser representado por

$$
A \mathbf{X}=\mathbf{b}
$$

onde $A$ é uma matriz simétrica e definida positiva de ordem $n, \mathbf{X}$ é o vetor solução de ordem $n$ e $\mathbf{b}$ é o vetor divergente de ordem $n$, sendo $n$ o número de células $\mathrm{F}$ da malha.

Para resolver este sistema utiliza-se o método dos gradientes conjugados, sendo o vetor $\mathbf{X}$ inicializado como um vetor da função potencial no passo anterior. Detalhes da implementação são apresentados em (Tomé e McKee, 1994) e (Oliveira, 1999). 


\subsection{Velocidades Finais}

Discretizando-se a equação (2.3) nos respectivos nós, tem-se

$$
\begin{aligned}
& u_{i+\frac{1}{2}, j}^{n+1}=\widetilde{u}_{i+\frac{1}{2}, j}-\left(\frac{\psi_{i+1, j}-\psi_{i, j}}{\delta x}\right), \\
& v_{i, j+\frac{1}{2}}^{n+1}=\widetilde{v}_{i, j+\frac{1}{2}}-\left(\frac{\psi_{i, j+1}-\psi_{i, j}}{\delta y}\right),
\end{aligned}
$$

onde $\psi$ é obtida pela solução de (3.27).

\subsection{Controle do Passo no Tempo}

Como o método GENSMAC é um método explícito, deve-se impor algumas restrições sobre o passo no tempo, afim de que o método se torne estável. Assim, em cada ciclo, o tamanho do passo no tempo é obtido segundo as restrições.

- Nenhuma partícula pode cruzar mais do que uma célula em um dado intervalo de tempo, ou seja

$$
\delta t<\frac{\delta x}{|u|} \quad \text { e } \quad \delta t<\frac{\delta y}{|v|}
$$

condição suficiente para satisfazer a restrição anterior

$$
\left|U_{\text {max }}\right| \delta t<\delta x \quad \text { e }\left|V_{\text {max }}\right| \delta t<\delta y
$$

em que $U_{\max }$ e $V_{\max }$ são os valores máximos de $\widetilde{u}$ e $\widetilde{v}$, respectivamente;

- Devido a discretização explícita das equações de conservação de quantidade de movimento, (Tomé et al., 1996) deve-se ter

$$
\delta t<\frac{R e}{2 \nu(q)} \frac{\delta x^{2} \delta y^{2}}{\delta x^{2}+\delta y^{2}}
$$

Uma condição suficiente para que essa restrição seja satisfeita é:

$$
\delta t<\frac{R e}{2 \nu_{\max }} \frac{\delta x^{2} \delta y^{2}}{\delta x^{2}+\delta y^{2}}
$$

onde $\nu_{\max }=\max \left|\nu_{i, j}\right|$. 


\subsection{Movimento das Partículas}

A representação do fluido é feita através de partículas virtuais, as quais permite indicar a posição da superfície livre, afim de que possam ser determinadas as configurações das células S.

No final de cada passo no tempo, as posições das partículas são atualizadas e assim, obtém-se a dinâmica do movimento do fluido.

As coordenadas dessas partículas são atualizadas através da solução numérica das equações diferenciais ordinárias,

$$
\frac{d x}{d t}=u \quad \text { e } \quad \frac{d y}{d t}=v
$$

pelo método de Euler.

Logo, após o cálculo da velocidade atualizada $\mathbf{u}(\mathbf{x}, t)$, as coordenadas das partículas são atualizadas de acordo com

$$
\begin{aligned}
& x_{p}^{n+1}=x_{p}{ }^{n}+u_{p} \delta t^{n+1} \\
& y_{p}{ }^{n+1}=y_{p}{ }^{n}+v_{p} \delta t^{n+1}
\end{aligned}
$$

onde $\left(x_{p}^{n}, y_{p}^{n}\right)$ representa a posição atual da partícula, $\delta t^{n+1}$ é o passo no tempo e $\left(x_{p}^{n+1}, y_{p}^{n+1}\right)$ é a posição atualizada. As velocidades $u_{p}, v_{p}$ são calculadas utilizando-se interpolação bilinear envolvendo as quatro velocidades $u$ e $v$ mais próximas. 


\section{Capítulo 4}

\section{Ambiente de Simulação FreeFlow-2D}

FreeFlow-2D é um sistema integrado para modelagem, simulação e visualização de escoamentos bidimensionais incompressíveis com superfícies livres.

O sistema FreeFlow-2D é composto por quatro módulos, a saber:

- Modflow-2D (modelador de moldes e escoamentos): Esse módulo é um sistema interativo para a especificação de um modelo de escoamento de fluidos que inclui a definição de elementos no domínio do escoamento como moldes, injetores, fluidos e a definição de propriedades do escoamento;

- Simflow-2D (simulador de escoamentos): Esse módulo é a parte central do FreeFlow-2D, pois é nele que se implementa a discretização das equações governantes, bem como as condições de fronteira. O método GENSMAC serviu de base para a implementação do simulador;

- Visflow-2D (visualizador de escoamentos): Um sistema interativo para a visualização dos resultados produzidos pelo simulador em imagens de fácil interpretação;

- Resimflow-2D (reinicializador de escoamentos): Esse módulo é responsável pela reinicialização de um dado problema.

A implementação dos quatro módulos que compõem o sistema FreeFlow-2D foi feita utilizando a linguagem $\mathrm{C}$ sobre o sistema operacional UNIX. As interfaces gráficas dos módulos Modflow-2D, Visflow-2D e Resimflow-2D utilizam o sistema de gerenciamento de janelas Xview sobre o Xwindows. A estrutura de dados adotada proporciona acesso fácil às informações e possui independência dos dados de forma a simplificar a manutenção e extensão do código. Os programas foram desenvolvidos em estação de trabalho Sun Solaris, 
com versões executando em ambientes Linux-PC. A comunicação entre os módulos do sistema é feita através de arquivos e os objetos geométricos (fluidos, contêineres, injetores e ejetores) são representados pela estrutura de dados B-Rep (Boundary Representation).

\subsection{Módulos do Sistema FreeFlow-2D para Escoa- mentos de Fluidos Não Newtonianos}

As principais etapas deste projeto podem ser divididas no desenvolvimento dos módulos do sistema FreeFlow-2D para escoamentos de fluidos não newtonianos. A etapa inicial começou com o desenvolvimento do modelador, denominado Modflow-2D, para escoamentos de fluidos não newtonianos. Posteriormente foi desenvolvido o simulador, Simflow-2D e, por fim, o módulo de visualização do escoamento, Visflow-2D.

\subsubsection{O Modelador (Modflow-2D)}

Este módulo permite ao usuário construir e manipular objetos. Tais operações podem ser feitas por meio de uma interface gráfica de fácil execução do Modflow-2D, a qual utiliza o sistema de gerenciamento de janelas Xview sobre o Xwindows. Os objetos geométricos básicos são pré-definidos. O usuário pode escolher, dentre os objetos disponíveis, o seu tamanho, formato, posição e orientação.

Ao dar início à construção de um modelo para fluido não newtoniano, o usuário deverá especificar, todos os dados que irão configurar o escoamento, tais como: domínio, dimensão das células, tempo inicial e final, ciclo inicial e final, escalas de velocidade e comprimento, força gravitacional (intensidade e direção) (ver figura 4.1), e, além disso, ele deve escolher um dos modelos (Cross ou "power-law") para representar a variação da viscosidade do fluido (ver figuras $4.2 \mathrm{a}$ e $4.2 \mathrm{~b}$ ).

\subsubsection{O Simulador (Simflow-2D)}

O módulo Simflow-2D tem a finalidade de simular numericamente escoamentos transientes de fluidos newtonianos e não newtonianos incompressíveis.

Este módulo não possue uma interface gráfica de entrada de dados. A execução deste módulo se faz seguindo uma sintaxe, efetuada por linha de comando. 


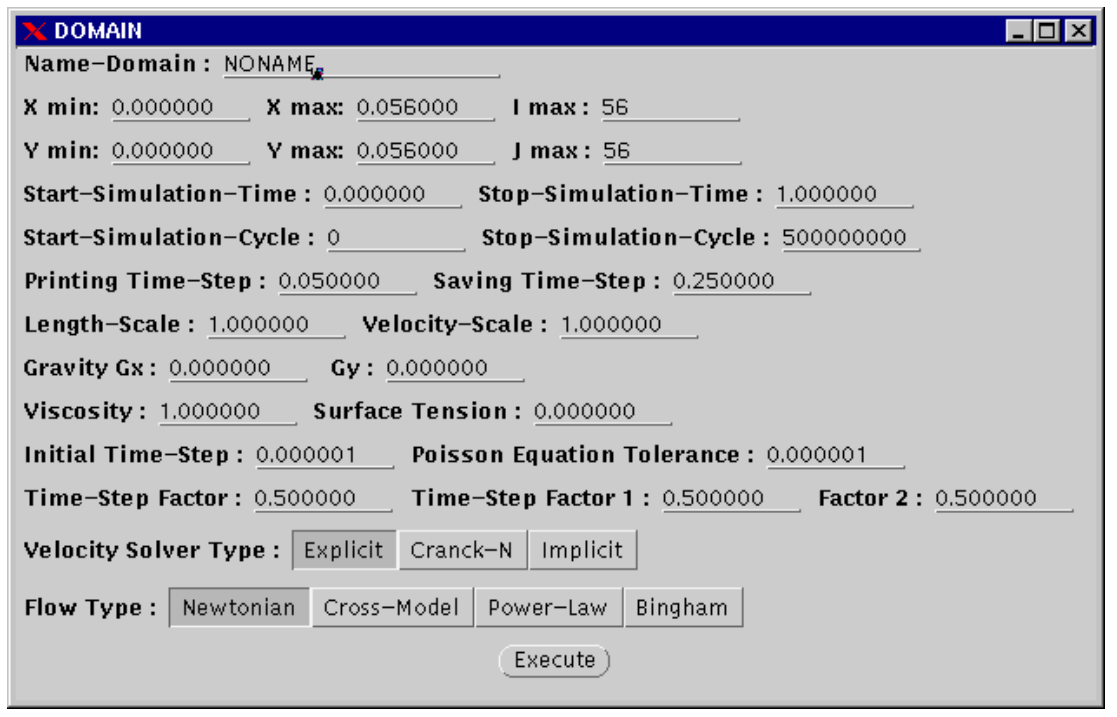

Figura 4.1: Janela de entrada de dados para definição do modelo de escoamento não newtoniano.

\begin{tabular}{|c|c|}
\hline DATA Cross-Model & $-\square \times$ \\
\hline Zero Viscosity: 1.000000 & \\
\hline Infty Viscosity : $\_1.000000$ & \\
\hline$K($ Constant $): 1.000000$ & \\
\hline M (Power): 1.000000 & \\
\hline Execute & \\
\hline
\end{tabular}

a)

\begin{tabular}{|c|c|}
\hline DATA Power Law & 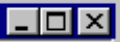 \\
\hline Zero Viscosity: 1.000000 & \\
\hline Infty Viscosity : 1.000000 & \\
\hline Density: 1.000000 & \\
\hline K (Constant): 1.000000 & \\
\hline N (Power): 1.000000 & \\
\hline Execute) & \\
\hline
\end{tabular}

b)

Figura 4.2: Janela de entrada de dados para os modelos a) Cross e b) power-law.

Na simulação de um escoamento utilizando o FreeFlow-2D, o módulo Simflow-2D faz uma leitura no arquivo de dados gerado pelo modelador. Este arquivo de dados armazena todas as informações dos objetos da simulação (containers, fluidos e suas dimensões), armazena também as propriedades de cada fluido (viscosidade, dados do modelo (Cross ou "power-law")). Por fim, armazena os parâmetros iniciais do escoamento (tempo inicial e final de simulação, dimensões da malha, etc.). Dessa forma, inicia-se um ciclo que vai desde os cálculos do campo de velocidade até a redefinição das células. Este ciclo segue os seguintes passos: 
passo 1: Cálculo das condições iniciais e condições de contorno:

- Cálculo de $q$ e $\nu$ utilizando-se a condição inicial de $\mathbf{u}$

- Cálculo das velocidades $u$ e $v$ na superfície livre;

- Cálculo das velocidades tangenciais $u$ e $v$ nas células $\mathrm{S}$ com as células E;

- Cálculo das velocidades $u$ e $v$ no contorno rígido;

- Cálculo das velocidades tangenciais $u$ e $v$ nos injetores e "outflows".

passo 2: Calcula-se a pressão $\widetilde{p}$ na superfície livre, utilizando-se a condição de contorno para a pressão.

passo 3: Calcula-se o campo de velocidade intermediária $\widetilde{\mathbf{u}}$.

passo 4: Resolve-se a equação de Poisson;

passo 5: Calcula-se o campo de velocidade final (atualizada) $\mathbf{u}$.

passo 6: Repete-se o passo 1.

passo 7: Calcula-se as novas posições das partículas virtuais (movimento da superfície livre).

passo 8: Inserem-se partículas virtuais nos injetores.

passo 9: Eliminam-se partículas virtuais.

passo 10: Inserem-se partículas virtuais.

passo 11: Redefinem-se as células após a inserção das partículas.

Com relação ao passo 1, vale destacar que o Simflow-2D para fluidos não newtonianos calcula o campo de velocidade utilizando-se as equações de conservação de quantidade de movimento (2.1) e massa, e utiliza um dos modelos (Cross" ou "power-law") para representar a variação da viscosidade.

No passo 2, a pressão é calculada nas células do tipo S. No passo 3, são aplicadas, nas células do tipo $\mathrm{F}$, as equações de conservação de quantidade de movimento e de conservação de massa para escoamentos não newtoniano.

O passo 4 resolve a equação de Poisson para a função potencial $\psi$, pelo método de gradientes conjugados, utilizando condições de fronteira adequadas para esta função. 
O campo de velocidade final, passo 5, é obtido por meio do campo de velocidade intermediária e o gradiente da função potencial $\psi$. Uma vez atualizado o campo de velocidade, é possível obter a nova posição das partículas marcadoras do fluido, que é efetuado no passo 7 .

Após fazer as operações de inserção e remoção de partículas (passos 8, 9 e 10), necessárias para se obter a representação fiel dos detalhes da superfície do fluido, redefinemse as células. Assim, células que contêm a superfície livre são marcadas por ter partículas virtuais. Encerra-se nesta redefinição o ciclo e retorna-se ao passo 1, até que se obtenha a simulação desejada.

\subsubsection{O Visualizador (Visflow-2D)}

O módulo de visualização, Visflow-2D, é responsável por apresentar graficamente os resultados gerados pelo Simflow-2D. Este módulo também possui uma interface gráfica para facilitar a sua utilização.

Para facilitar a visualização dos resultados obtidos da simulação, este módulo apresenta imagens gráficas de fácil interpretação. Estas imagens estão baseadas nos objetos geométricos, nas propriedades de cada fluido e nos resultados gerados pelo simulador. Para a visualização dos campos de velocidade, pressão, taxa de deformação e viscosidade, utiliza-se uma técnica de escala de cores, associada aos valores destes campos. No caso bidimensional a velocidade é visualizada pelas suas duas componentes: a velocidade $u$ na direção $x$ e a velocidade $v$ na direção $y$.

Existe uma comunicação entre os módulos, Modflow-2D, Simflow-2D e Visflow-2D efetuada por meio de arquivos de dados, gerados por rotinas específicas, divididas em duas classes distintas: rotina grava, responsável por armazenar as informações em arquivos e rotina carrega, responsável por fazer a leitura destes dados gravados.

Dados como viscosidade, parâmetros dos modelos (Cross e "power-law"), são gravados e carregados por estas rotinas em cada módulo, exceto no Visflow-2D, que somente faz a leitura destas propriedades geradas pelas rotina grava dos módulos Modflow-2D e Simflow$2 \mathrm{D}$, para ser efetuada a visualização do escoamento.

A extensão do módulo Visflow-2D para fluidos não newtonianos permite que o usuário visualize a variação no escoamento de dados como taxa de deformação e viscosidade. Para isso o usuário deve entrar no módulo de visualização, carregar a simulação desejada, clicar na opção View e escolher dentre elas Shear Rate ou Viscosity. Nas figuras 4.3 e 4.4 pode-se 
ver exemplos da visualização da taxa de deformação e da viscosidade, respectivamente, produzidas pelo Visflow-2D.

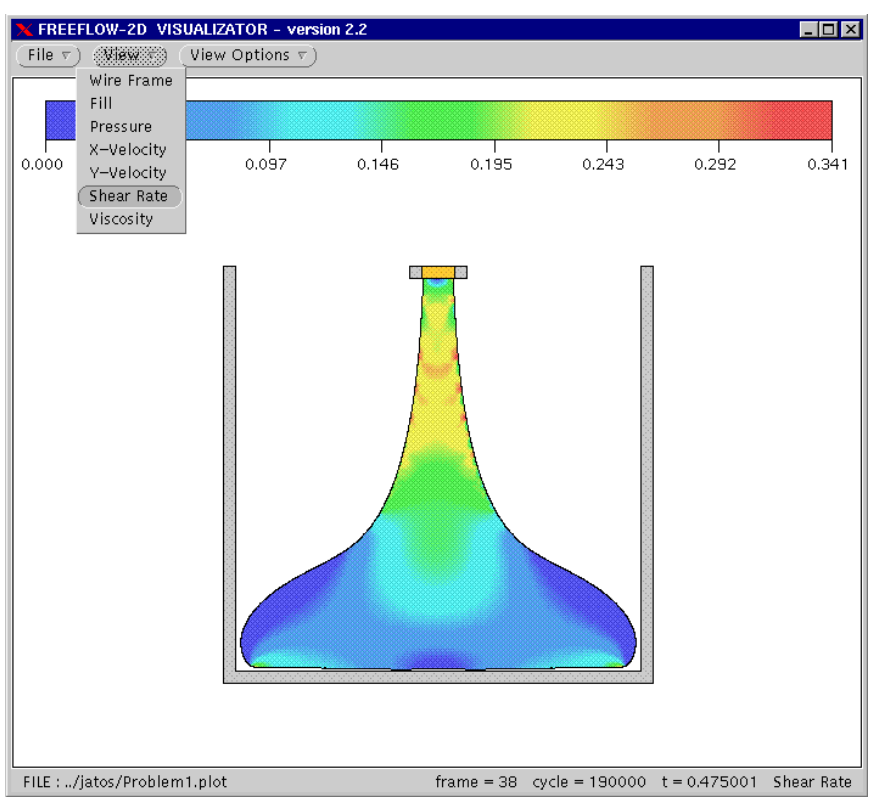

Figura 4.3: Visualização da variação da taxa de deformação ("Shear Rate") utilizando o módulo Visflow-2D.

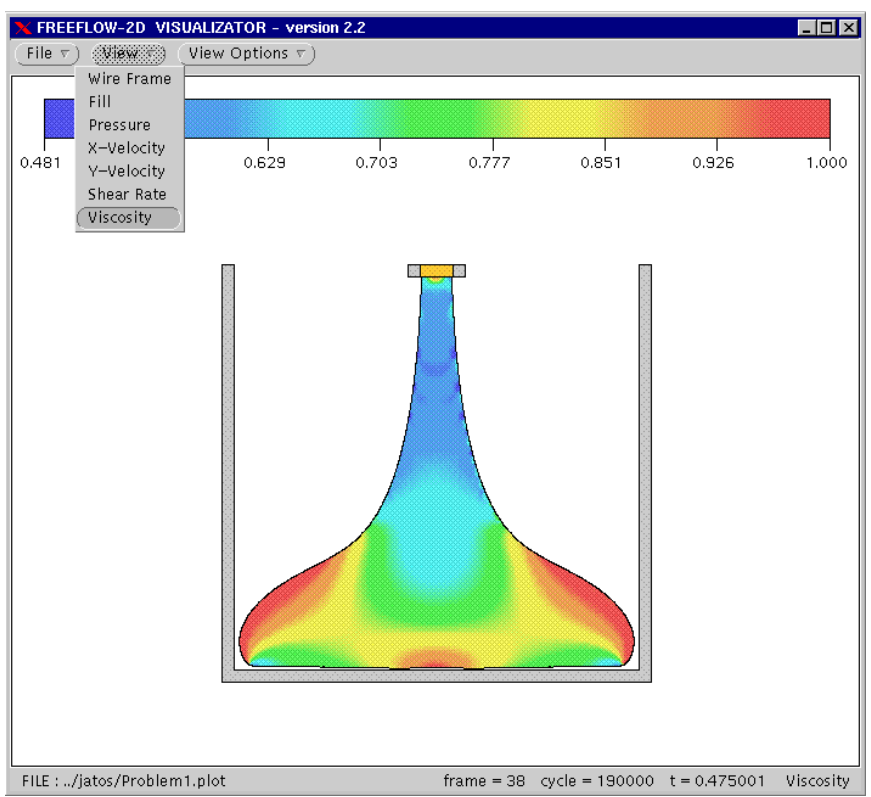

Figura 4.4: Visualização da variação da viscosidade ("Viscosity") utilizando o módulo Visflow-2D. 


\section{Capítulo 5}

\section{Resultados Numéricos}

As aproximações por diferenças finitas descritas no capítulo 3 foram incorporadas no código FreeFlow-2D para simular escoamentos de fluidos não newtonianos incompressíveis com superfície livre. Para verificar que o sistema FreeFlow-2D é capaz de simular escoamentos de fluidos não newtonianos do tipo fluido newtoniano generalizado, motrar-se alguns exemplos numéricos para diferentes comportamentos, newtonianos e não newtonianos utilizando-se os modelos "power-law" e Cross, para a viscosidade.

\subsection{Modelo Power-Law}

Muitos fluidos "shear-thinning" apresentam comportamento newtoniano quando estão escoando a taxas de deformações muito baixas, ou seja quando $q \rightarrow 0$; ou quando a taxa de deformação é suficientemente elevada, ou seja quando $q \rightarrow \infty$ (ver figura 5.1).

Na figura 5.1 pode-se observar que a viscosidade $\mu$, decresce à medida que $q$ aumenta. Este é o comportamento típico de polímeros fundidos, mas não o único. A valores intermediários da taxa de deformação o comportamento da viscosidade pode ser aproximado por uma reta no gráfico 5.1. Essa região é chamada de região "power-law", que pode-se aproximar por

$$
\log \mu(q)=a+b \log q
$$

onde $\mu$ é a viscosidade aparente.

Explicitando $\mu(q)$ em (5.1) obtém-se,

$$
\mu(q)=K q^{b}
$$




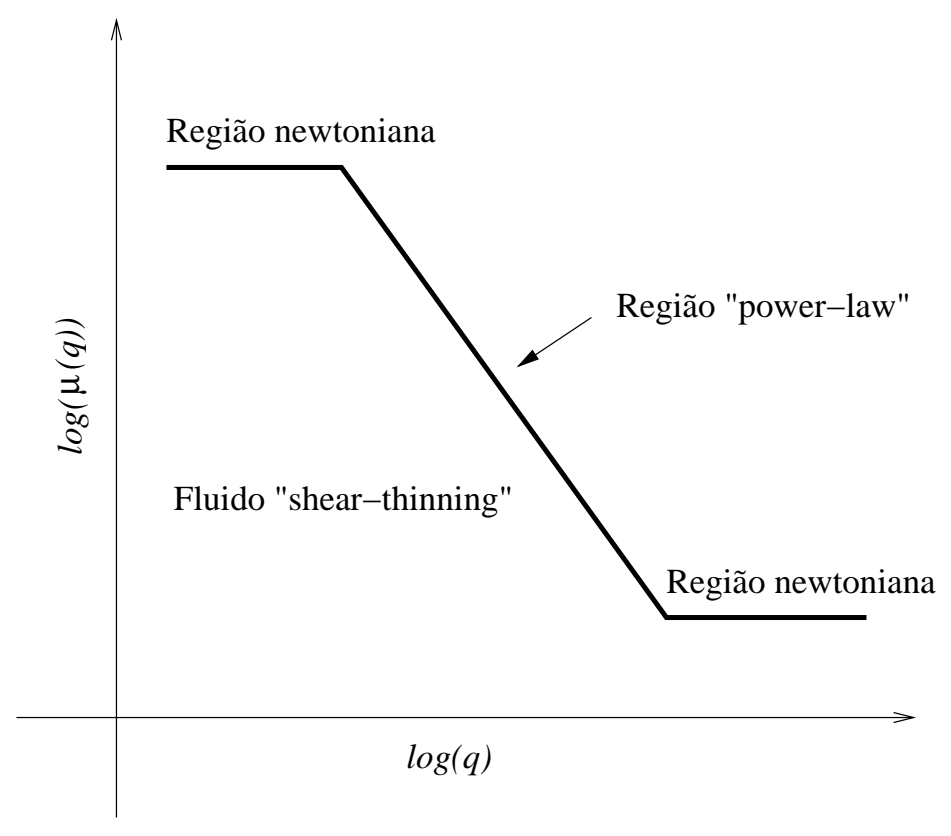

Figura 5.1: Fluido "shear thinning".

onde $K=\exp (a)$, e no lugar de $b$ é comum usar o expoente $(n-1)$. Logo a viscosidade aparente torna-se

$$
\mu(q)=K q^{n-1}
$$

onde $K$ é chamado de consistência e $n$ de índice "power-law".

$A$ viscosidade cinemática é dada por

$$
\nu(q)=\frac{K}{\rho} q^{n-1},
$$

na região após o platô newtoniano. Assim por exemplo, se a viscosidade de um polímero aumenta com o aumento de $q$, ela apresenta um comportamento chamado "shear-thickening" ou dilatante (Bird et al., 1977), (Bretas e DAvila, 2000). Esse comportamento é observado em algumas soluções de policloreto de vinila, PVC e alguns polímeros carregados (Bird et al., 1977), (Bretas e DAvila, 2000). Se a viscosidade do polímero diminui com o aumento da taxa de deformação, ela terá um comportamento "shear-thinning" ou pseudoplástico. Em ambos os casos a viscosidade pode ser representada pela equação (5.2) (Bretas e DAvila, 2000).

Na equação (5.2) o valor de $n$ é uma medida da "pseudoplasticidade" do polímero. Quando $n=1$, a equação (5.2) fica equivalente à do fluido newtoniano, já que a viscosidade é constante. Quando $n<1$, o polímero apresenta comportamento pseudoplástico e, 
quanto menor o valor de $n$, maior a pseudoplasticidade do polímero. Se $n>1$, o material apresenta comportamento dilatante. Normalmente para fluidos "shear-thinning", $n$ deve estar entre $\frac{1}{3}$ e $\frac{1}{2}$, mas outros valores também são possíveis (Bretas e DAvila, 2000).

\subsubsection{Simulação do Efeito "Jet Buckling"}

Para demonstrar a capacidade do sistema FreeFlow-2D em simular escoamentos de fluidos não newtonianos, nesta seção é apresentada a simulação de um jato viscoso que produz o fenômeno conhecido como "buckling". Esse fenômeno tem sido investigado por vários pesquisadores dentre eles Cruickshank e Munson (Cruickshank, 1987), (Cruickshank e Munson, 1981), tais autores apresentaram resultados teóricos e experimentais baseados em análise unidimensional para jatos planar e "axissimetrico" (simetria axial). Eles mostraram que o fenômeno "buckling" irá ocorrer quando,

$$
R e<0.56 \text { e } H / L>3 \pi
$$

no caso planar.

Recentemente, esse problema foi estudado por (Kim et al., 2001) utilizando a técnica VOF (volume-of-fluid) no contexto do método de elementos finitos. Porém, nos resultados apresentados por (Kim et al., 2001), observa-se que a superfície livre do jato não é bem definida. Para simular esse problema vamos utilizar os dados utilizados por (Kim et al., 2001), conforme mostrado na tabela 5.1.

\begin{tabular}{|c|c|c|c|c|c|c|c|}
\hline & $\rho\left(\mathrm{kg} / \mathrm{m}^{3}\right)$ & $K(\mathrm{~Pa} \cdot \mathrm{s})$ & $\nu_{0}\left(\mathrm{~m}^{2} \mathrm{~s}^{-1}\right)$ & $n($ índice PL) & $H / D$ & $\mathrm{U}\left(\mathrm{ms}^{-1}\right)$ & $R e$ \\
\hline \hline caso 1 & 1000 & 10 & 0.01 & 1.0 & 12 & 0.2 & 0.08 \\
\hline caso 2 & 1000 & 10 & 0.01 & 0.8 & 12 & 0.2 & 0.08 \\
\hline caso 3 & 1000 & 10 & 0.01 & 1.0 & 12 & 0.3 & 0.12 \\
\hline caso 4 & 1000 & 10 & 0.01 & 0.8 & 12 & 0.3 & 0.12 \\
\hline caso 5 & 1000 & 10 & 0.01 & 0.6 & 12 & 0.2 & 0.08 \\
\hline
\end{tabular}

Tabela 5.1: Propriedades físicas e dados do modelo power-law.

Todas as condições e propriedades fisicas apresentadas na tabela 5.1, satisfazem o critério (5.3).

Nas figuras 5.2 e 5.3 podem-se ver resultados para os casos newtoniano e não-newtoniano, respectivamente. No caso newtoniano (figura 5.2) pode-se observar o fenômeno "buckling" 
no tempo $t=0.60 \mathrm{~s}$, enquanto que no fluido não newtoniano (figura 5.3) tal fenômeno ocorre a partir de $t=0.70 \mathrm{~s}$.

a) $t=0.36 \mathrm{~s}$

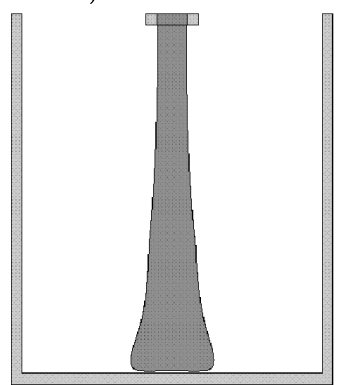

c) $t=0.52 \mathrm{~s}$

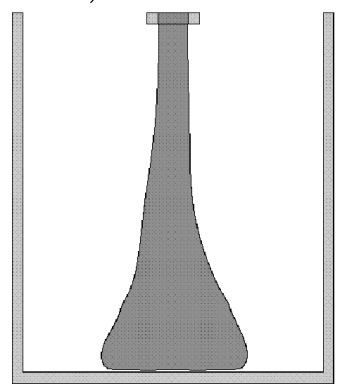

e) $t=0.70 \mathrm{~s}$

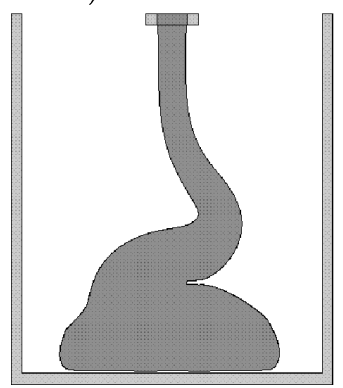

Figura 5.2: Caso 1 newtoniano. a) $t=0.36 \mathrm{~s}$

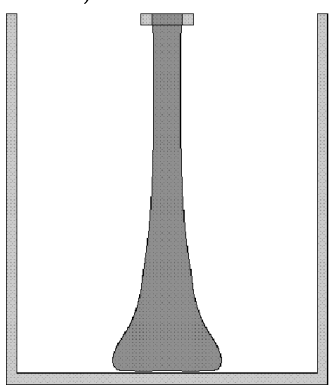

c) $t=0.52 \mathrm{~s}$

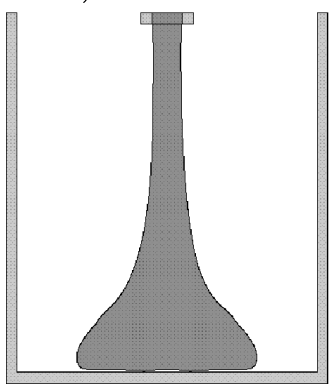

e) $t=0.70 \mathrm{~s}$
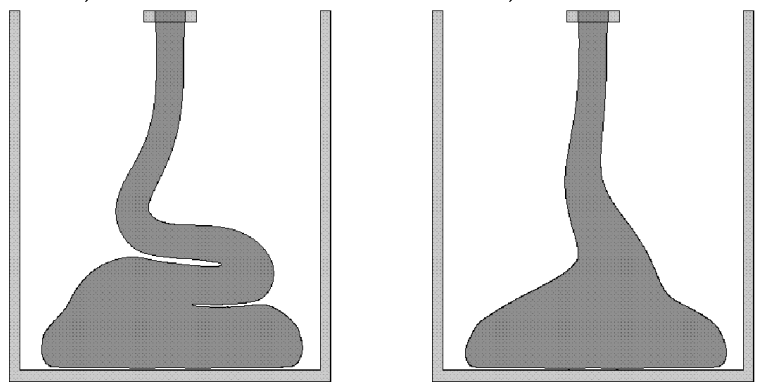

Figura 5.3: Caso 2 não newtoniano. b) $t=0.46 \mathrm{~s}$

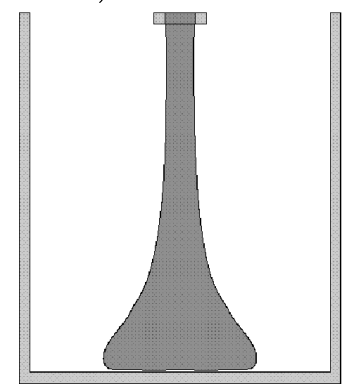

d) $t=0.60 \mathrm{~s}$

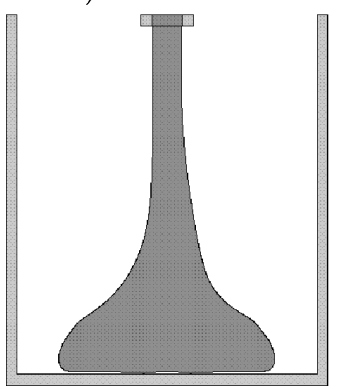

f) $t=0.80 \mathrm{~s}$

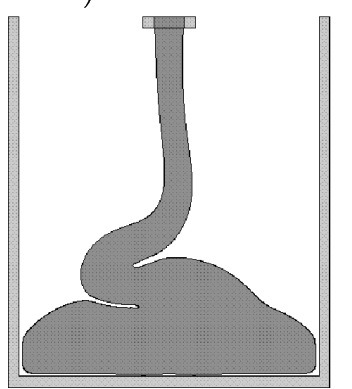

Nas simulações apresentadas nas figuras 5.4 e 5.5, em que o número de Reynolds é maior, observa-se que a viscosidade do jato foi reduzida significativamente provocando um retardamento no fenômeno "buckling", em relação ao caso anterior. Na figura 5.6 apresenta-se os resultados utilizando-se $n=0.6$ (índice "power-law"), os outros dados são os mesmos dos casos anteriores. Nesse caso (ver figura 5.6) pode-se observar que o fenômeno "buckling" não ocorre até o tempo mostrado na figura 5.6. Este resultado mostra que o fenômeno "buckling" é mais lento quando o efeito "shear-thinning" (menor viscosidade, maior número de Reynolds) for mais forte $(n<<1)$. Isso ocorre pois, quando 
o fluido bate na parede oposta ao injetor devido a condição de não deslizamento, temse altos valores da taxa de deformação, com isso tem-se baixa viscosidade, levando a um maior espalhamento do fluido, e, como consequência, o fenômeno "buckling" quase desaparece. Ao passo que no caso newtoniano, quando o fluido bate na parede oposta ao injetor, ele sofre uma desaceleração, provocada pela condição de não deslizamento. Com isso há retardo no escoamento e acumulo de fluido, o que leva a provocar o fenômeno "buckling".

a) $t=0.36 \mathrm{~s}$

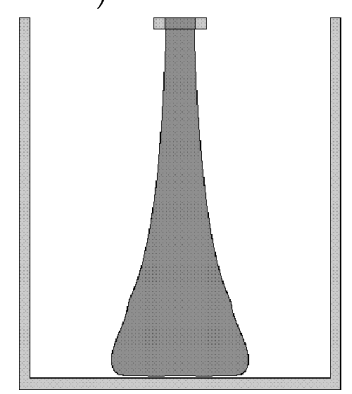

c) $t=0.52 \mathrm{~s}$

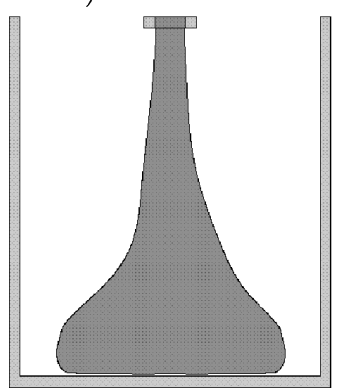

e) $t=0.70 \mathrm{~s}$

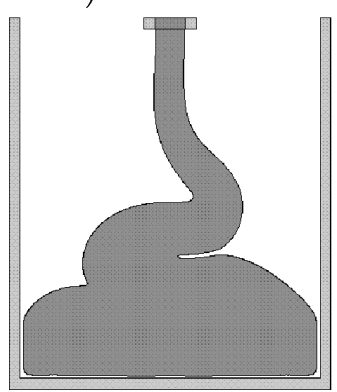

Figura 5.4: Caso 3 newtoniano. a) $t=0.36 \mathrm{~s}$

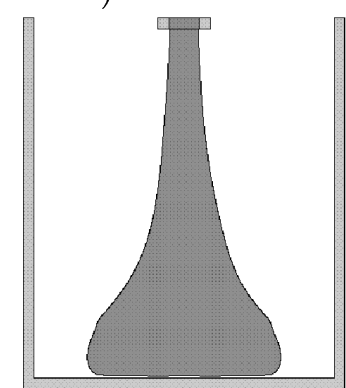

d) $t=0.60 \mathrm{~s}$

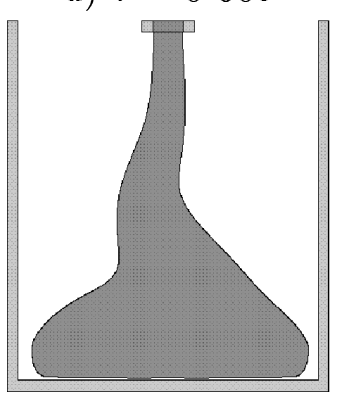

f) $t=0.80 \mathrm{~s}$

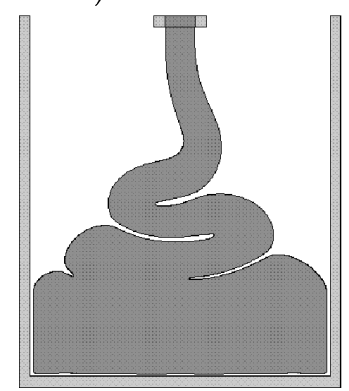

e) $t=0.70 \mathrm{~s}$

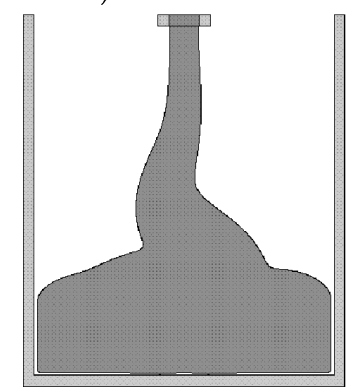

f) $t=0.80 \mathrm{~s}$

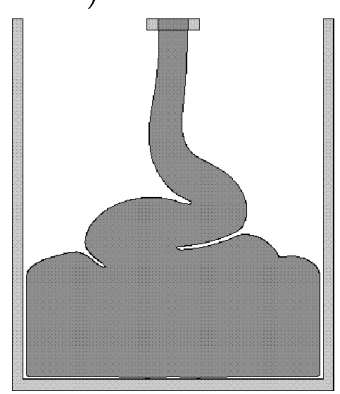

Figura 5.5: Caso 4 não newtoniano.

Os resultados obtidos são qualitativamente satisfatórios, concordado com os resultados de (Kim et al., 2001).

As figuras 5.7 e 5.8 mostram o esquema em mapa de cores para os campos de ve- 

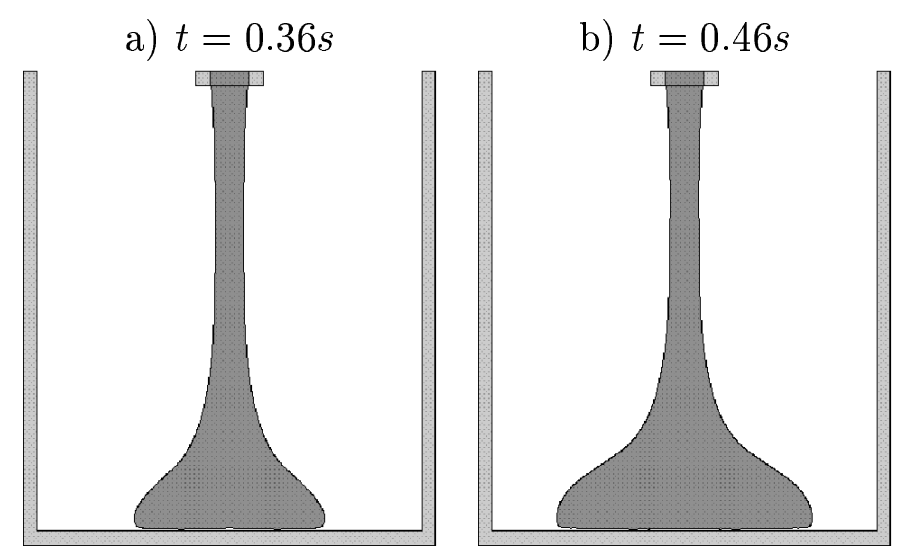

c) $t=0.52 \mathrm{~s}$
d) $t=0.60 \mathrm{~s}$
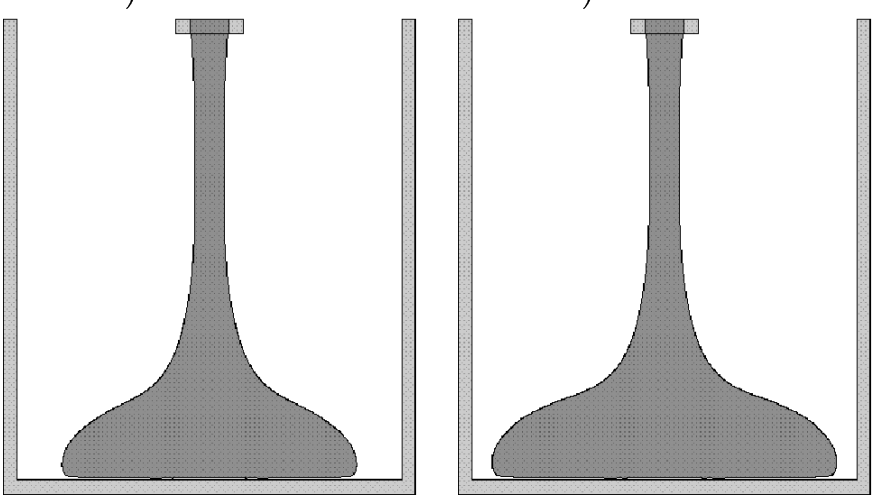

e) $t=0.70 \mathrm{~s}$

f) $t=0.80 \mathrm{~s}$
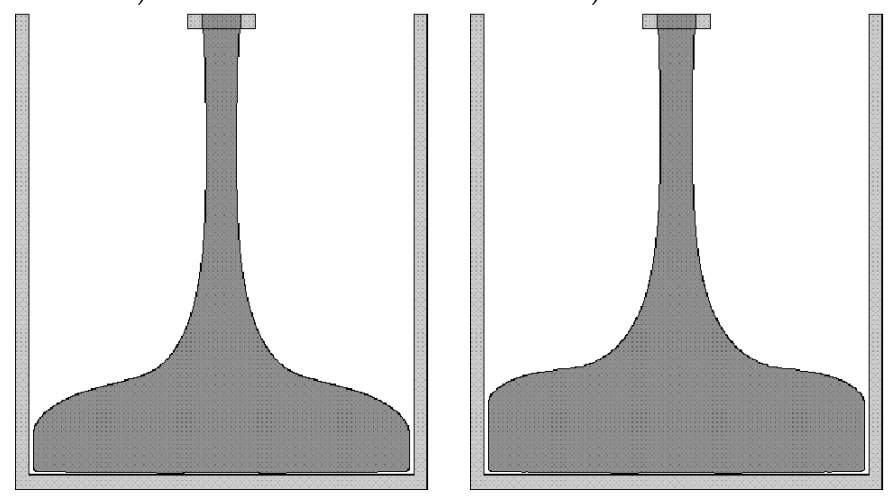

Figura 5.6: Caso 5 não newtoniano.

locidade, viscosidade e pressão respectivamente, no tempo $t=0.80 \mathrm{~s}$ para o escoamento descrito na tabela 5.1 como caso 5 . 


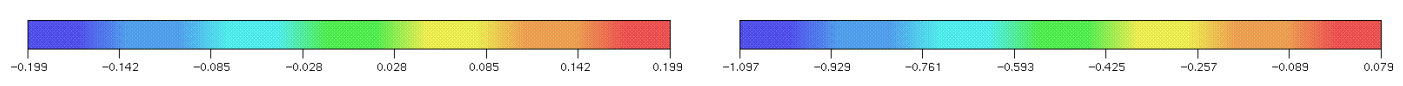

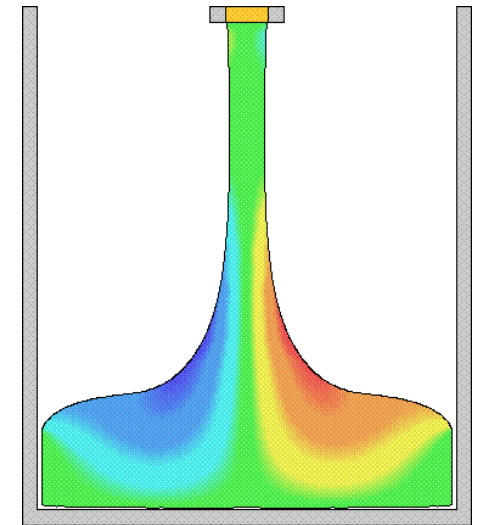

a) Velocidade na direção $x$.

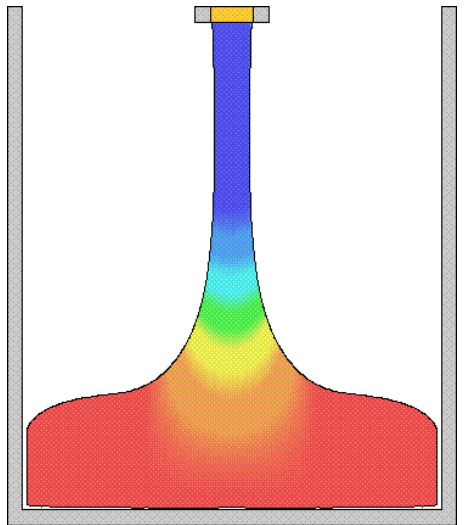

b) Velocidade na direção $y$.

Figura 5.7: Campo de velocidade no tempo $t=0.80 \mathrm{~s}$, para o caso 5 não newtoniano.

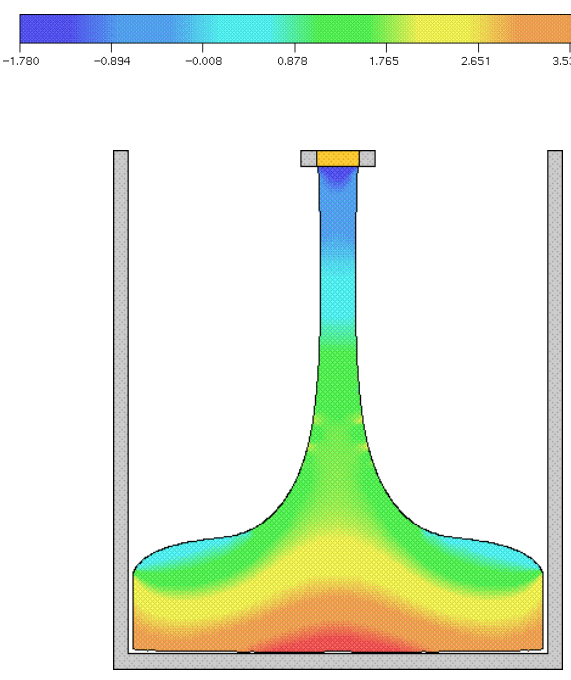

c) Pressão.

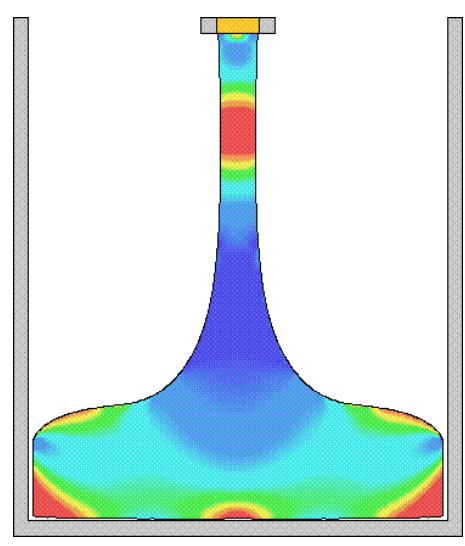

d) Viscosidade.

Figura 5.8: Campo de pressão e viscosidade no tempo $t=0.80 \mathrm{~s}$, para o caso 5 não newtoniano.

\subsubsection{Validação Quantitativa}

A validação do código é feita comparando-se a solução analítica, derivada a seguir, com os dados numéricos obtidos a partir do sistema FreeFlow-2D.

Nesta seção, apresentam-se resultados numéricos de um escoamento entre duas placas 
paralelas separadas por uma distância $L$ (ver figura 5.9). Ambas as placas são consideradas estacionárias e o escoamento simétrico. O gradiente de pressão é prescrito, gerando diferentes perfis de velocidades ao longo do canal.

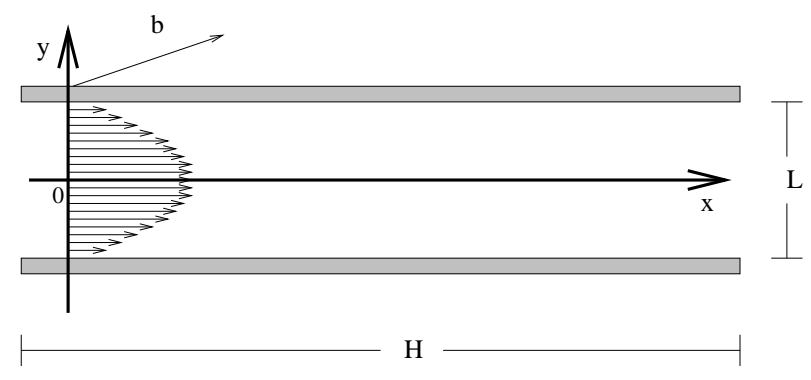

Figura 5.9: Escoamento entre duas placas.

Para esse tipo de problema, é possível obter uma solução análitica para vários tipos de fluidos não newtonianos (Bird et al., 1977).

De fato, para o escoamento entre duas placas paralelas considera-se que o escoamento é completamente desenvolvido, de modo que

$$
\frac{\partial u}{\partial x}=0, \quad \frac{\partial v}{\partial x}=0, \quad v=0 .
$$

Então da equação (1.10) obtém-se,

$$
\frac{\partial u}{\partial t}=-\frac{1}{\rho} \frac{\partial p}{\partial x}+\nu(q) \frac{\partial^{2} u}{\partial y^{2}}+\frac{\partial u}{\partial y} \frac{\partial \nu(q)}{\partial y} .
$$

Assumindo estado estacionário, $\frac{\partial u}{\partial t}=0$, tem-se

$$
\frac{\partial}{\partial y}\left(\nu(q) \frac{\partial u}{\partial y}\right)=\frac{1}{\rho} \frac{\partial p}{\partial x}
$$

onde $q=\left|\frac{\partial u}{\partial y}\right|$ e $\nu(q)$, é dado pelo modelo de viscosidade.

Utilizando-se os dados do modelo "power-law", por exemplo $n=0.4$ e $K=5.4$, com $\frac{1}{\rho} \frac{\partial p}{\partial x}=-1000$ e $L=0.02 m$, pode-se escrever a equação (5.4) como

$$
3.24 \frac{\left(\frac{\partial^{2} u}{\partial y^{2}}\right)\left(\frac{\partial u}{\partial y}\right)}{\left(-\left(\frac{\partial u}{\partial y}\right)\right)^{1.6}}+5.4 \frac{\left(\frac{\partial^{2} u}{\partial y^{2}}\right)}{\left(-\left(\frac{\partial u}{\partial y}\right)\right)^{0.6}}=-1000.0 .
$$

Aqui foi utilizado $q(y)=\left\{\left(x_{0}, y\right) ; 0<y<\frac{L}{2}\right\}$. 
Utilizando-se a condição de não deslizamento e o fato do escoamento ser simétrico (com eixo de simetria no centro do canal), tem-se

$$
u(L / 2)=0 \quad \text { e } \quad \frac{\partial u(0)}{\partial y}=0 .
$$

Portanto, utilizando-se as condições acima, e fazendo uso do software MAPLE, pode-se mostrar que a solução de (5.5) é dada por:

$$
u(y)=-\frac{50000000}{45927} y^{3.5} \sqrt{15000}+0.0133336041 .
$$

A escala de velocidade $U$, é determinada por:

$$
U=\frac{\mathrm{V}}{\mathrm{A}}
$$

onde, $\mathrm{V}=b \int_{-L / 2}^{L / 2} u(y) d y$, vazão por unidade de profundidade e $\mathrm{A}=b \int_{-L / 2}^{L / 2} d y$ é a área da seção transversal do canal.

Então

$$
U=\frac{1}{L} \int_{-L / 2}^{L / 2} u(y) d y=\frac{2}{L} \int_{0}^{L / 2} u(y) d y .
$$

Para enfatizar a não linearidade da equação (5.4), mostra-se na figura 5.10 a solução analítica para vários valores de $n$.

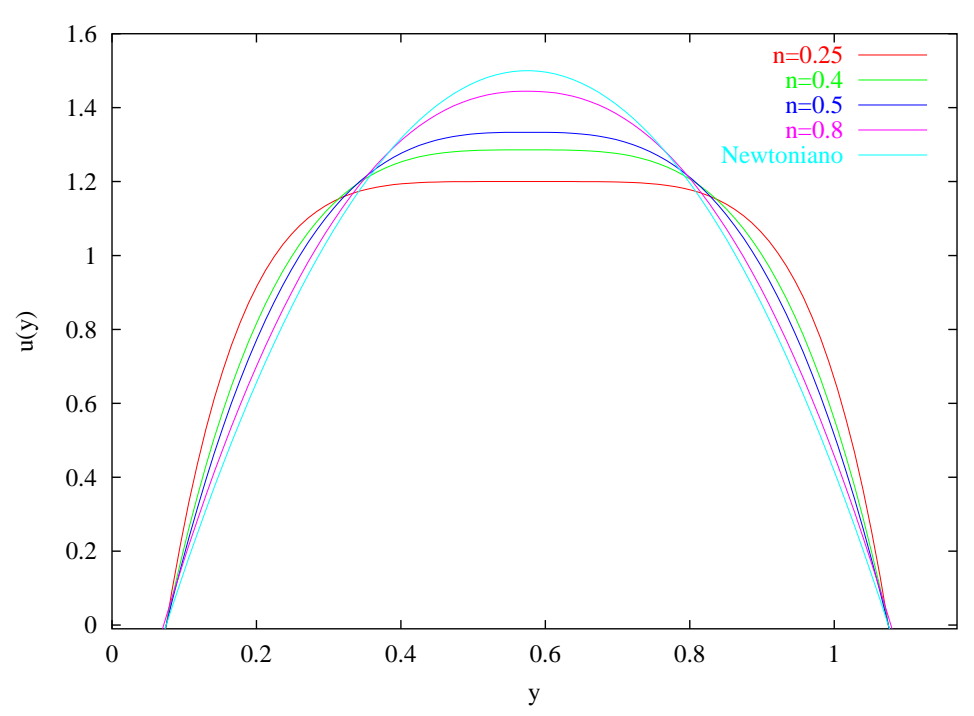

Figura 5.10: Solução analítica para vários valores de $n$.

Observa-se a partir da figura 5.10 que, com o aumento de $n$, o perfil de velocidade tende ao perfil de um fluido newtoniano. 
Para simular numericamente esse problema, utiliza-se os dados da tabela 5.2. O comprimento do canal é escolhido de modo que os efeitos de algumas pertubações causadas pelas condições de contorno sejam minimizadas. Nos resultados que se seguem foi utilizado $H=6 L$.

\begin{tabular}{cccccc}
\hline$n$ & $K(\mathrm{~Pa} \cdot \mathrm{s})$ & $\nu_{0}\left(\mathrm{~m}^{2} \mathrm{~s}^{-1}\right)$ & $L(\mathrm{~m})$ & $U\left(\mathrm{~ms}^{-1}\right)$ & $R e$ \\
\hline \hline 0.25 & 5.4 & 0.01 & 0.02 & 0.01960 & 0.03920 \\
0.4 & 5.4 & 0.01 & 0.02 & 0.01037 & 0.02074 \\
0.5 & 5.4 & 0.01 & 0.02 & 0.00857 & 0.01714 \\
0.8 & 5.4 & 0.01 & 0.02 & 0.00664 & 0.01329 \\
\hline
\end{tabular}

Tabela 5.2: Propriedades físicas e dados do modelo power-law.

A figura 5.11 mostra a malha computacional utilizada na simulação de um escoamento entre duas placas paralelas. Note que o injetor é colocado do lado esquerdo da figura e o ejetor esta $12 \mathrm{~cm}$ à direita (ver figura 5.11). Para mostrar a convergência do método, utilizamos também uma malha mais fina com $240 \times 40$ células.

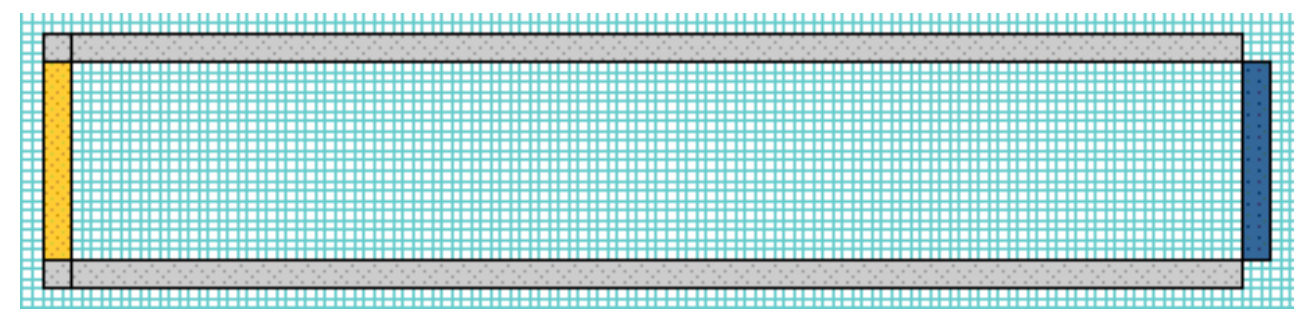

Figura 5.11: Malha computacional com $120 \times 20$ células.

Utilizando o sistema FreeFlow-2D, esse problema foi simulado nas duas malhas até se obter o estado estacionário. O erro entre a solução numérica e a solução analítica, para vários valores de $n$, é mostrado na tabela 5.3.

\begin{tabular}{|c|c|c|c|c|}
\hline malha & $n=0.25$ & $n=0.4$ & $n=0.5$ & $n=0.8$ \\
\hline \hline $120 \times 20$ & 0.105699 & 0.011813 & 0.009348 & 0.012765 \\
\hline $240 \times 40$ & 0.017648 & 0.008261 & 0.004824 & 0.009074 \\
\hline
\end{tabular}

Tabela 5.3: Erros relativos $\left(E_{r e l}\right)$ na norma $l_{2}$ entre solução analítica e simulação numérica no ponto $x=0.09 \mathrm{~m} . E_{\text {rel }}=\left\|S_{\text {analítica }}-S_{\text {numérica }}\right\|_{2} /\left\|S_{\text {analítica }}\right\|_{2}$. 
Pode-se observar da tabela 5.3 que ao refinarmos a malha grossa $(120 \times 20)$ ocorre uma diminuição no erro relativo. Isso mostra a convergência do método numérico.

Para melhor avaliar os resultados e compará-los com a solução exata, as figuras 5.12 e 5.13, mostram a comparação entre a solução exata e o solução numérica na posição $x=0.09 \mathrm{~m}$, para a velocidade. Esses resultados foram obtidos na malha fina com $n=0.4$ e $n=0.8$ respectivamente.

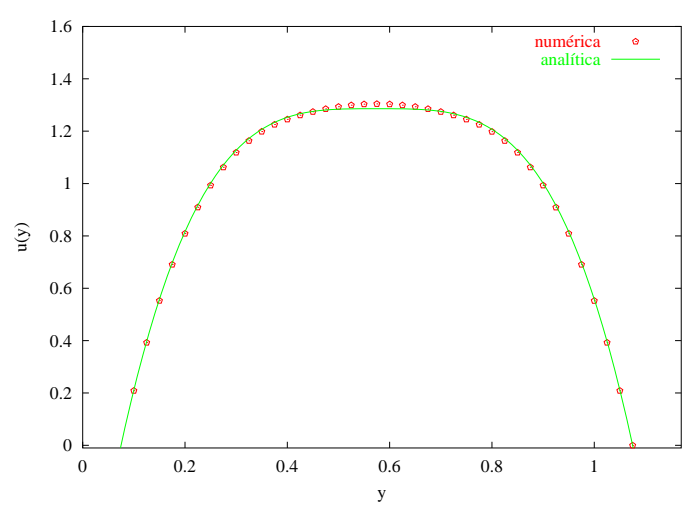

Figura 5.12: Perfil para $n=0.4$.

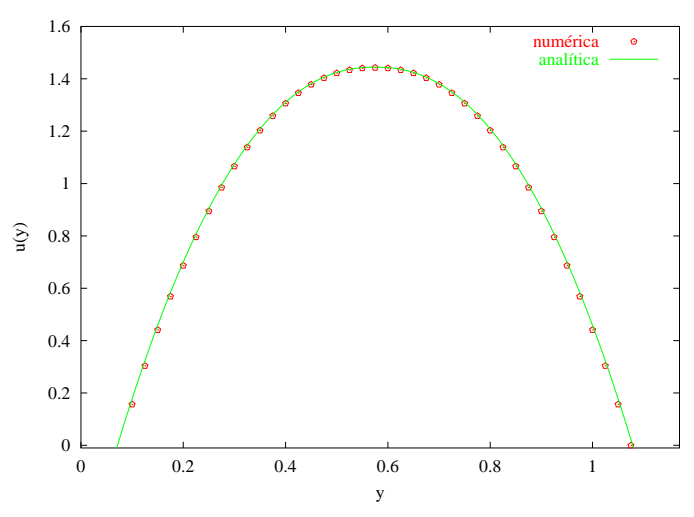

Figura 5.13: Perfil para $n=0.8$.

As figuras 5.12 e 5.13 mostram que há uma boa concordância entre as soluções numéricas e analítica.

As figuras 5.14 e 5.15 mostram o esquema em mapa de cores para a velocidade e viscosidade respectivamente. Para um escoamento do tipo "power-law" com $n=0.8$. As "singularidades" que aparecem nos cantos do canal são causadas pelas condições de contorno no ejetor e o fato do perfil de velocidade, no injetor, ser constante. Esses erros são desprezíveis no desemvolvimento do escoamento.
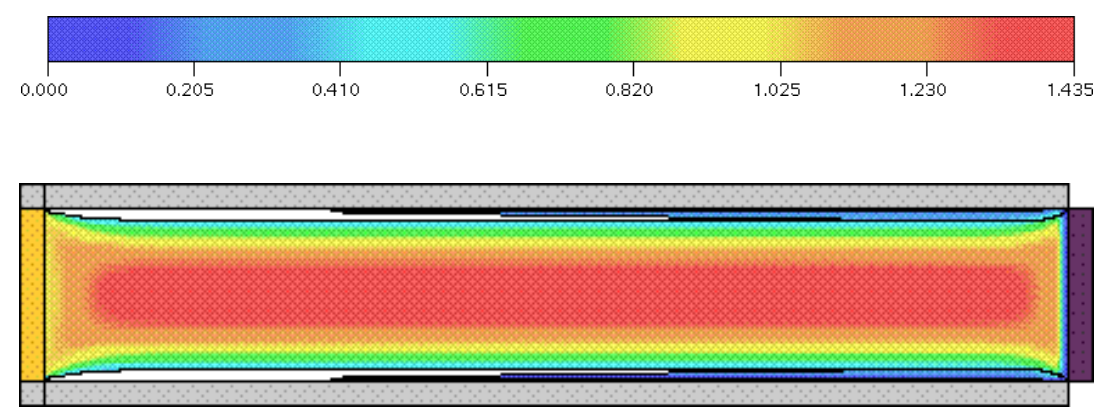

Figura 5.14: Campo de velocidade na direção $x$, no tempo $t=25.20$. 

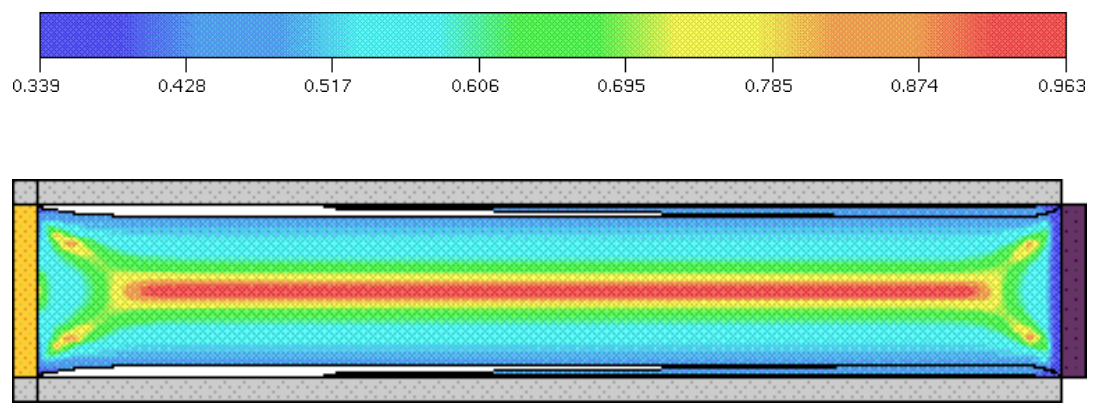

Figura 5.15: Campo de viscosidade no tempo $t=25.20$.

\subsection{Modelo de Cross}

O modelo de Cross permite descrever o comportamento da viscosidade do material a baixas e médias taxas de deformações (Bretas e DAvila, 2000). Matematicamente esse modelo pode ser representado por:

$$
\nu(q)=\nu_{\infty}+\frac{\nu_{0}-\nu_{\infty}}{1+(K q)^{m}}
$$

onde $m, \nu_{0}, \nu_{\infty}$ e $K$ são constantes positivas.

\subsubsection{Simulação de um Jato Incidindo Perpendicularmente em uma Superfície Plana}

Nessa seção considera-se um jato de fluido que incide sobre uma superfície plana. Considera-se um jato escoando de um injetor situado a uma altura $H=0.05 \mathrm{~m}$ acima de uma placa plana de comprimento $L=0.05 \mathrm{~m}$. O diâmetro do jato é $D=0.004 \mathrm{~m}$ e a velocidade no injetor é $U=0.5 \mathrm{~ms}^{-1}$ (ver figura 5.16).

Nas simulações, utiliza-se uma malha com $100 \times 100$ células $(\delta x=\delta y=0.05 \mathrm{~m})$. A viscosidade é modelada pelo modelo de Cross com $\nu_{0}=0.002 \mathrm{~m}^{2} \mathrm{~s}^{-1}, \nu_{\infty}=0.0002$ $m^{2} s^{-1}, m=1$ e o parâmetro $K$ assume os valores $K=0.1,1$, e 10 . A condição de não deslizamento é imposta na placa. As equações foram adimensionalizadas utilizando-se $U$, $D$ e $\nu_{0}$, obtendo-se assim $R e=U D / \nu_{0}=1$ e $F r=U / \sqrt{g D}=2.52409$.

O modelo descrito acima foi simulado para os vários valores de $K$. Na figura 5.17 está mostrada a superfície do jato para vários instantes do tempo. Também é mostrado o resultado das simulações com $K=0$ (escoamento newtoniano com $R e=1$ ) e $K=\infty$ (escoamento newtoniano com $R e=U D / \nu_{\infty}=10$ ). 


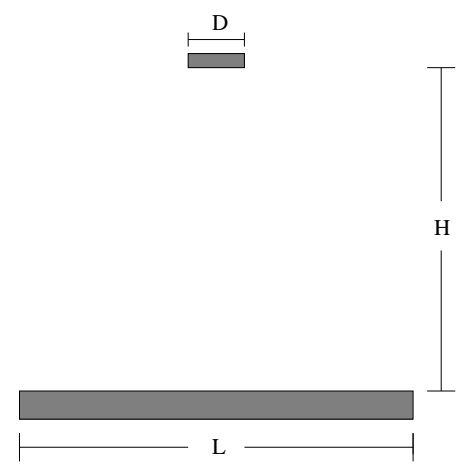

Figura 5.16: Representação esquemática do molde para a simulação de um jato incidindo perpendicularmente em uma superfície plana.
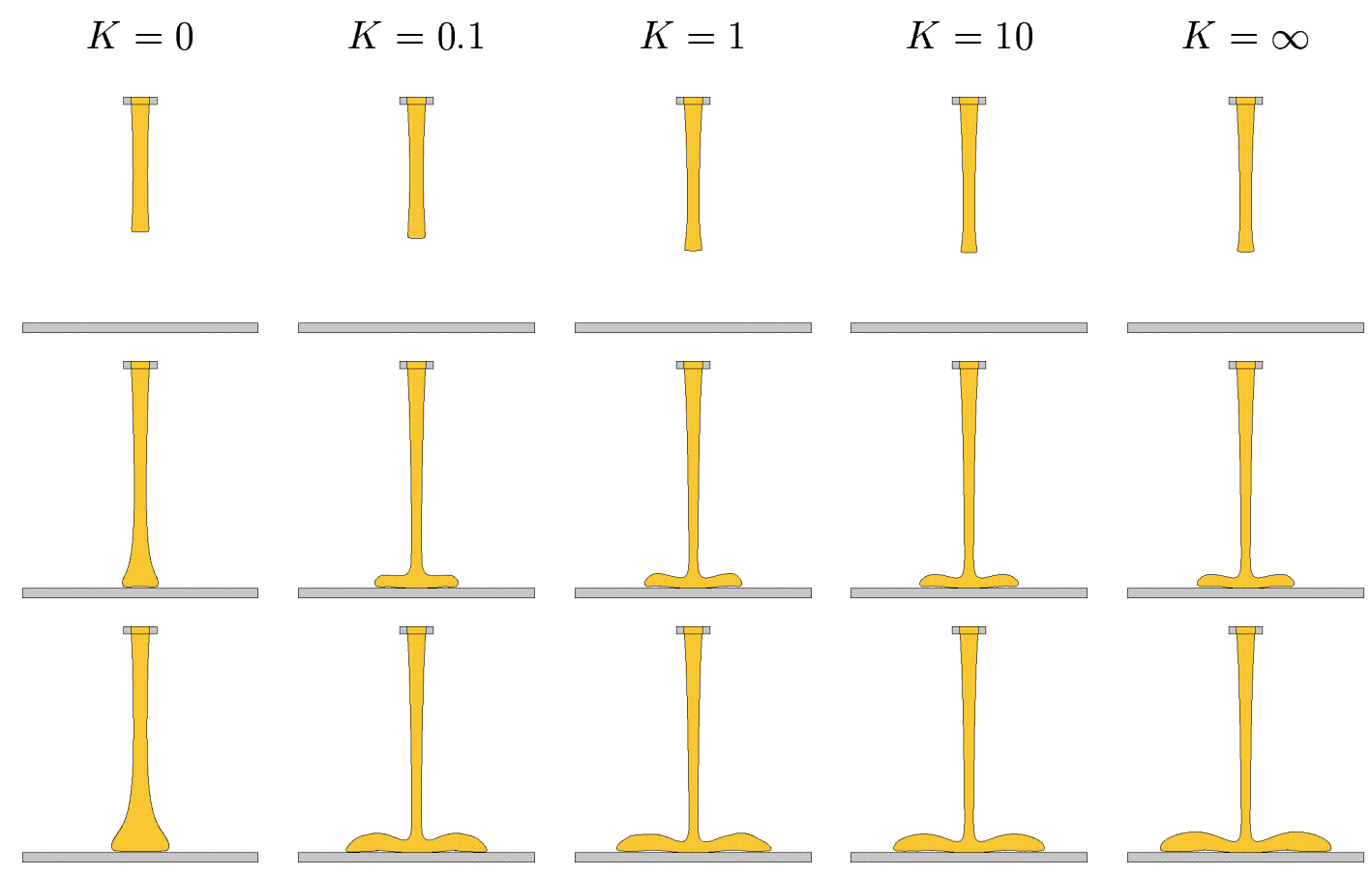

Figura 5.17: Simulação numérica de um jato incidindo em uma superfície plana.

Observando a figura 5.17, notamos que com o aumento de $K$ o fluido torna-se menos viscoso e consequentemente tem-se um maior espalhamento.

A medida que o valor de $K$ aumenta, a visualização do escoamento se aproxima daquele obtido com $K=\infty$. De fato, como mostra a figura 5.18, a medida que se aumenta o valor de $K$ a viscosidade se aproxima do valor de $\nu_{\infty}$, mesmo para valores pequenos da taxa de deformação. Isso sugere que os resultados numéricos obtidos com o sistema FreeFlow-2D estão "qualitativamente" corretos. 


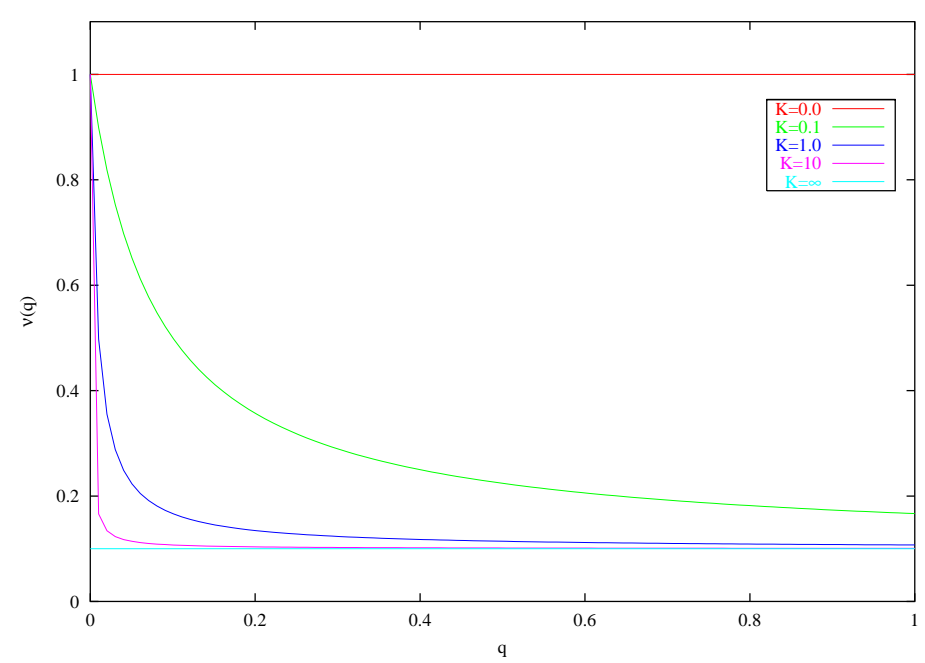

Figura 5.18: Variação da viscosidade

\subsubsection{Instabilidade na Simulação Numérica de Escoamentos de Fluidos Não Newtonianos}

Com relação a fluidos newtonianos generalizados, a equação de conservação de quantidade de movimento pode tornar-se mal posta se o fluido for modelado com o modelo de Cross. Para mostrar o mal condicionamento consideremos o escoamento entre duas placas paralelas como mostra a figura 5.19.

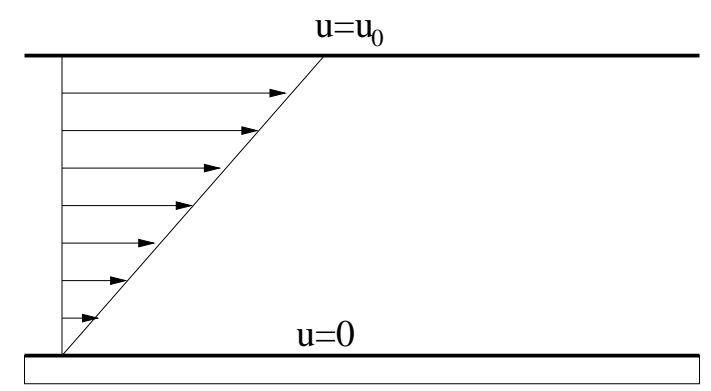

Figura 5.19: Escoamento entre duas placas paralelas

Nesse caso, o escoamento é governado pela equação

$$
\frac{\partial u}{\partial t}=\frac{1}{R e}\left[\nu(q) \frac{\partial^{2} u}{\partial y^{2}}+\frac{\partial u}{\partial y} \frac{\partial \nu(q)}{\partial y}\right]
$$

onde $q=\frac{\partial u}{\partial y}$. 
Tomando-se $\bar{u}$ uma solução de (5.8) no estado estacionário e considerando-se o fato de $\frac{\partial \nu(q)}{\partial y}=\frac{\partial \nu(q)}{\partial q} \frac{\partial q}{\partial y}=\frac{\partial \nu(q)}{\partial q} \frac{\partial^{2} u}{\partial y^{2}}$, tem-se,

$$
\frac{1}{R e}\left[\nu(q) \frac{\partial^{2} \bar{u}}{\partial y^{2}}+\frac{\partial \bar{u}}{\partial y} \frac{\partial \nu(q)}{\partial q} \frac{\partial^{2} \bar{u}}{\partial y^{2}}\right]=0 \Rightarrow \frac{1}{R e}\left[\nu(q)+\frac{\partial \bar{u}}{\partial y} \frac{\partial \nu(q)}{\partial q}\right] \frac{\partial^{2} \bar{u}}{\partial y^{2}}=0
$$

A equação (5.9) possui duas possíveis soluções

$$
\text { a) } \frac{\partial^{2} \bar{u}}{\partial y^{2}}=0, \quad \text { b) } \frac{\partial \bar{u}}{\partial y}=-\frac{\nu(q)}{\frac{\partial \nu(q)}{\partial q}} .
$$

Agora, fazendo uma pequena perturbação na equação (5.8), tomando $u=\bar{u}+\widetilde{u}$, onde $\widetilde{u}$ é uma perturbação muito pequena, substituindo-se em (5.8) obtém-se

$$
\frac{\partial \widetilde{u}}{\partial t}=\frac{1}{R e}\left[\nu(q) \frac{\partial^{2} \widetilde{u}}{\partial y^{2}}+\frac{\partial(\bar{u}+\widetilde{u})}{\partial y} \frac{\partial \nu(q)}{\partial q} \frac{\partial}{\partial y} \frac{\partial(\bar{u}+\widetilde{u})}{\partial y}\right]
$$

Considerando-se $\frac{\partial^{2} \bar{u}}{\partial y^{2}}=0, \frac{\partial u}{\partial y}>0, \widetilde{u}<<\bar{u}$ e desprezando-se os termos de mais alta ordem que aparecem na equação tem-se

$$
\frac{\partial \widetilde{u}}{\partial t}=\frac{1}{R e}\left[\nu(q) \frac{\partial^{2} \widetilde{u}}{\partial y^{2}}+\frac{\partial \bar{u}}{\partial y} \frac{\partial \nu(q)}{\partial q} \frac{\partial^{2} \widetilde{u}}{\partial y^{2}}\right]
$$

o qual pode ser escrito como

$$
\frac{\partial \widetilde{u}}{\partial t}=\frac{\nu(q)}{R e}\left[1+\frac{\bar{q}}{\nu(q)} \frac{\partial \nu(q)}{\partial q}\right] \frac{\partial^{2} \widetilde{u}}{\partial y^{2}}
$$

Observemos que a equação (5.10) tem a forma da equação do calor,

$$
\frac{\partial \widetilde{u}}{\partial t}=\frac{\nu(q)}{R e} \alpha \frac{\partial^{2} \widetilde{u}}{\partial y^{2}}
$$

onde $\alpha=1+\frac{\bar{q}}{\nu(q)} \frac{\partial \nu(q)}{\partial q}$.

Portanto, a equação (5.11) torna-se instável se $\alpha<0$, ou seja em regiões onde

$$
\gamma(q)<-1
$$

$\operatorname{para} \gamma(q)=\frac{\bar{q}}{\nu(q)} \frac{\partial \nu(q)}{\partial q}$

Analisando-se o gráfico na figura 5.20 pode-se notar que, para valores de $m$ maiores ou iguais a 1.8, o escoamento passa pela região de instabilidade. 


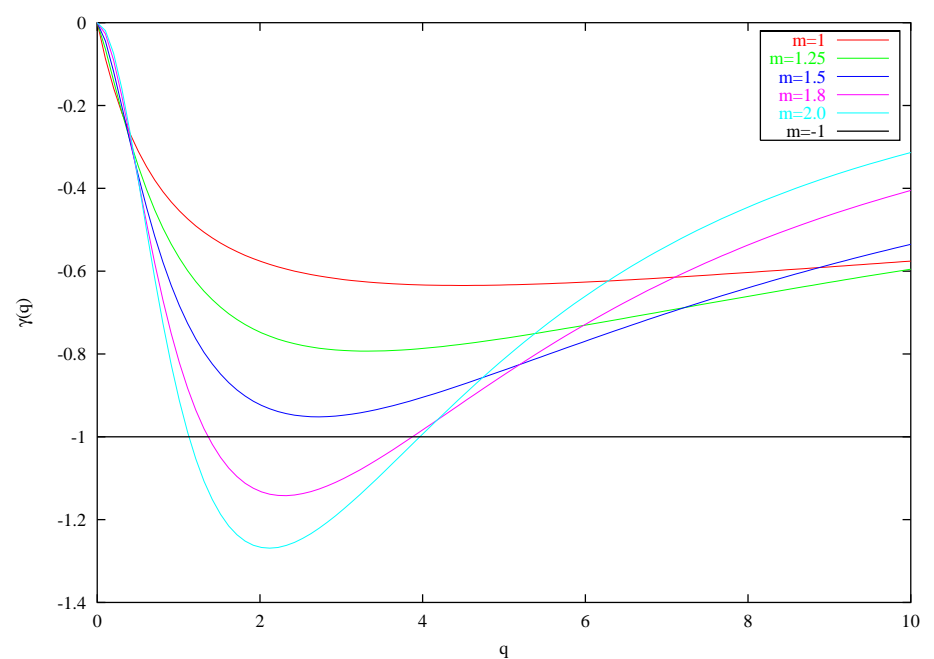

Figura 5.20: Variação da função $\gamma(q)$ para vários valores de $m$. Com os parâmetros do modelo Cross: $\nu_{0}=0.02, \nu_{\infty}=0.001, K=1$ e $U=0.5, L=0.01$.

Logo, quando os parâmetros do modelo de Cross forem tais que $\gamma(q)<-1$, para certos valores da taxa de deformação, o problema é dito ser mal-posto, e portanto instável em regiões do escoamento onde a razão de cisalhamento atinge esses valores. As simulações numéricas para esse caso são sempre instáveis, concordando com a análise. As figuras 5.21a e 5.21b mostram exemplos típicos de um problema que se torna mal-posto com a variação do parâmetro $m$.

a)

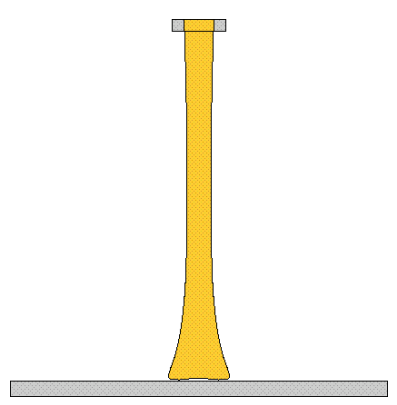

b)

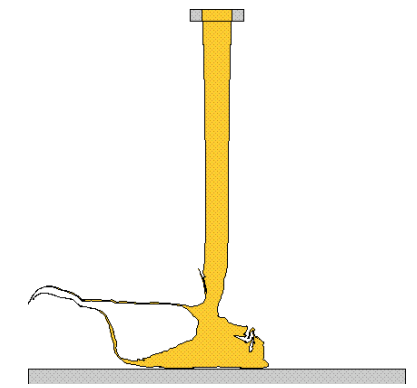

Figura 5.21: Simulação numérica de um jato planar utilizando os parâmetros: $\nu_{0}=0.02$, $\nu_{\infty}=0.001, K=1, U=0.5, L=0.01$, e no caso a) $m=1$ e no caso b) $m=2$.

Nesse caso o escoamento desenvolve a instabilidade logo após o fluido bater na placa, assumindo uma solução fisicamente incorreta. 


\subsubsection{Validação Quantitativa}

A validação quantitativa para o modelo Cross é feita como na seção 5.1.2 utilizando-se o escoamento entre duas placas paralelas.

Considerando-se o escoamento totalmente desenvolvido e tomando-se os dados do modelo de Cross; por exemplo, $m=1, \nu_{0}=0.02 m^{2} s^{-1}, \nu_{\infty}=0.002 m^{2} s^{-1}$ e $K=0.0034$, $\operatorname{com} \frac{1}{\rho} \frac{\partial p}{\partial x}=-1000$ e largura $L=0.02 \mathrm{~m}$, pode-se utilizar a equação (5.4) e as condições de fronteira corretas para encontrar a solução analítica para esse escoamento. Novamente, utilizando o software MAPLE pode-se mostrar que a solução analítica com esses dados é dada por:

$$
\begin{aligned}
u(y)= & 1470.5882 y-1.25 \times 10^{5}-735.2941 y \sqrt{\alpha}+3.4602 \sqrt{\alpha} \\
& -1.5571 \ln \left(0.425 \times 10^{9} y-0.2 \times 10^{7}+0.25 \times 10^{7} \sqrt{\alpha}\right)+26.0085,
\end{aligned}
$$

onde $\alpha=1-272 y+28900 y^{2}$. Uma vez conhecido o valor de $u(y)$, o valor exato de $\nu(q)$ também pode ser calculado.

Para enfatizar a não linearidade da equação (5.4) calculamos a solução analítica para quatro valores de $K$, que produz quatro perfis de velocidade (ver figura 5.22).

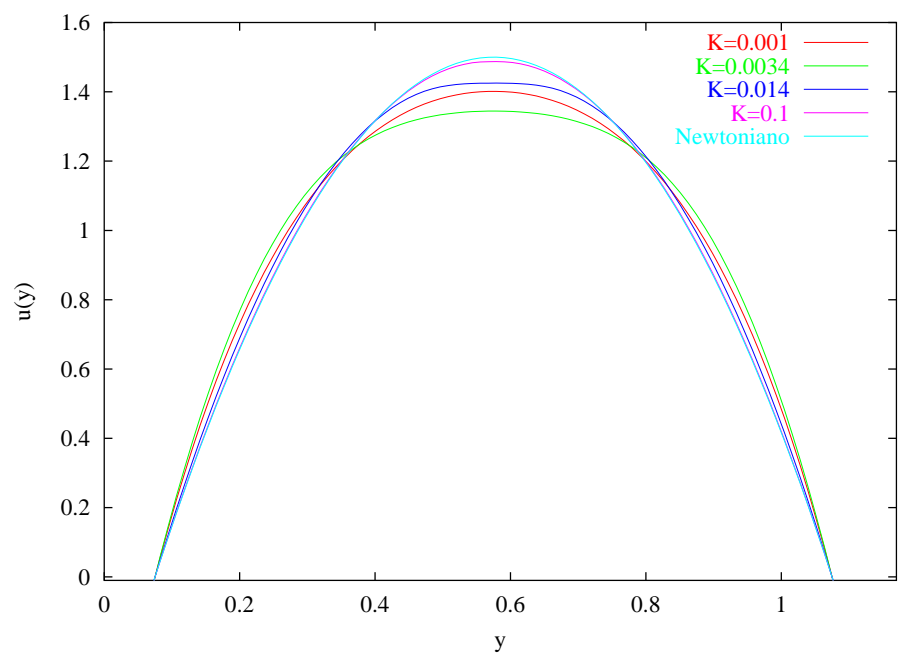

Figura 5.22: Solução analítica para vários valores do parâmetro K.

Observa-se na figura 5.22 que, quando aumenta-se o valor de $K$, o perfil de velocidade tende ao perfil de velocidade de um fluido newtoniano.

Para simular numericamente esse problema, utilizou-se os dados da tabela 5.4. O comprimento do canal é escolhido de modo que os efeitos de algumas pertubações causadas 
pelas condições de contorno sejam minimizados. Nos resultados que se seguem foi utilizado $H=6 L$.

\begin{tabular}{cccccc}
\hline$K$ & $\nu_{0}\left(m^{2} s^{-1}\right)$ & $\nu_{\infty}\left(m^{2} s^{-1}\right)$ & $L(m)$ & $\mathrm{U}\left(m s^{-1}\right)$ & $R e$ \\
\hline \hline 0.0034 & 0.02 & 0.002 & 0.02 & 6.72109 & 6.72109 \\
0.014 & 0.02 & 0.002 & 0.02 & 13.5877 & 13.5877 \\
1.4 & 0.02 & 0.002 & 0.02 & 16.6345 & 16.6345 \\
\hline
\end{tabular}

Tabela 5.4: Propriedades físicas e dados do modelo Cross.

Esse problema foi executado utilizando-se três malhas, grossa, $120 \times 20$ células, intermediária, $240 \times 40$ células e fina, $480 \times 80$ células . O erro entre a solução analítica e a solução numérica (no estado estacionário) para diferentes perfis de velocidade, pode ser visto na tabela 5.5 .

\begin{tabular}{|c|c|c|c|}
\hline$K$ & malha $1(120 \times 20)$ & malha $2(240 \times 40)$ & malha $3(480 \times 80)$ \\
\hline \hline 0.0034 & 0.100156 & 0.00162 & 0.000425 \\
\hline 0.014 & 0.016539 & 0.013413 & 0.00943 \\
\hline 1.4 & 0.0362668 & 0.033678 & 0.030584 \\
\hline
\end{tabular}

Tabela 5.5: Erros relativos $\left(E_{r e l}\right)$ na norma $l_{2}$ entre a solução analítica e a solução numérica no ponto $x=0.09 \mathrm{~m} . E_{\text {rel }}=\left\|S_{\text {analítica }}-S_{\text {numérica }}\right\|_{2} /\left\|S_{\text {analítica }}\right\|_{2}$.

Para melhor avaliar os resultados e compará-los com a solução analítica, a figura 5.23 mostra uma comparação entre o perfil de velocidade análitico e o numérico, na posição, $x=0.09 m$, nas malhas $120 \times 20,240 \times 40$ e $480 \times 80$ células para $K=0.0034$. A figura 5.24 mostra um "zoom" da figura 5.23 na região mais crítica do perfil, nota-se que ao refinarmos a malha ocorre uma melhor aproximação produzida pela malha fina, $480 \times 80$ células, o que mostra a convergência do método (resultado quantitativamente visto na tabela 5.5). 


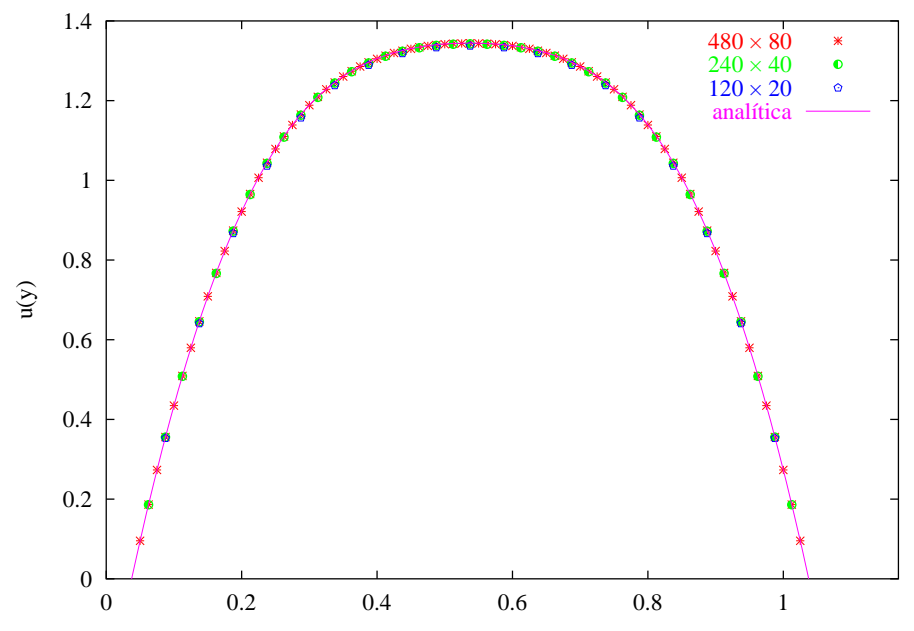

Figura 5.23: Comparação entre soluções numéricas e analítica, para um perfil de velocidade com $K=0.0034$, nas três malhas (fina, intermediária e grossa).

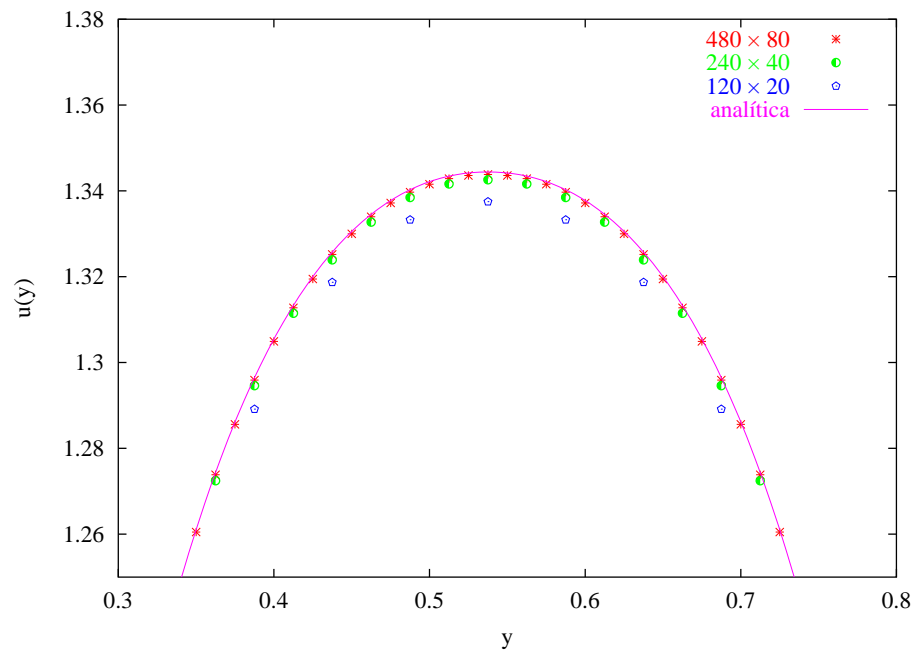

Figura 5.24: Zoom da região mais crítica do perfil de velocidade dado na figura 5.23.

Como pode-se observar nas figuras 5.23 e 5.24, tem-se uma boa correspondência entre a solução analítica e numérica. 


\subsubsection{Extrudate Swell}

Nessa seção apresenta-se a simulação numérica do escoamento de um jato planar (ver figura 5.25), o qual exibe o fenômeno característico chamado "extrudate swell". Esse problema tem atraído a atenção de vários pesquisadores e varias técnicas para simular "extrudate swell" de um fluido não newtoniano, bem como fluidos newtonianos, tem sido desenvolvidas ao longo dos anos (Crochet et al., 1984), (Tomé et al., 1996).

Para simular esse problema, considera-se o escoamento de um jato em duas dimensões com velocidade prescrita no injetor $U_{i}=5 \mathrm{~ms}^{-1}$, e um injetor de comprimento $L=0.01 \mathrm{~m}$, com "slit" de comprimento $S=0.03 m$ (ver figura 5.25). A condição de não deslizamento é imposta nas paredes do "slit" $(u=v=0)$. $D_{\text {max }}$ é a dilatação máxima do jato (ver figura 5.25).

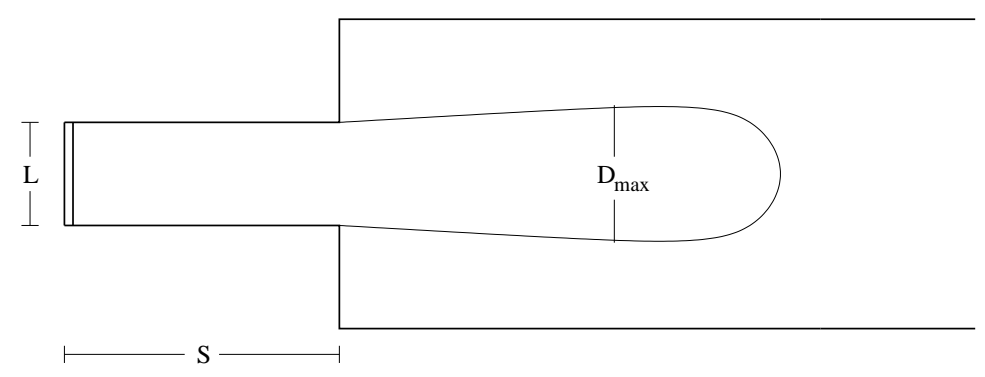

Figura 5.25: Representação esquemática de um molde para a simulação do escoamento "extrudate swell".

Nesta simulação calcula-se o parâmetro $S_{r}$, chamado de razão de dilatação do jato, pela fórmula

$$
S_{r}=\frac{D_{\max }}{L} .
$$

O cálculo de $S_{r}$ é de grande importância, dependendo do fluido e do escoamento, a razão de dilatação do jato pode atingir valores surpreendentes ((Tanner, 1988), p. 306).

Quando um fluido newtoniano sai de um cano normalmente ele tem uma leve contração, se o número de Reynolds $R e>1$. Este efeito é visualizado facilmente quando abrimos uma torneira de cozinha (ver figura 5.26). Neste caso o fluido, que foi previamente freado pelo contato com as paredes do cano, simplesmente adota a velocidade do fluido que esta escoando mais livremente na linha de simetria no centro do cano.

Se o fluido é muito viscoso (de modo que a inércia se torna desprezível) mas ainda newtoniano, o jato sofrerá uma dilatação por volta de $13 \%$ (ver figura 5.27). Aqui a 


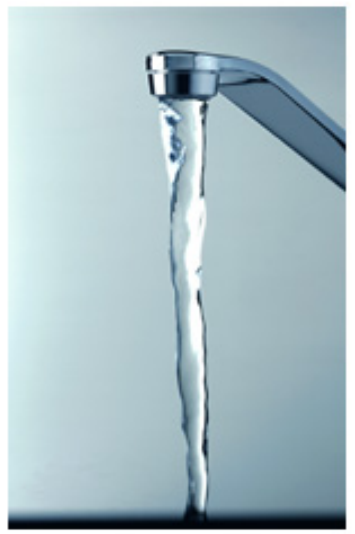

Figura 5.26: Visualização de um jato de agua saindo de uma torneira.

pequena variação é causada pelo rearranjamento do campo de velocidade, proveniente de um perfil parabólico dentro do cano, para um escoamento na atmosfera (Tanner, 1988).

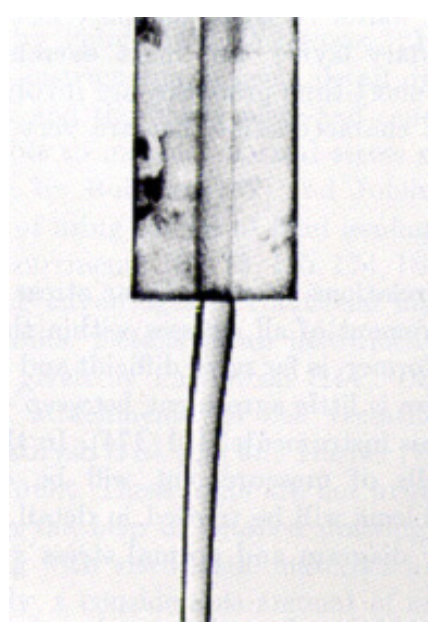

Figura 5.27: Visualização de um jato newtoniano viscoso.

Para fluidos newtonianos generalizados pseudoplásticos, a razão de dilatação é menor que para fluidos newtonianos; conforme aumenta-se o comportamento não newtoniano do fluido, a dilatação tende a zero ((Tanner, 1988), p. 327). Esse resultado é conhecido somente em simulações computacionais. Isto ocorre porque o perfil de velocidade do escoamento dentro do cano, no caso de fluidos newtonianos generalizados pseudoplásticos, está mais próximo do escoamento livre do que o perfil parabólico de um fluido newtoniano. Deste modo, quando o fluido sai do cano para o escoamento livre, ele requer um menor rearranjamento do campo de velocidade.

$\mathrm{Na}$ simulação numérica que iremos apresentar a viscosidade é definida por (5.7), com 


$$
t=0.004 s
$$

a)

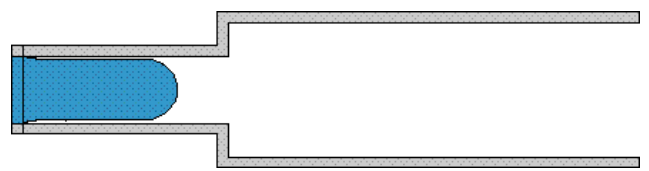

b)

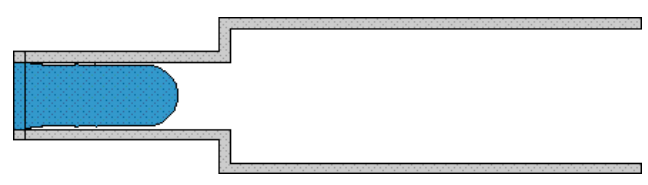

c)

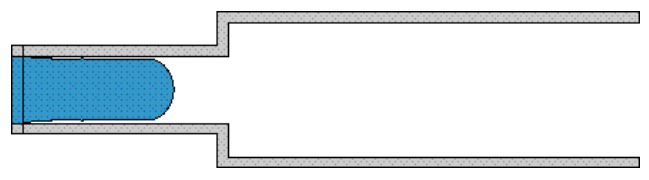

d)

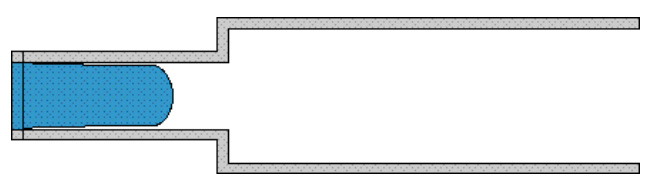

$t=0.008 s$

a)

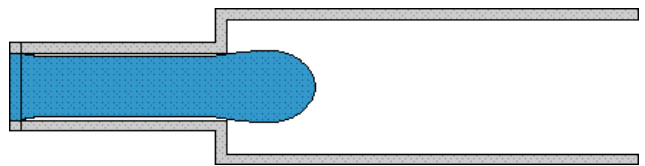

b)

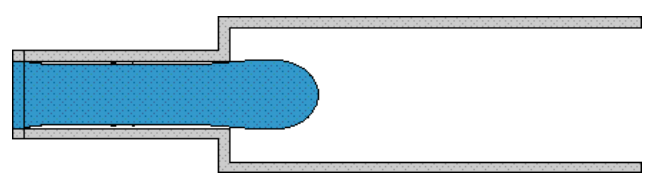

c)

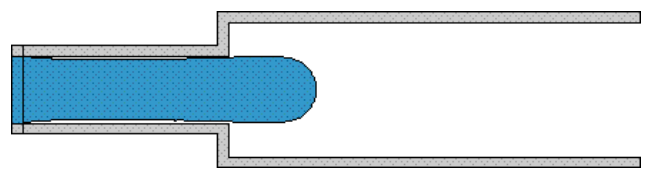

d)

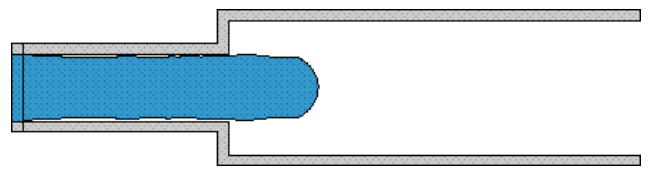

Figura 5.28: Simulação numérica do "extrudate", para a) newtoniano, b) $K=0.15$, c) $K=0.75$ e d) $K=1.0$, utilizando uma malha $180 \times 40$ células.

os valores das constantes dadas por: $\nu_{\infty}=0.001 \mathrm{~m}^{2} \mathrm{~s}^{-1}, \nu_{0}=0.05 \mathrm{~m}^{2} \mathrm{~s}^{-1}$ e $m=1$. Os parâmetros de escala são dados por $L, U=U_{i}$ resultando em $R e=U L / \nu_{0}=1.0$. A força gravitacional nesse problema foi desprezada porque $\mathrm{Fr}>>1$.

Na figura 5.28 temos a simulação do "extrudate-swell", onde o jato de fluido ainda se encontra dentro do canal (tempo $t=0.004 \mathrm{~s}$ ), observe que aqui o escoamento tem praticamente a mesma forma para todos os valores de $K$. No tempo $t=0.008 \mathrm{~s}$, vemos o jato deixando o "slit" e apresentando uma leve dilatação.

A figura 5.29 mostra o escoamento no tempo $0.016 \mathrm{~s}$. No caso newtoniano figura $5.29 \mathrm{a}$ $S_{r}=1.11807$, ou seja o jato apresentou uma dilatação de $11.807 \%$ em relação a largura do tamanho do canal $(L=0.01 \mathrm{~m})$. Observe que conforme aumentamos o valor de $K$ temos uma diminuição no valor de $S_{r}$. Para $K=0.15$ o jato sofreu uma dilatação de $7.228 \%$, enquanto que para $K=0.75$ o jato dilatou $2.168 \%$ e para $K=1.0$, o jato dilatou $0.289 \%$.

Portanto nossos resultados estão satisfatórios e concordando com os resultados teóricos 
a)

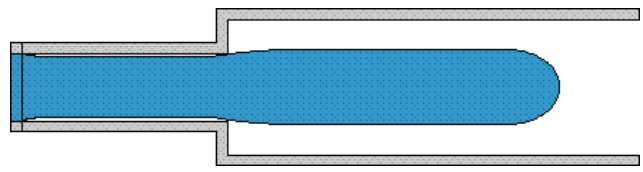

b)

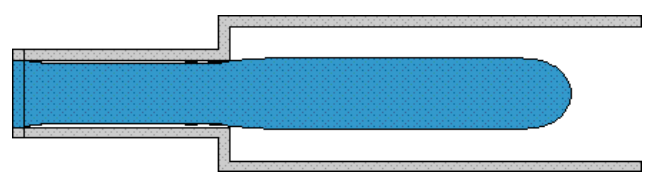

c)

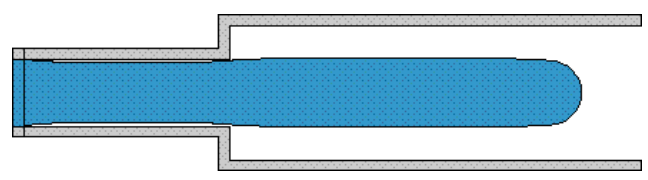

d)

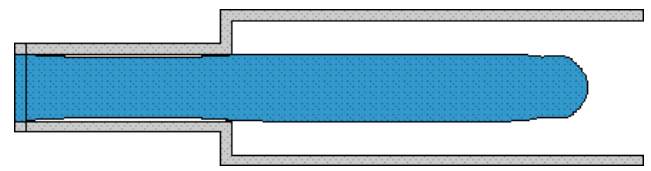

Figura 5.29: Simulação numérica do "extrudate swell", no tempo $t=0.016 \mathrm{~s}$, para a) newtoniano, $S_{r}=1.11807$, b) $K=0.15, S_{r}=1.07228$, c) $K=0.75, S_{r}=1.02168$ e d) $K=1.0, S_{r}=1.002898$.

de Tanner (Tanner, 1988).

As figuras 5.30 e 5.31 mostram os campos de velocidade, viscosidade e pressão respectivamente, no tempo $t=0.016 s$.

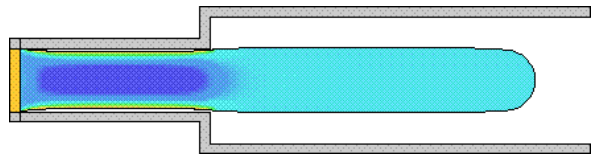

a) Velocidade na direção $x$.
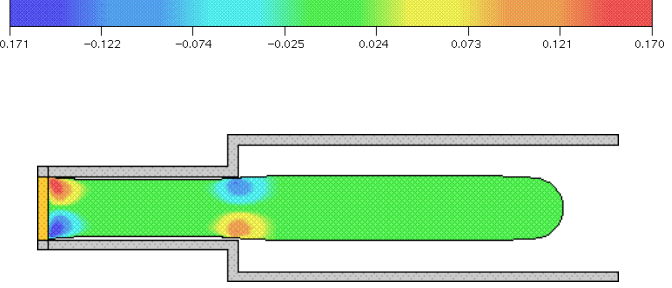

b) Velocidade na direção $y$.

Figura 5.30: Campo de velocidade no tempo $t=0.016 s$, para $K=0.75$. 


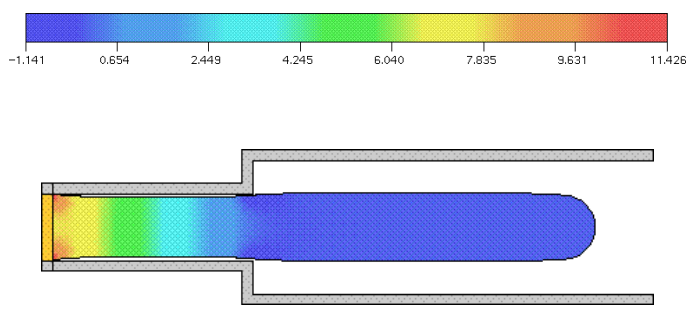

c) Pressão.

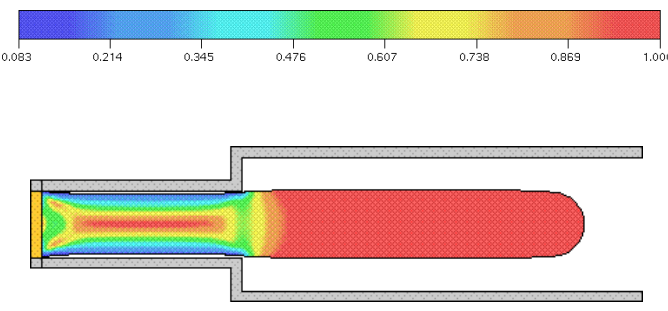

d) Viscosidade.

Figura 5.31: Campo de pressão e viscosidade no tempo $t=0.016 s$, para $K=0.75$.

\subsubsection{Efeito "Jet Buckling"}

Para demonstrar a capacidade do sistema FreeFlow-2D em simular escoamentos de fluidos não newtonianos, apresenta-se um problema que simula o efeito "Jet buckling" utilizando-se o modelo de Cross para a viscosidade (Tomé et al., 1996).

Considere a condição de "buckling" dada por (Cruickshank e Munson, 1981) e (Cruickshank, 1987)

$$
R e<0.56 \text { e } H / L>3 \pi
$$

Para o jato newtoniano, o número de Reynolds é um fator importante, no comportamento do escoamento, enquanto que para o jato não newtoniano o número de Reynolds é mudado de acordo com o valor da taxa de deformação local. Para ilustrar que a variação da viscosidade com a taxa de deformação tem um efeito relevante no fenômeno "jet buckling", apresentam-se dois problemas que contrastam o comportamento newtoniano e não newtoniano. Em ambos os casos, a condição (5.14) é satisfeita, prevendo o efeito "buckling" no jato newtoniano.

A primeira simulação (newtoniano) diz respeito a um fluido que é injetado em um contêiner quadrado de tamanho $0.05 \times 0.05 \mathrm{~m}$ com inflow de tamanho $0.004 \mathrm{~m}(\mathrm{H} / \mathrm{L}=$ 12.5) e escala de velocidade $U=0.5 \mathrm{~ms}^{-1}$ (Re $=0.2$ ). A segunda simulação (não newtoniano), utilizam-se os mesmos dados da primeira, com os parâmetros do material dado por

$$
\nu_{\infty}=0.001 \quad m^{2} s^{-1}, \quad \nu_{0}=0.01 \quad m^{2} s^{-1}, \quad m=1 \quad e \quad K=4.0,
$$

$\operatorname{assim} R e=U L / \nu_{0}=0.2$ e $F r=2.52377$.

A figura 5.32 mostra a comparação dos resultados para fluidos newtonianos e não newtonianos em tempos diferentes. Nota-se que no fluido newtoniano o fenômeno "buckling" 
é evidente, enquanto que no caso do fluido não newtoniano as dobras causadas pelo efeito são praticamente suprimidas.

a)

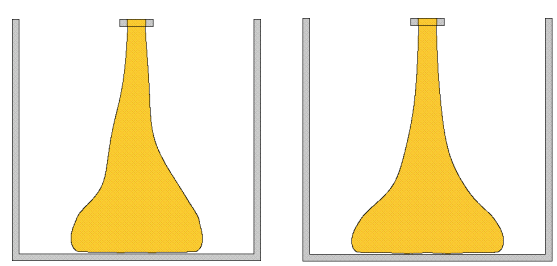

b)

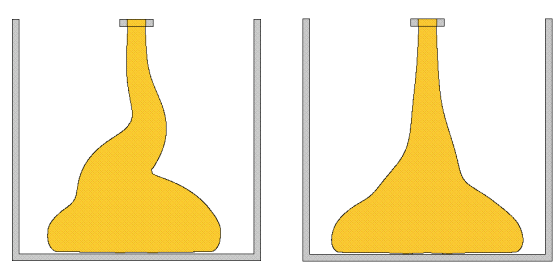

c)

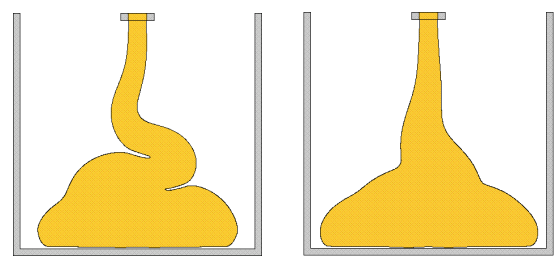

d)

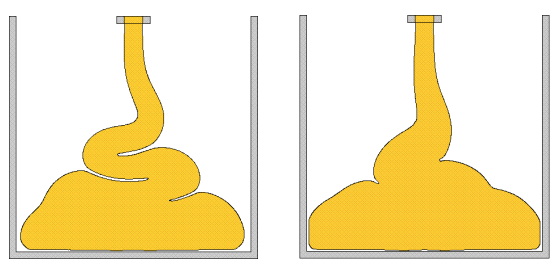

Figura 5.32: Jato newtoniano (lado esquerdo) e não-newtoniano (lado direito) para tempos diferentes. a) $t=0.3250 \mathrm{~s}, \mathrm{~b}) t=0.40 \mathrm{~s}, \mathrm{c}) t=0.450 \mathrm{~s}, \mathrm{~d}) t=0.50 \mathrm{~s}$. 


\section{Capítulo 6}

\section{Conclusão}

Este trabalho teve como objetivo a extensão do ambiente FreeFlow-2D de simulação numérica de escoamentos incompressíveis com superfícies livres, de forma a permitir a simulação de escoamentos de fluidos newtonianos generalizados, do tipo Cross e "powerlaw".

A implementação do código para fluidos não newtonianos foi feita de forma modular no ambiente FreeFlow-2D, construindo um modelador de moldes, um simulador e um visualizador para escoamentos de fluidos não newtonianos.

O modelador foi modificado para a entrada de novos dados referentes ao escoamento de fluidos não newtonianos, como as janelas de entrada de dados para os modelos Cross e "power-law". No simulador foram modificadas as equações de conservação de quantidade de movimento para simular escoamentos de fluidos não newtonianos. No visualizador foram incluidos opções que possibilitam a visualização, em escala de cores, da variação de dados como taxa de deformação e viscosidade.

O código foi validado utilizando-se resultados numéricos obtidos de um escoamento entre duas placas paralelas e comparando-os com suas respectivas soluções analíticas. Os resultados foram quantitativamente bons, tanto para o modelo Cross quanto para o modelo "power-law". Alguns resultados como o efeito "jet buckling", foram comparados qualitativamente com experimentos numéricos publicados, com boa concordância. 


\section{Referências Bibliográficas}

Amsden, A. A. e Harlow, F. H. (1970). A Simplified MAC Technique for Incompressible Fluid Flow Calculation. Jornal Computational Physics, 6:332-335.

Bird, R. B., Armstrong, R. C., e Hossager, O. (1977). Dynamics of Polymeric Liquids Fluid Mechanics. John Wiley.

Bretas, R. E. S. e DAvila, M. A. (2000). Reologia de Polímeros Fundidos. UFSCAR.

Crochet, M. J., Davis, A. R., e Walters, K. (1984). Numerical simulation of NonNewtonian Flow. Elsevier Science Publishing Company.

Cruickshank, J. O. (1987). Low-Reynolds-Number Instabilities in Stagnating Jet Flows. Journal of Fluid Mechanics, 193:111-127.

Cruickshank, J. O. e Munson, B. R. (1981). Viscous Fluid Buckling of Plane and Axisymmetric Jets. Journal of Fluid Mechanics, 113:221-239.

Ferreira, V. G. (2001). Análise e Implementação de Esquemas Convecção e Modelos de Turbulência para Simulação de Escoamentos Incompressíveis Envolvendo Superfícies Livres. Tese de Doutorado, Universidade de São Paulo - ICMC/USP.

Ferreira, V. G., Azevedo, J. L. F., e Cuminato, J. A. (1997). Métodos Numéricos para Escoamentos Incompressível. Notas Didáticas 26, ICMC-USP.

Ferreira, V. G., Tomé, M. F., Fortuna, A. O., Cuminato, J. A., Castelo, A. F., Mangiavacchi, N., e McKee, S. (2002). High Order Upwinding and the hydraulic jump. International journal for Numerical Methods in Fluids.

Hirt, C. W. e Shannon, J. P. (1968). Calculating Three-dimensional Around Strutures and Over Rough Terrain. Jornal Computational Physics, 10:324-340. 
Kim, J. M., Ahn, K. H., Lee, S. J., e Lee, S. J. (2001). Numerical Simulation of Moving Free Surface Problems in Polymer Processing Using Volume-of-Fluid Method. Polymer Engineering and Science, 41(5):858-866.

Nichols, B. D. e Hirt, C. W. (1973). Calculating Three-dimensional Free Surface Flows in the Vicinity of Submerged and Exposed Strutures. Jornal Computational Physics, 12:234-246.

Oliveira, J. (1999). Desenvolvimento de um Sistema de Simulação de Escoamentos de Fluidos com Superfícies Livres Bidimensionais. Dissertação de Mestrado, ICMCUSP, São Carlos.

Tanner, R. I. (1988). Engineering Rheology. Claredon, Oxford.

Tomé, M. F. (1993). GENSMAC: A Multiple Free Surface Fluid Flow Solver. Tese de Doutorado, University of Strathclyde, Glasgow, U. K.

Tomé, M. F., Duffy, B., e McKee, S. (1996). A Numerical Technique for Solving Unsteady non-Newtonian Free Surface Flows. Jornal of non-Newtonian Fluid Mechanics, 62:934 .

Tomé, M. F. e McKee, S. (1994). GENSMAC: A Computational Marker and Cell Method for Free Surface Flows in General Domains. Jornal Computational Physics, 110(1):171-186.

Varonos, A. e Bergeles, G. (1998). Development and Assessment of a Variable-Order Non-Oscillatory Scheme for Convection Term Discretization. International journal for Numerical Methods in Fluids, 26:1-16. 